\title{
Wind Shear Climatology for Large Wind Turbine Generators
}

D. L. Elliott

L. L. Wendell

S. K. Heflick

October 1982

Prepared for the U.S. Department of Energy under Contract DE-AC06-76RLO 1830

Pacific Northwest Laboratory Operated for the U.S. Department of Energy by Battelle Memorial Institute 


\title{
DISCLAIMER
}

This report was prepared as an account of work sponsored by an agency of the United States Government. Neither the United States Government nor any agency thereof, nor any of their employees, makes any warranty, express or implied, or assumes any legal liability or responsibility for the accuracy, completeness, or usefulness of any information, apparatus, product, or process disclosed, or represents that its use would not infringe privately owned rights. Reference herein to any specific commercial product, process, or service by trade name, trademark, manufacturer, or otherwise, does not necessarily constitute or imply its endorsement, recommendation, or favoring by the United States Government or any agency thereof. The views and opinions of authors expressed herein do not necessarily state or reflect those of the United States Government or any agency thereof.

\author{
PACIFIC NORTHWEST LABORATORY \\ operated by \\ BATTELLE \\ for the \\ UNITED STATES DEPARTMENT OF ENERGY \\ under Contract DE-AC06-76RLO 1830
}

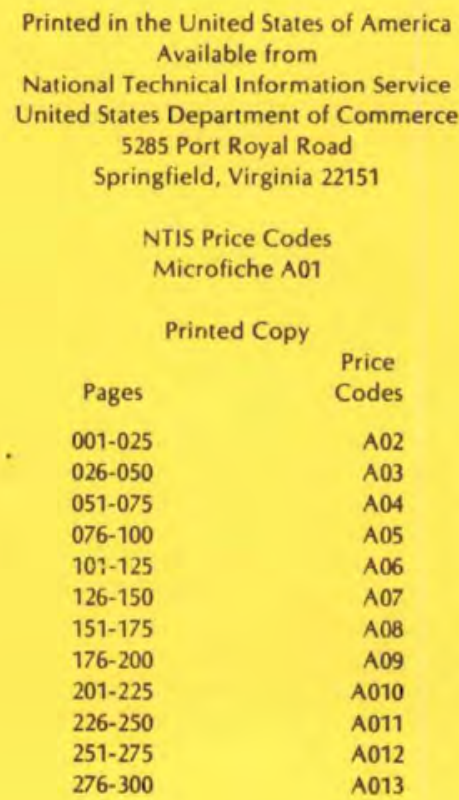


D. L. Elliott

L. L. Wendell

S. K. Heflick

October 1982

Prepared for

the U.S. Department of Energy

under Contract DE-AC06-76RLO 1830

Pacific Northwest Laboratory

Richland,Washington 99352 



\section{ACKNOWLEDGMENTS}

Appreciation is expressed to L. V. Divone of DOE and Dr. C. I. Aspliden for their persistence and encouragement in the pursuit of a closer look at the phenomena of time-varying shear as it might affect large wind turbines.

The help of Dr. W. R. Barchet in the setup of the joint frequency distribution computations and $K$. Packard in producing the contour analyses is gratefully acknowledged.

The cooperative attitude and timely response of $L$. Gordon and T. Sullivan of NASA/Lewis Research Center in providing strip-chart data of MOD-2 parameters are also gratefully acknowledged. 


\section{SUMMARY}

The major objective of this report is to provide climatological wind shear analyses relevant to the design and operation of multimegawatt wind turbines. Early sections of the report are intended to provide insight for relating the wind experienced by a rotating blade in a shear flow to the analysis results.

A simple analysis of the wind experienced by a rotating blade for three types of wind shear profiles under steady-state conditions is presented in graphical form. Comparisons of the magnitude and frequency of the variations in 1) the wind sensed by a single blade element, 2) the sum, and 3) the difference of the winds sensed by opposite blade elements show strong sensitivity to profile shape. These three items represent forcing functions that can be related to 1) flatwise bending moment, 2) torque on the shaft, and 3) teeter angle.

A computer model was constructed to simulate rotational sampling of $10-\mathrm{s}$ sampled winds from a tall tower for three different types of large wind turbines. Time series produced by the model indicated that the forcing functions on a rotating blade vary according to the shear profile encountered during each revolution as opposed to a profile derived from average wind conditions, e.g., hourly average winds.

An analysis scheme was developed to establish a climatology of wind shear profiles derived from 10 -s sampled winds and hourly average winds measured over a one-year period at several levels on a tall tower. Because of the sensitivity of the forcing function variability to profile shape, the analyses performed and presented are in the form of joint frequency distributions of velocity differences of the top-to-hub versus the hub-to-bottom portion of disks of rotation for the three turbine configurations.

The major conclusions from these analyses at the tower location used are: 
- The 10-s sampled winds show a much greater percentage of severe and unusual profile shapes than the hourly average winds.

- Sampling interval tests showed that the frequency distributions of wind shear profiles could be computed with 2- to 5-minute instantaneous samples almost as reliably as with 10-second wind measurement samples.

- The Type 3 turbine would be exposed to considerably less severe velocity differences and fewer unusual profiles than either the Type 1 or Type 2 wind turbines (see Table 3-1 on page 3-3 for a description of each turbine's characteristics).

- The Type 2 turbine experienced velocity differences of $6 \mathrm{~m} / \mathrm{s}$ or greater $18 \%$ of the time when winds were within the operating range of the turbine, which was about 3 times as often as the Type 1 turbine and more than 20 times as often as the Type 3 turbine.

- Velocity differences for all three wind turbines were typically much greater during the night than during the day for all seasons.

Steps for extending this analysis approach to provide the basis for producing more reliable estimates of fatigue life and power quality will be taken with the coordination and cooperation of design engineers. 


\section{CONTENTS}

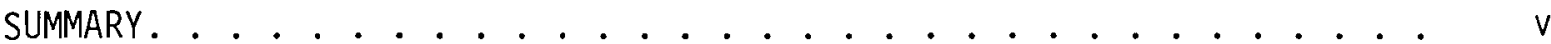

1.0 INTRODUCTION. . . . . . . . . . . . . . . 1-1

2.0 WIND SHEAR AND A ROTATING BLADE ............ 2-1

3.0 SiMUlATION MODEL. . . . . . . . . . . . . . . 3-1

4.0 WIND SHEAR CLIMATOLOGY. . . . . . . . . . . . 4-1

4.1 METHODOLOGY FOR WIND SHEAR PROFILE ANALYSIS. . . . . . . 4 4-1

4.2 RESULTS OF WIND SHEAR PROFILE ANALYSIS . . . . . . . 4-4

4.2.1 Joint Frequency Distribution Analyses of Wind Shear Profiles. . . . . . . . . . 4-4

4.2.2 Contours of Wind Shear Profiles . . . . . . . 4-22

5.0 CONCLUSIONS AND RECOMMENDATIONS ............ . . .

6.0 REFERENCES. .................. . . 6-1 


\section{FIGURES}

2-1 Wind Shear and Turbulence Simulated for a Rotating Blade Compared to the Wind Observed by a Fixed Anemometer at

Hub Height. . . . . . . . . . . . . . . . . . 2-2

2-2 Schematic Drawing of the 49-m Diameter Vertical Plan Array Used to Sample Wind Speeds in a Rotating Frame. . . . 2-2

2-3 Characteristic Time Series of Rotationally Sampled Wind Under Constant Shear Conditions .. . . . . . . . . 2-4

3-1 Sequential 10-s Wind Profiles Derived From WKY-TV Tower Data Beginning at 1830:00 CST, March 10,1977..... . 3-2

3-2 Comparison of Rotational Sampling Simulation for Three Types of Wind Turbines During the Period 1830:00 to 1831:00, March 10, 1977, Shown in Figure 3-1 for a) a Single Blade Element and b) for Opposite Blade Elements . . 3-4

3-3 Results of a) Averaging and b) Differencing Time Series of Rotationally Sampled Winds for Opposite Blade Elements as Shown in Figure 3-2b. . . . . . . . . . .

3-4 Sample Comparison of Type 1 Turbine Simulations With Goodnoe Hills Tower Data for a) l-s Samples and b) Interpolation From 10-s Samples. . . . . . . . .

3-5 Sample Record of MOD-2 Teeter Angle Beginning on the Right at $2324: 00$, March 10, 1982, at Goodnoe Hills, Washington. .................. 3-8

4-1 Key to Interpretation of Information Within Each Cell of the Wind Shear Profile Tables. . . . . . . . . . 4-3

4-2 Frequency of Occurrence of Wind Shear Profiles for a Type 1 Turbine During Windy Hours in October 1976 for Conditions Within Turbine Operating Range Using

(a) 10-s Sampled Winds, and (b) Hourly Average Winds. . . 4-7

4-3 Type 2 Turbine for Autumn (October 1976). . . . . . . . 4-8

4-4 Type 3 Turbine for Autumn (October 1976). . . . . . . . 4-9

4-5 Type 1 Turbine for Winter (January 1977). . . . . . . . 4-10

4-6 Type 2 Turbine for Winter (January 1977). . . . . . . . 4-11

4-7 Type 3 Turbine for Winter (January 1977). . . . . . . . . 4-12 
4-8 Type 1 Turbine for Spring (Apri1 1977). . . . . . . . 4-13

4-9 Type 2 Turbine for Spring (April 1977). . . . . . . . 4-14

4-10 Type 3 Turbine for Spring (April 1982). . . . . . . . . 4-15

4-11 Type 1 Turbine for Summer (July 1977) . . . . . . . . . 4-16

4-12 Type 2 Turbine for Summer (JuTy 1977) . . . . . . . . 4-17

4-13 Type 3 Turbine for Summer (July 1977) . . . . . . . . . 4-18

4-14 Type 1 Turbine - Annual Average ............ 4-19

4-15 Type 2 Turbine - Annuat Average . . . . . . . . . . 4-20

4-16 Type 3 Turbine - Annuar Average ............ 4-21

4-17 Percent Frequency Contours of Wind Shear Profites for October 1976 (Autumn) Under Same Conditions for 10-s Sampled Winds Described in Figure 4-2 for a) Day and b) Night, and Three Types of Wind Turbines. ....... . 4-24

4-18 Percent Frequency Contours for Winter (January 1977). . . . 4-25

4-19 Percent Frequency Contours for Spring (Apri1 1977). . . . . 4-26

4-20 Percent Frequency Contours for Summer (JuTy 1977) . . . . . 4-27

4-21 Percent Frequency Contours (A11 Hours) for (a) Winter (January 1977) and (b) Summer (July 1977) . . . . . . . 4-28

4-22 Percent Frequency Contours (A11 Hours) for (a) Autumn (October 1976) and (b) Spring (Apri1 1977). ....... 4-29

4-23 Percent Frequency Contours - Annual Average . . . . . . 4-30

4-24 Percent Frequency Contours (A11 Hours) - Annual Average . . 4-31 


\section{TABLES}

3-1 Wind Turbine Configurations Used in Rotational Sampling

Simulation. . . . . . . . . . . . . . . 3-3

4-1 Percentage of Total Hours With Mean Hourly Wind Speeds

Greater Than or Equal to $7 \mathrm{~m} / \mathrm{s}$ at Either $45 \mathrm{~m}$ or $89 \mathrm{~m}$

at the WKY TV Tower............. . . . 4-2

4-2 Wind Speed Operating Ranges Used for the Wind Turbines.

Speeds are at hub height. . . . . . . . . . . . 4-2 


\subsection{INTRODUCTION}

The advent of horizontal-axis wind turbines with blade diameters greater than $76 \mathrm{~m}(250 \mathrm{ft})$ and hub heights of more than $61 \mathrm{~m}(200 \mathrm{ft})$ has raised questions about the nature of the wind shear that will be encountered by these large turbines. The conventional concept of the increase of wind speed with height in the lowest $150 \mathrm{~m}$ (492 ft) above ground level is based on timeaveraged conditions. This has led to the use of the classical logarithmic profile and the power law concept to extrapolate wind speeds from lower heights to higher heights.

A potential problem in applying the average profile concept to a rotating turbine blade in design or operational considerations is that the blade does not encounter an average wind profile. Rather, the blade experiences the wind shear that occurs during the two to four seconds that it takes to complete one rotation. A high percentage of extreme shears occurring over this short time scale could have an effect on the amount of fatigue experienced by the blades and on the quality of power produced by the turbine. In order to estimate the amount of extreme shear a turbine will experience and the subsequent effects on fatigue life and power quality, it is extremely important to obtain and analyze appropriate wind data.

Some aspects of fluctuating vertical wind shears have been addressed in a previous study by Doran (1981). The data used for Doran's study were obtained from an anemometer array configured for high frequency sampling. The physical size of the anemometer array limited the analyses to blade spans of 17 to $35 \mathrm{~m}$ ( 55 to $115 \mathrm{ft}$ ) and hub heights of 37 to $45 \mathrm{~m}(121$ to $148 \mathrm{ft}$ ). One of the primary conclusions of Doran's study was that fluctuating wind shears two or more times the mean values are readily observable. The fact that this result was applicable to strong wind speeds, generally associated with low shear conditions, and for height ranges somewhat less than required for the large turbines, provided added incentive to acquire data for the appropriate height ranges of large wind turbines with a high sampling rate over a wide range of atmospheric conditions. 
An available data set that comes close to meeting all the criteria just enumerated was one year of wind measurements sampled once every 10 seconds at four levels between $26 \mathrm{~m}(85 \mathrm{ft})$ and $177 \mathrm{~m}(580 \mathrm{ft})$ on the WKY-TV tower in Oklahoma City, Oklahoma. The vertical resolution and sampling interval are not ideal, but they provide an opportunity to make a preliminary analysis of the data. Two comparisons are made in the analysis. In the first, the frequency of occurrence of shear conditions from 10-s samples is compared with hourly average shear conditions. In the second, shear conditions experienced by different configurations of large wind turbines are compared.

One of the major objectives of this report is to make the shear analysis information as useful as possible to wind turbine design and operations engineers. For this reason, section 2 of this report deals in a heuristic fashion with some concepts of the variability of the wind forcing on a rotating wind turbine blade under different shear flow conditions. In Section 3 a computational scheme for the simulation of rotational sampling is applied to a sample of the tower data to provide some insight into the wind experienced by a rotating blade in a time-varying shear flow. A more complete treatment of the effect of wind speed fluctuations encountered by a rotating blade is provided by Connell (1981). Section 4 of the report provides a climatological summary of the diurnal (night versus day), seasonal and annual frequencies of a variety of shear conditions for three wind turbines.

This report is intended to be neither a sophisticated nor complete statistical analysis on the subject of wind shear and large wind turbines. Data from more locations are becoming available for analysis and the results of interactions with the people who need to apply this type of information should provide the basis for expediting a cost-effective and comprehensive research analysis. 


\subsection{WIND SHEAR AND A ROTATING BLADE}

The ideal operating condition for a wind turbine would be a steady uniform flow over the disk of rotation of the turbine blade. Although this condition may be simulated in the atmosphere, it is rarely observed for any length of time in the free atmosphere. Besides turbulent fluctuations that are measured by a single anemometer, there are variations in the speed over the disk of rotation.

One of the major variations over the disk is the increase of speed with height above ground due to the frictional retarding of the flow at the surface. In general, the vertical profile of mean wind speed (averaged over a few minutes to an hour) near the surface has a shape similar to the one shown in the schematic drawing in Figure 2-1. Profiles measured over time intervals on the order of a second will fluctuate around the mean profile. The ambient wind speed encountered by an element near the tip of a rotating blade is shown with the corresponding wind speed measured by a single hub height anemometer in Figure 2-1. The striking feature of this plot is that the one-cycle-perrevolution oscillations in the rotating frame of reference have significantly higher amplitude than the fluctuations measured by the single anemometer.

The measurements used to generate the wind traces in Figure 2-1 were made on a circular array of anemometers mounted in a vertical plane (shown in Figure 2-2) for an experimental analysis described by Connel1 (1981). The thrust of that analysis was to show the drastic difference between the spectral content of the wind fluctuations measured by a single anemometer and the wind fluctuations that would be seen by a rotating blade element. This information has been presented for use by turbine designers in the analyses of the natural frequencies and excitation frequencies of the turbine-tower system.

In the present study the primary concern is the nature of the wind shear in the real atmosphere to heights appropriate to the rotor size and hub height of existing multi-megawatt turbines and the larger turbines planned for the future. 

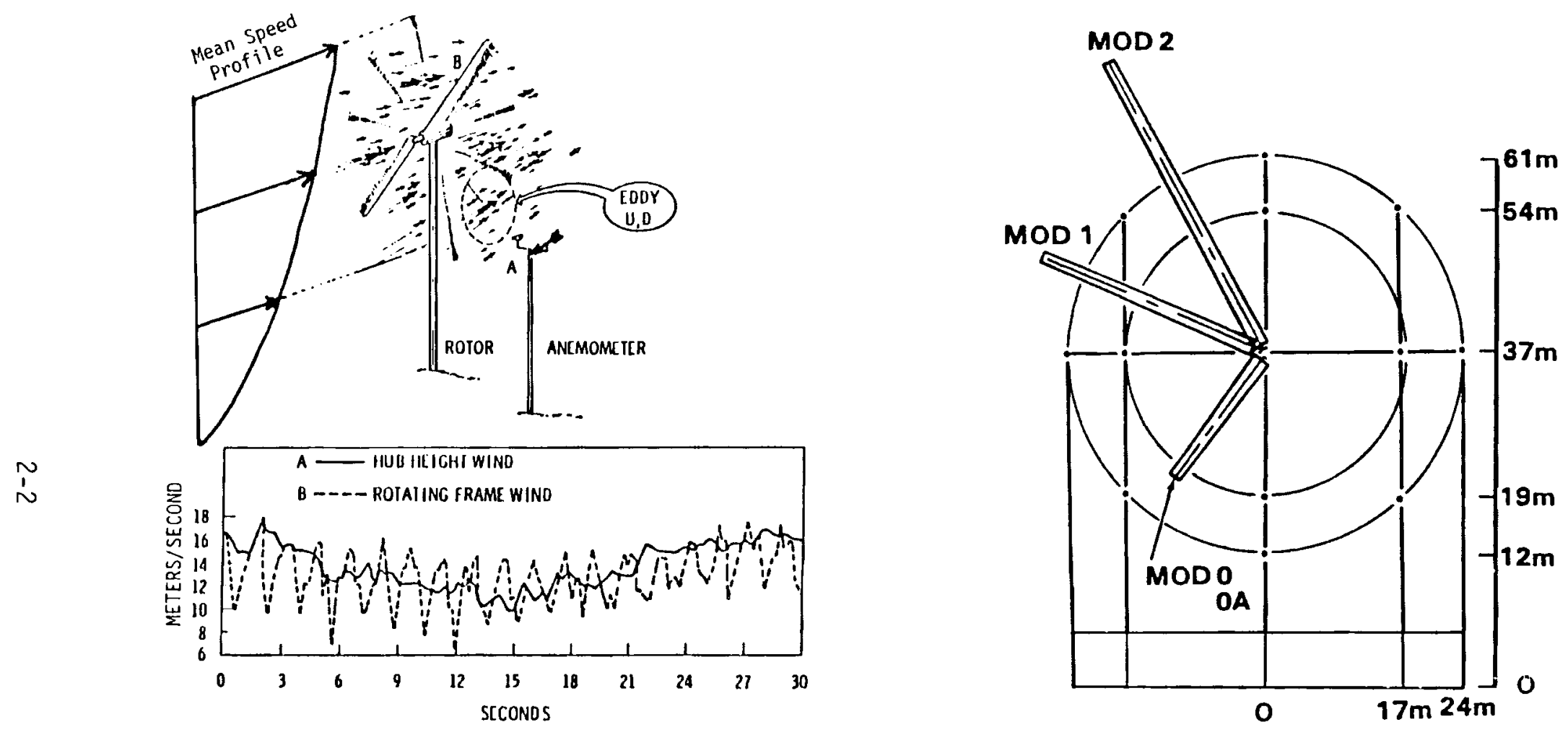

$U$ represents a measure of the velocity in the eddy.

$D$ represents a measure of the eddy size.

FIGURE 2-1. Wind Shear and Turbulence Simulated for a Rotating Blade Compared to the Wind Observed by a Fixed Anemometer at Hub Height (Conne11 1981)
FIGURE 2-2. Schematic Drawing of the 49-m Diameter Vertical Plane Array Used to Sample Wind Speeds in a Rotating Frame. Superimposed wind turbine blades indicate the relative size of the array. (Connell 1981) 
Before discussing actual turbine dimensions and the data used in the study, it may be appropriate to examine the nature of rotationally sampled wind records for some typical profile shapes. This should provide some insight into the relationship of the profile shape to the wind that would be sensed by a turbine blade.

This simulation was performed by assuming three profile shapes (shown in Figure 2-3) which do not change with time and do not change across the horizontal dimension of the disk of rotation. The wind record sensed by the element near the tip of the rotating blade was then generated by interpolating linearly along the vertical profile according to the position of the blade element on its circle of rotation.

As one would expect, the blade element rotating through a linear profile encounters a wind varying sinusoidally at one cycle per revolution. However, if the speed increases from the bottom of the disk to the hub height and then is constant to the top of the disk, the tops of the sine waves have a clipped appearance. If the speed increases from the bottom of the disk to the hub then decreases to the top of the disk, the wind sensed by the blade element has a cusped appearance and a frequency of variation of two cycles per revolution.

The wind variability encountered by an element of a single blade is related, through the resulting lift and drag on the blade, to the blade bending moment perpendicular to the disk of rotation. This relationship will depend on the characteristics of the airfoil and is only pointed out in a heuristic manner in this study to provide some general insight into the windrelated forces that affect a wind turbine. In this way the emphasis of this study can be placed on the wind characteristics and shear statistics, which can then be applied by the engineers in design and performance studies.

Other useful relationships may be pointed out by considering combinations of the variability of the wind encountered by similar elements on opposite blades. The simultaneous averaging of the winds experienced by the opposite elements can be related to the torque on the shaft while the simultaneous 


$\begin{array}{ccc}\text { Wind } & \text { Turbine } & \text { Wind Sensed by a } \\ \text { Profile } & \text { Blade } & \text { Single Blade Element }\end{array}$

Two-Blade Average
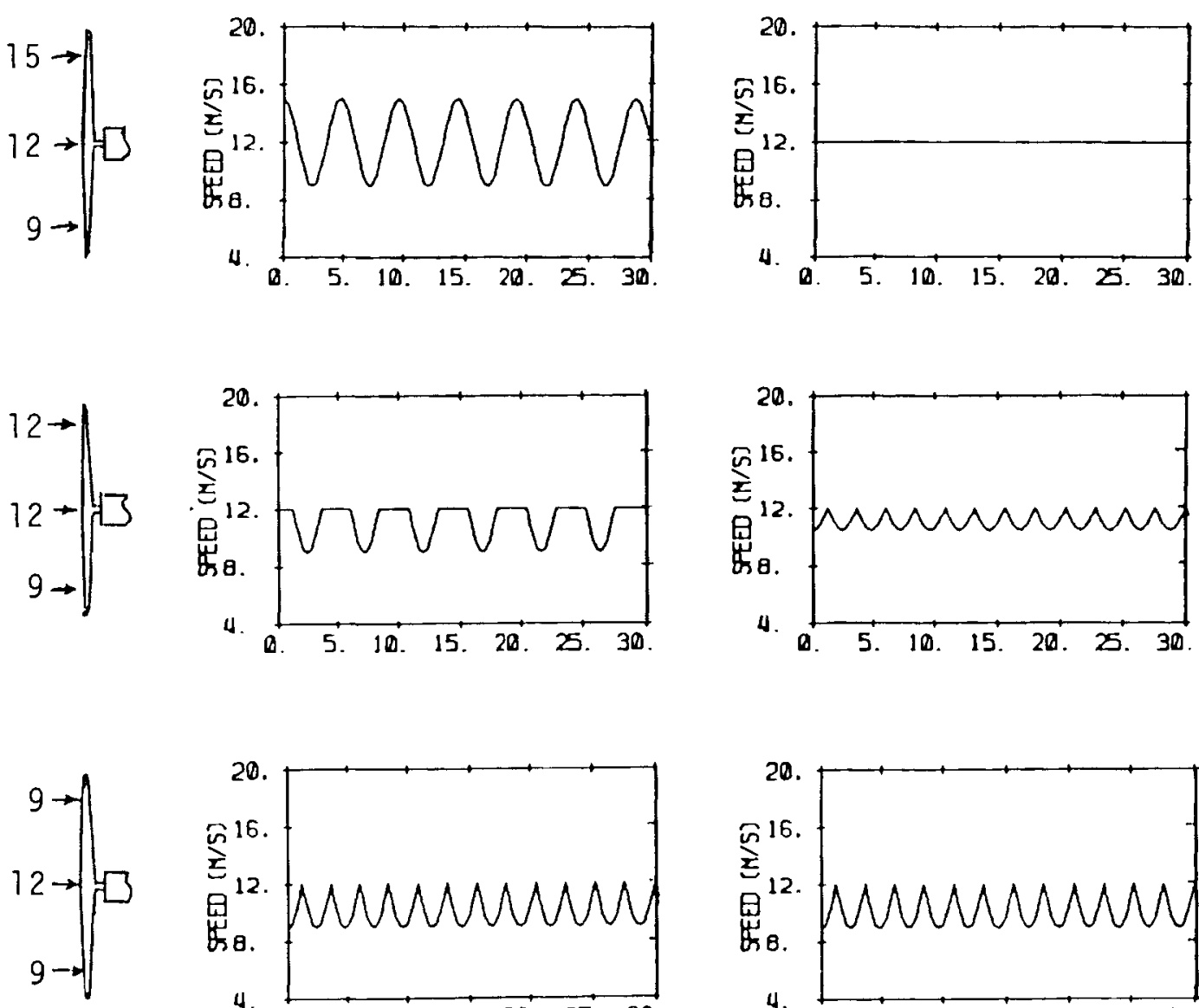
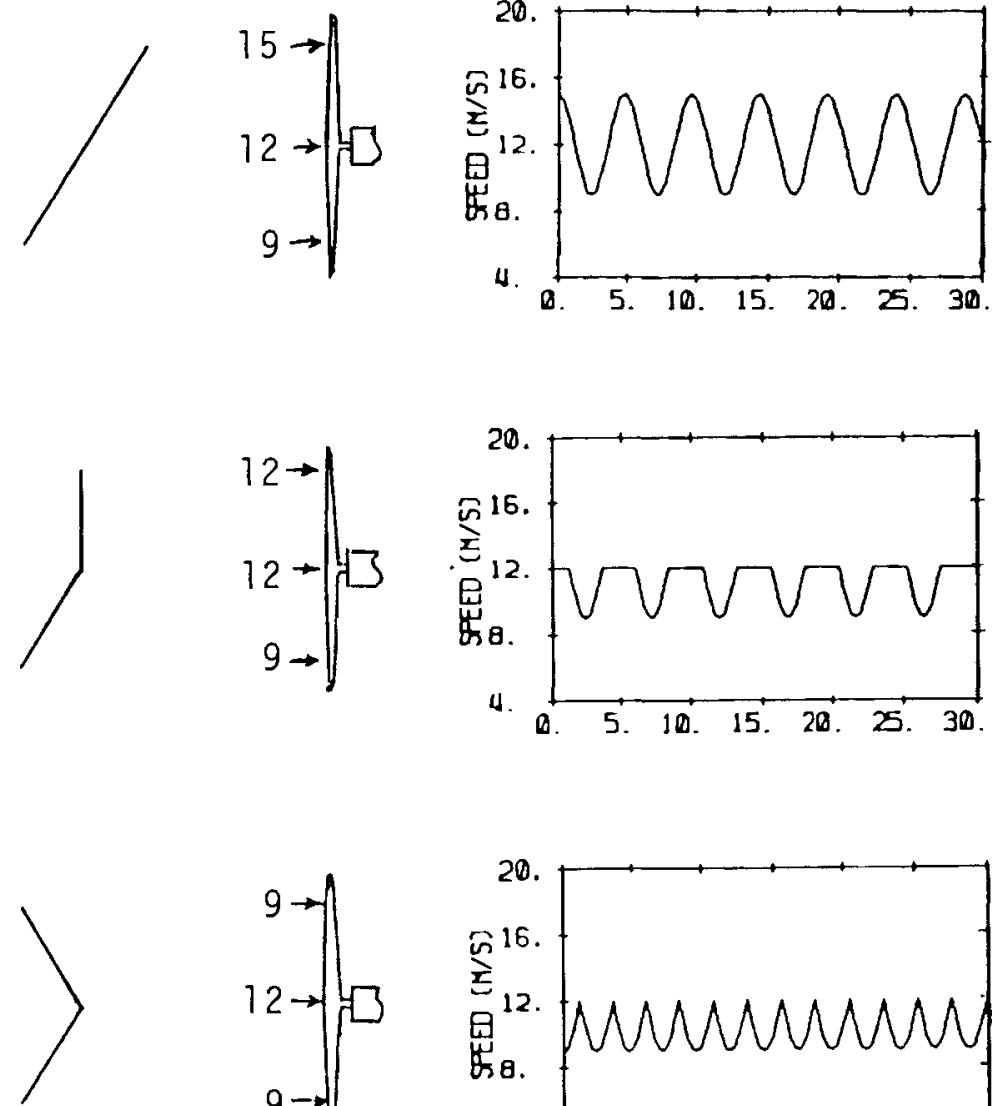
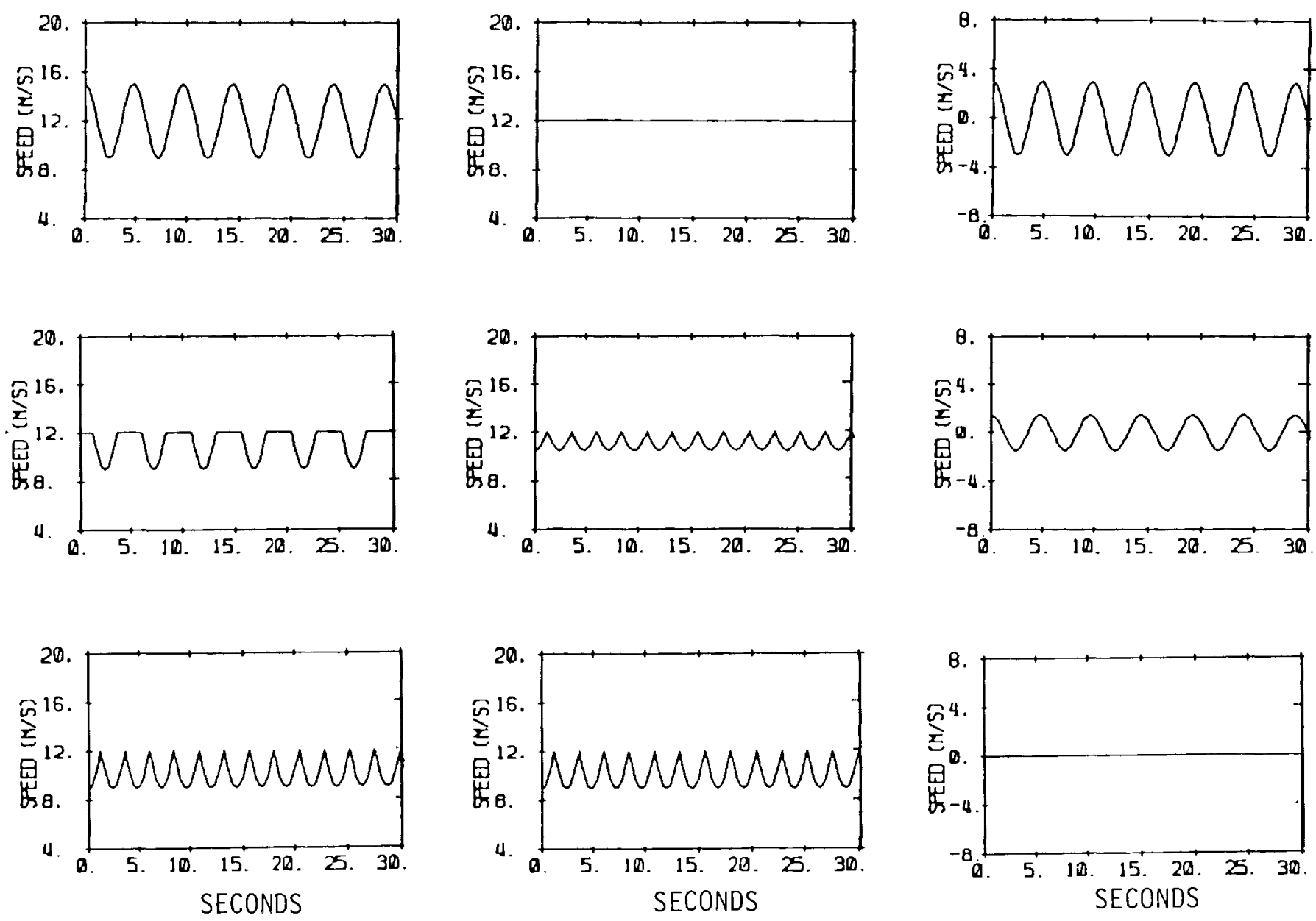

FIGURE 2-3. Characteristic Time Series of Rotationally Sampled Wind Under Constant Shear Conditions. The qualitative shapes of the profiles are shown at left. The quantitative wind values at the hub and at the $77 \%$ of the blade radius upward and downward from the hub are shown in units of $\mathrm{m} / \mathrm{s}$. The blade rotation rate is $12.5 \mathrm{rpm}$ for this simulation. 
differencing can be related to the force that would cause a blade with a pinned hub to teeter in a direction perpendicular to the disk of rotation. These two combinations are shown for the three types of shear profiles in Figure 2-3.

For linear shear, the two-blade average is constant while the two-blade difference varies exactly as the wind sensed by a single blade element. The simplified analogy for the turbine would be constant torque on the shaft, which would produce a constant power output, while the blade would be teetering at one cycle per revolution to alleviate the flatwise bending force indicated in the trace for the single blade element.

For the case with positive shear in the lower half of the disk of rotation and no shear in the upper half, the two-blade average varies at two cycles per revolution while the two-blade difference still varies sinusoidally at one cycle per revolution. The analogy for the turbine would be a two-cycleper-revolution variation in the torque on the shaft, which could produce a similar variation in the power output, while the blade would be teetering as it did in the case of linear shear to alleviate the flatwise bending force.

For the case of positive shear in the lower half of the disk of rotation and negative shear in the upper half, the two-blade average varies exactly as the wind sensed by a single blade element while the two-blade difference has a constant zero value. The analogy for the turbine in this case is a two-cycleper-revolution variation (with twice the amplitude of the previous case) in the torque on the shaft. This would contribute to a similar variation in the power output, while the blade would not be teetering to alleviate the flatwise bending force indicated in the single blade element trace.

Similar traces could be produced for other combinations of shear profiles, but one can mentally construct traces from various combinations of the three shown in Figure 2-3. For example, if the shears are reversed in the upper and lower halves of the disk of rotation, the traces would simply be inverted but still have the same characteristics. 
. 


\subsection{SIMULATION MODEL}

Wind data from anemometers mounted on the 481-m, WKY-TV tower near Oklahoma City, Oklahoma, provided the opportunity to investigate wind shear profiles and their variability over a range of multimegawatt turbine sizes. The elevations of the anemometers in the lowest $183 \mathrm{~m}(600 \mathrm{ft})$ of the tower are indicated in Figure 3-1 in relation to the dimensions of three large turbine types selected to be representative of a range of blade size and hub heights. The blade diameters, hub heights, highest and lowest sampling points and rotation rate for each of the three turbine types are shown in Table 3-1.

The wind measurements from the WKY-TV tower were made by the National Severe Storms Laboratory, National Oceanic and Atmospheric Administration, at 10-s intervals. A 1-min sequence of 10-s measurements is shown in Figure 3-1 to illustrate the variability that can occur in the wind profile. Between 10 and 20 seconds a strong surge in the wind speed near the $92-\mathrm{m}(300-\mathrm{ft})$ level caused a strong shear condition, which weakened over the next 20 seconds to a very low shear condition. Over the last 20 seconds there was a short excursion to a reversal of the strong shear condition at 20 seconds and then the low shear condition returned.

In order to examine the nature of the oscillations in the wind sensed by elements of the blades and in the combinations illustrated and discussed in the previous section of this report, a simulation model was constructed to interpolate both in space between the anemometers on the tower and in time between the 10-s samples to produce a time series of winds sensed by the elements at points $77 \%$ of the way from the hub to each blade tip.

For illustrative purposes, time series of rotationally sampled winds were constructed for the 1-min sequence of wind profiles shown in Figure 3-1. The time series of wind sensed by single blade elements of the three turbines are shown in Figure $3-2 a$ and $b$. The two-blade averages and differences are shown in Figure $3-3 a$ and $b$. The striking feature of these plots is the variety

of shear conditions that can occur over a 1-min period and the differences in the resulting forcing functions due to different blade lengths and hub heights. 

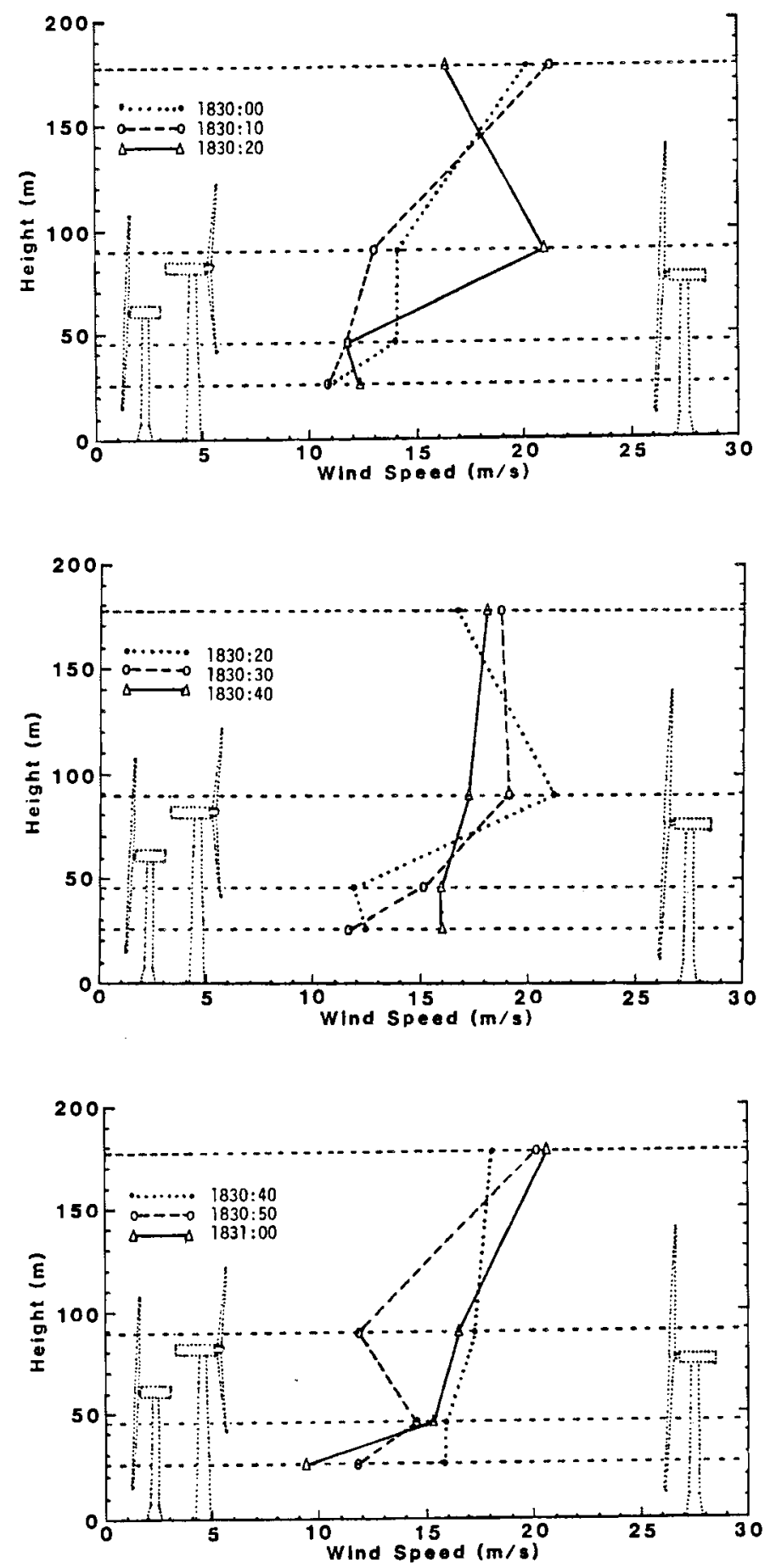

FIGURE 3-1. Sequential 10-s Wind Profiles Derived From WKY-TV Tower Data Beginning at 1830:00 CST, March 10, 1977. The dashed horizontal lines indicate the levels of the anemometers. The dotted turbine outlines are included to show relative size and represent from left to right Type 1, Type 3, and Type 2 wind turbines. 
TABLE 3-1. Wind Turbine Configurations Used in Rotational Sampling Simulation

\begin{tabular}{|c|c|c|c|c|c|}
\hline Turbine & $\begin{array}{c}\text { Blade } \\
\text { Diameter } \\
\mathrm{m}(\mathrm{ft})\end{array}$ & $\begin{array}{c}\text { Hub } \\
\text { Height } \\
\mathrm{m}(\mathrm{ft})\end{array}$ & $\begin{array}{c}\text { Upper } \\
\text { Sampling } \\
\text { Level (a) } \\
\mathrm{m}(\mathrm{ft})\end{array}$ & $\begin{array}{c}\text { Lower } \\
\text { Sampling } \\
\text { Level(a) } \\
\mathrm{m}(\mathrm{ft})\end{array}$ & $\begin{array}{c}\text { Rotation } \\
\text { Rate } \\
(\mathrm{rpm})\end{array}$ \\
\hline $\begin{array}{c}\text { Type 1 } \\
\omega \\
\text { (MOD-2 Size) }\end{array}$ & $91.4(300)$ & $61.0(200)$ & $96.0(315)$ & $26.0(85)$ & 17.5 \\
\hline $\begin{array}{c}\text { Type 2 } \\
\text { (MOD-5 Size) }\end{array}$ & $128.0(420)$ & $76.2(250)$ & $125.6(412)$ & $26.8(88)$ & $10-15$ \\
\hline $\begin{array}{c}\text { Type 3 } \\
\text { (WTS-4 Size) }\end{array}$ & $78.2(256)$ & $80.2(263)$ & $110.4(362)$ & $50.0(164)$ & 30 \\
\hline
\end{tabular}

(a) These values are obtained by assuming a resultant wind may be applied $77 \%$ of the distance from the hub to the blade tip. 
a) Wind Sensed by a Single Blade Element (related to flatwise bending moment)

$\stackrel{w}{\vdots}$
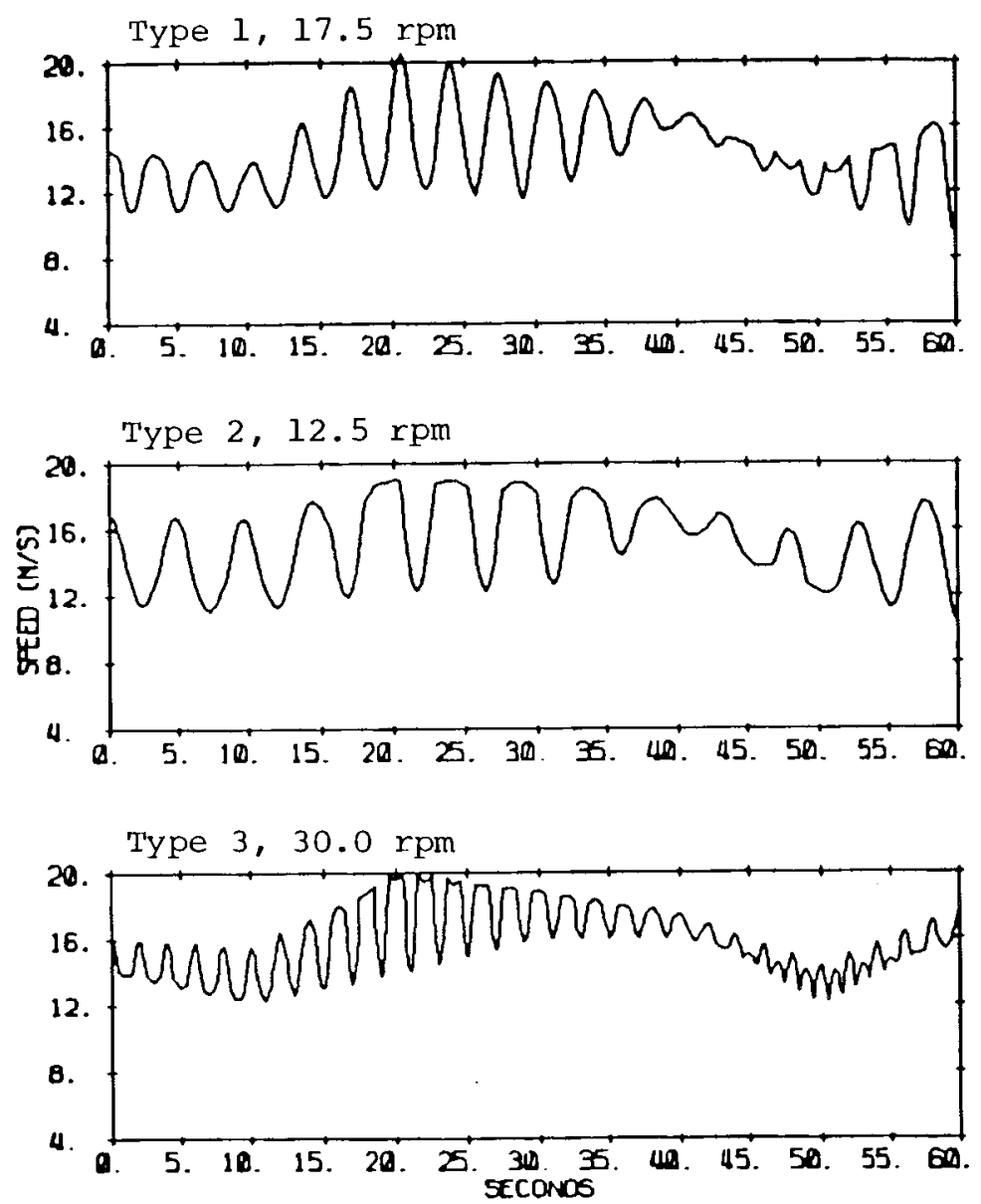

b) Wind Sensed by Two Blades - blade 1 ... blade 2
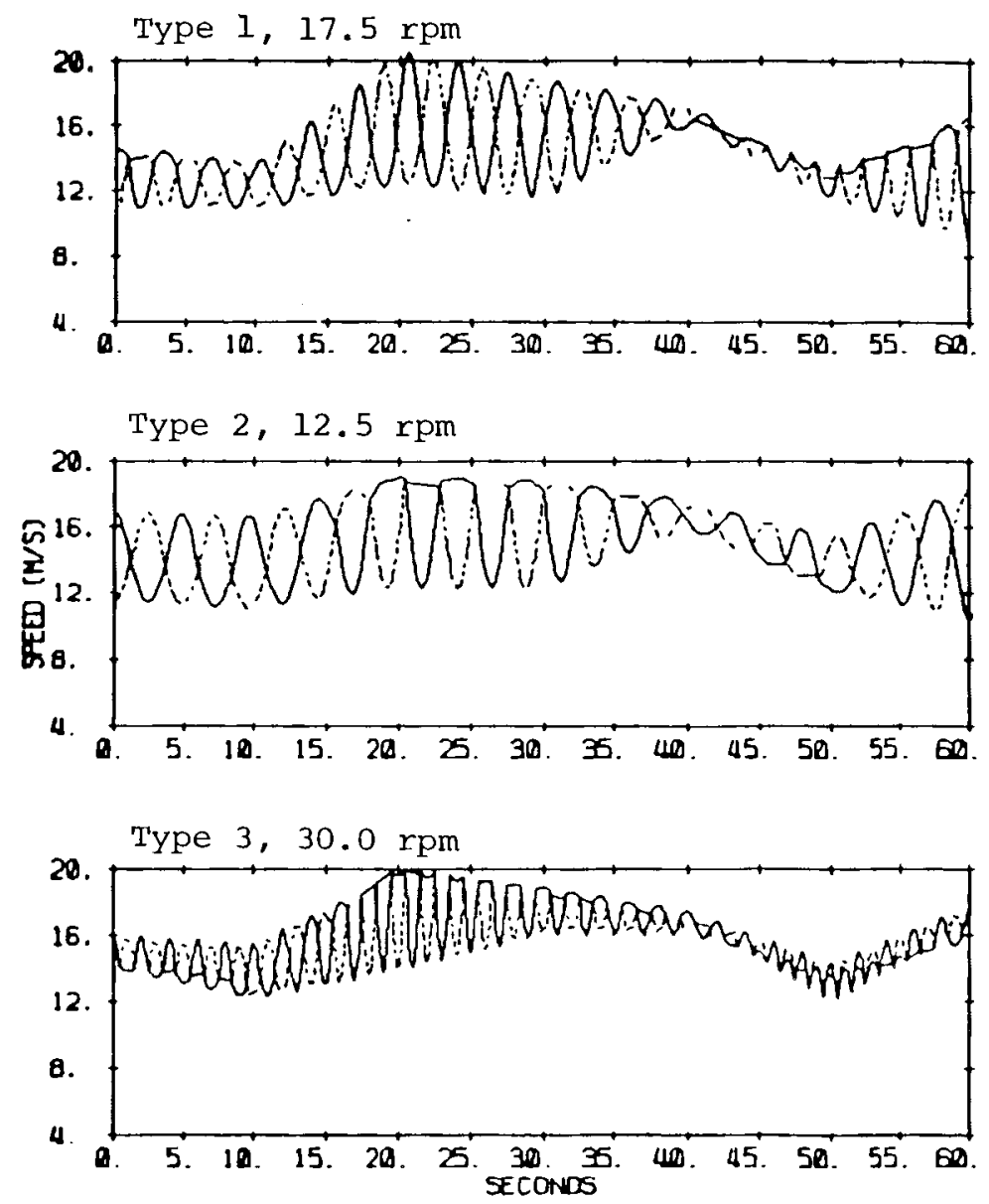

FIGURE 3-2. Comparison of Rotational Sampling Simulation for Three Types of Wind Turbines During the Period 1830:00 to 1831:00, March 10, 1977, Shown in Figure 3-1 for a) a single Blade Element and b) for Opposite Blade Elements 
a) Two-Blade Average

(related to torque on the shaft)

Type 1, $17.5 \mathrm{rpm}$

$\omega$
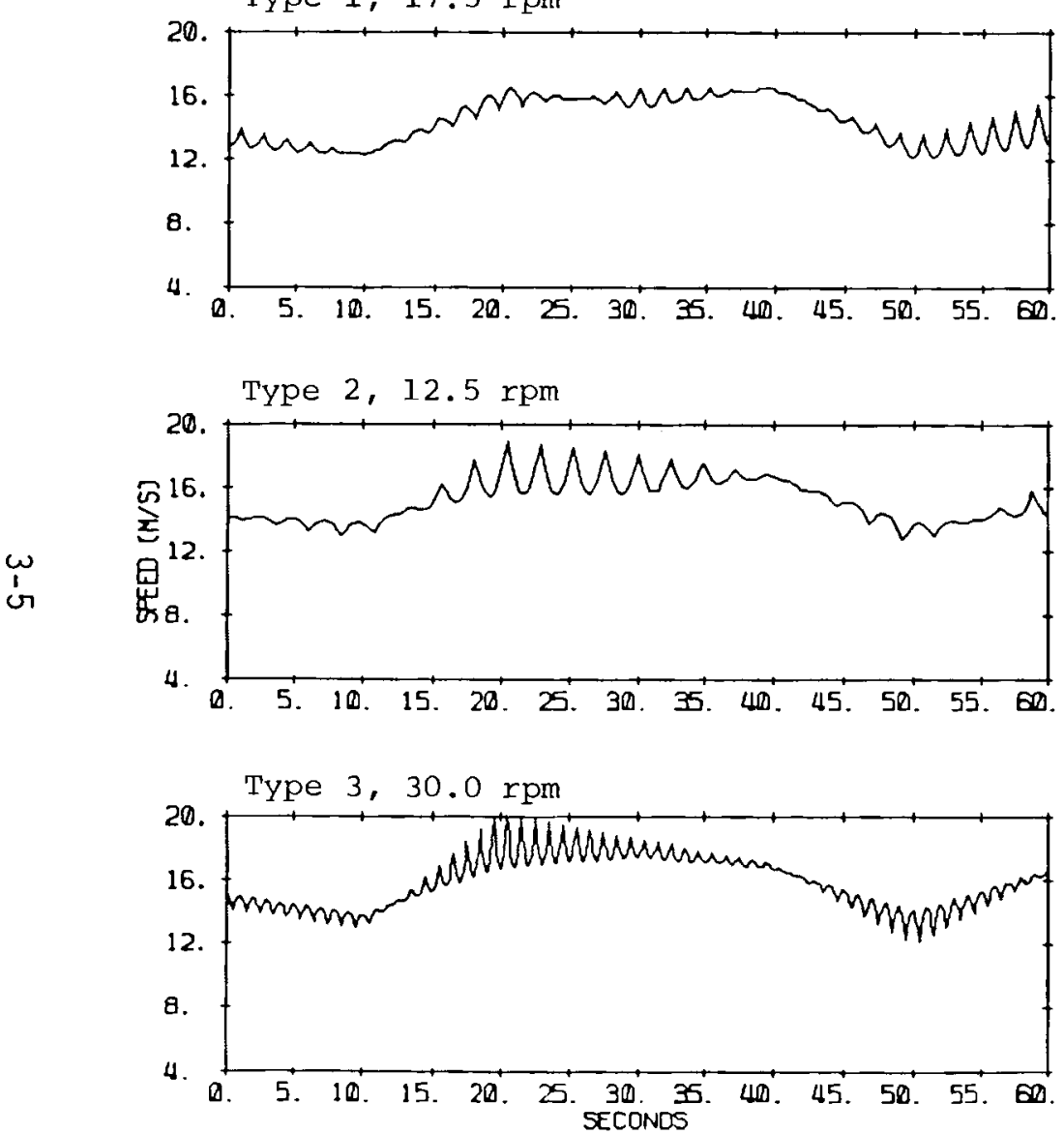

b) Two-Blade Difference/2

(related to teeter angle)

Type 1, $17.5 \mathrm{rpm}$
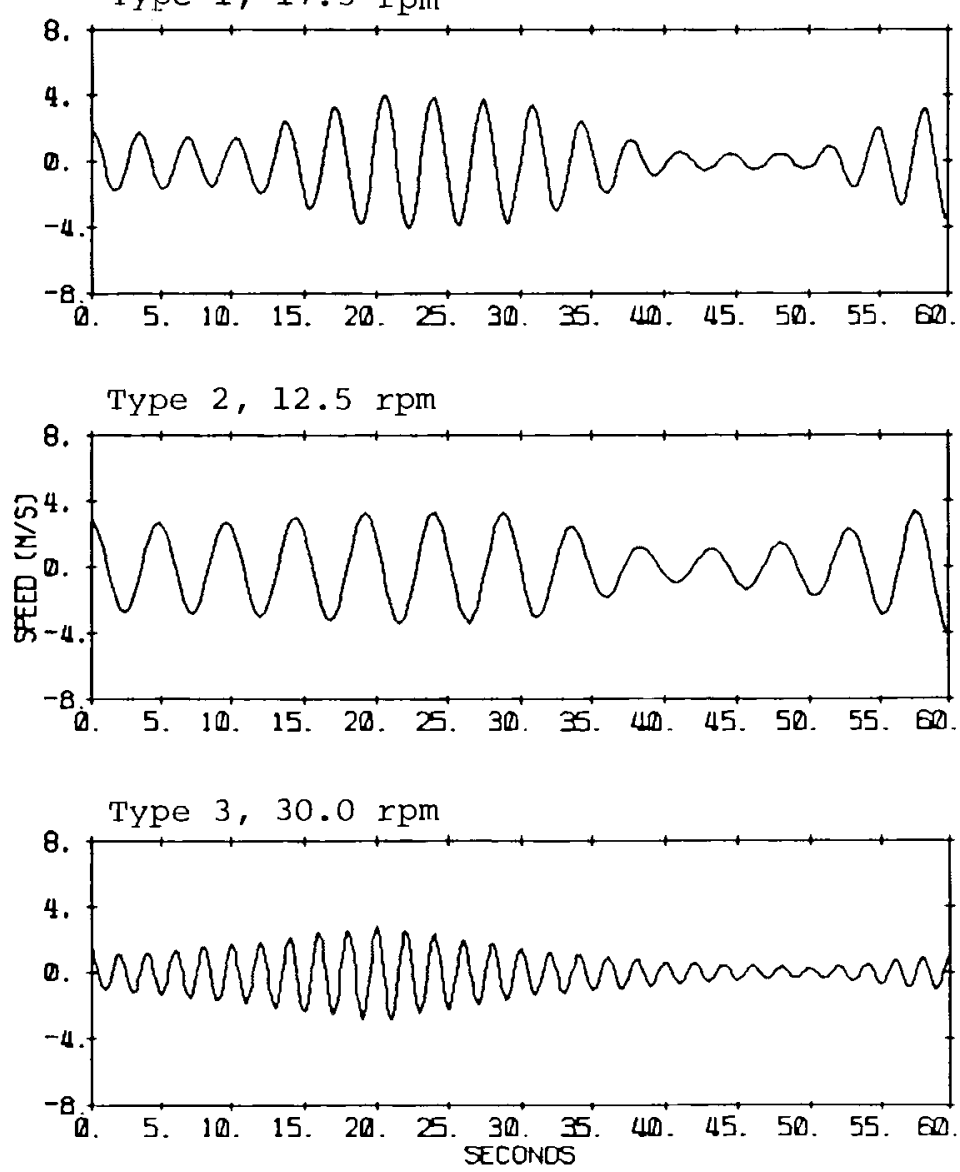

FIGURE 3-3. Results of a) Averaging and b) Differencing Time Series of Rotationally Sampled Winds for Opposite Blade Elements as Shown in Figure 3-2b. 
One has to keep in mind that the space and time resolution of the wind data along with the assumption of uniform conditions in the horizontal across the disk of rotation will make the time series of rotationally sampled winds appear artificially smooth. However, comparisons with similar series, such as the one shown in Figure 2-1 that have been produced by rotational sampling on a vertical plane array, indicate that the major features are representative.

This was further verified through comparisons of simulations of rotationally sampled winds based on data sampled once per second at three levels on a tower at Goodnoe Hi11s, Washington, with simulations based on every tenth value of the same data and interpolated as with the WKY-TV tower data. A sample comparison is shown in Figure 3-4. The major features of the fluctuations are easily identifiable in the interpolated time series. There has been no opportunity to test the sensitivity to a data set with more measurement levels, except on the smaller scale of the vertical plane array.

NASA-Lewis Research Center has recently provided some data for comparison from one of the MOD-2 wind turbines at Goodnoe Hills, Washington. A brief portion of the trace of the teeter angle is shown in Figure 3-5. Even though the time and place are not the same, the one-cycle-per-revolution variation and the nature of the fluctuations in amplitude are very similar to the characteristics of the two-blade difference for the Type 1 turbine shown in Figure 3-3b.

The plots in Figures $3-2$ and $3-3$ suggest that a more sophisticated analysis might be pursued incorporating the airfoil characteristics and a more quantitative calculation of the effects of the time-varying forcing function. However, the objective of this work is to examine the nature of the shear characteristics over the height of multi-megawatt turbines, in particular, those characteristics measured over the time scale of a few revolutions of the turbine. In order to do this, a climatology of profile types is required. A climatology for the WKY-TV tower site is described and presented in the next section. 
a) ONE-SECOND SAMPLES
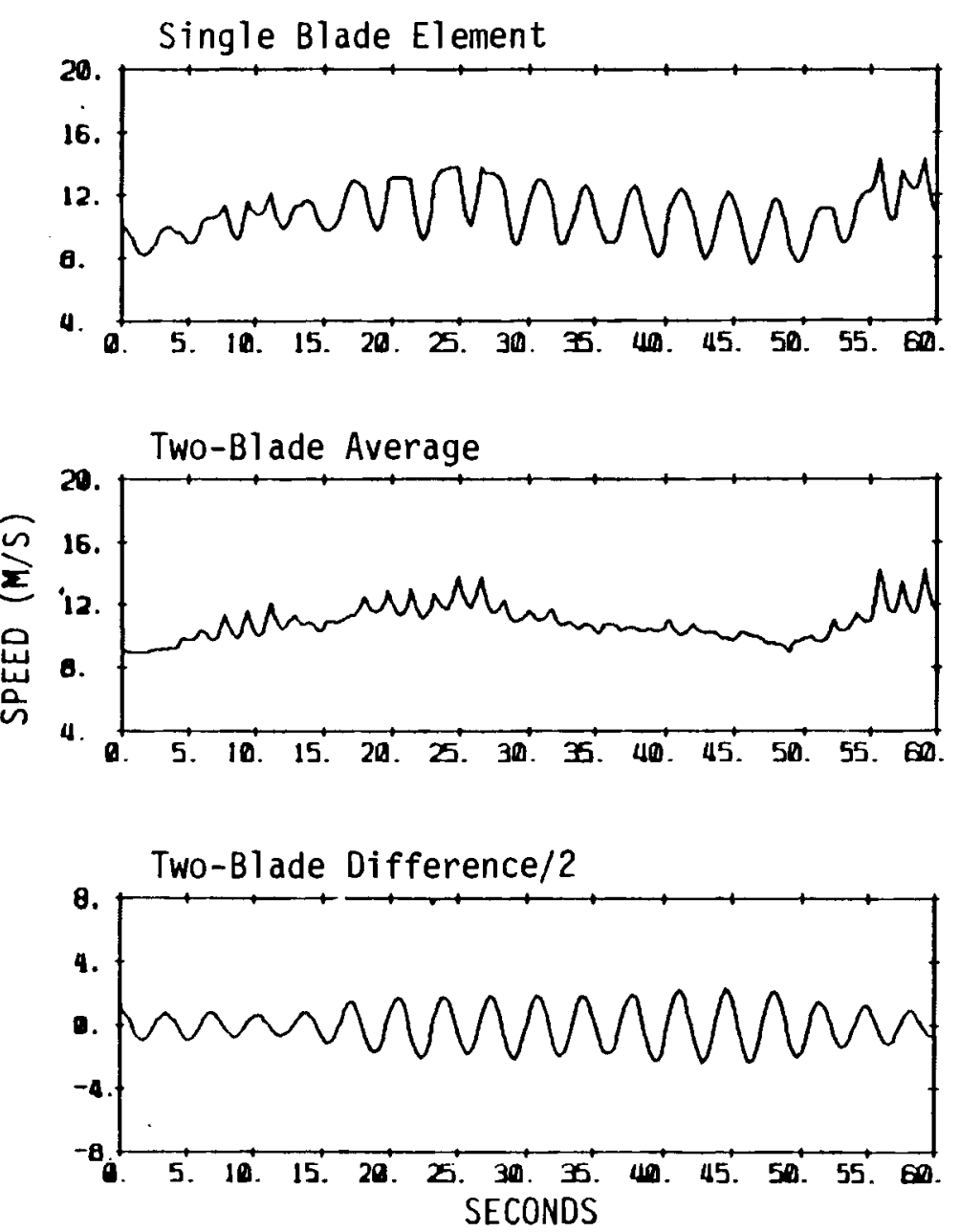

b) INTERPOLATION FROM TEN-SECOND SAMPLES
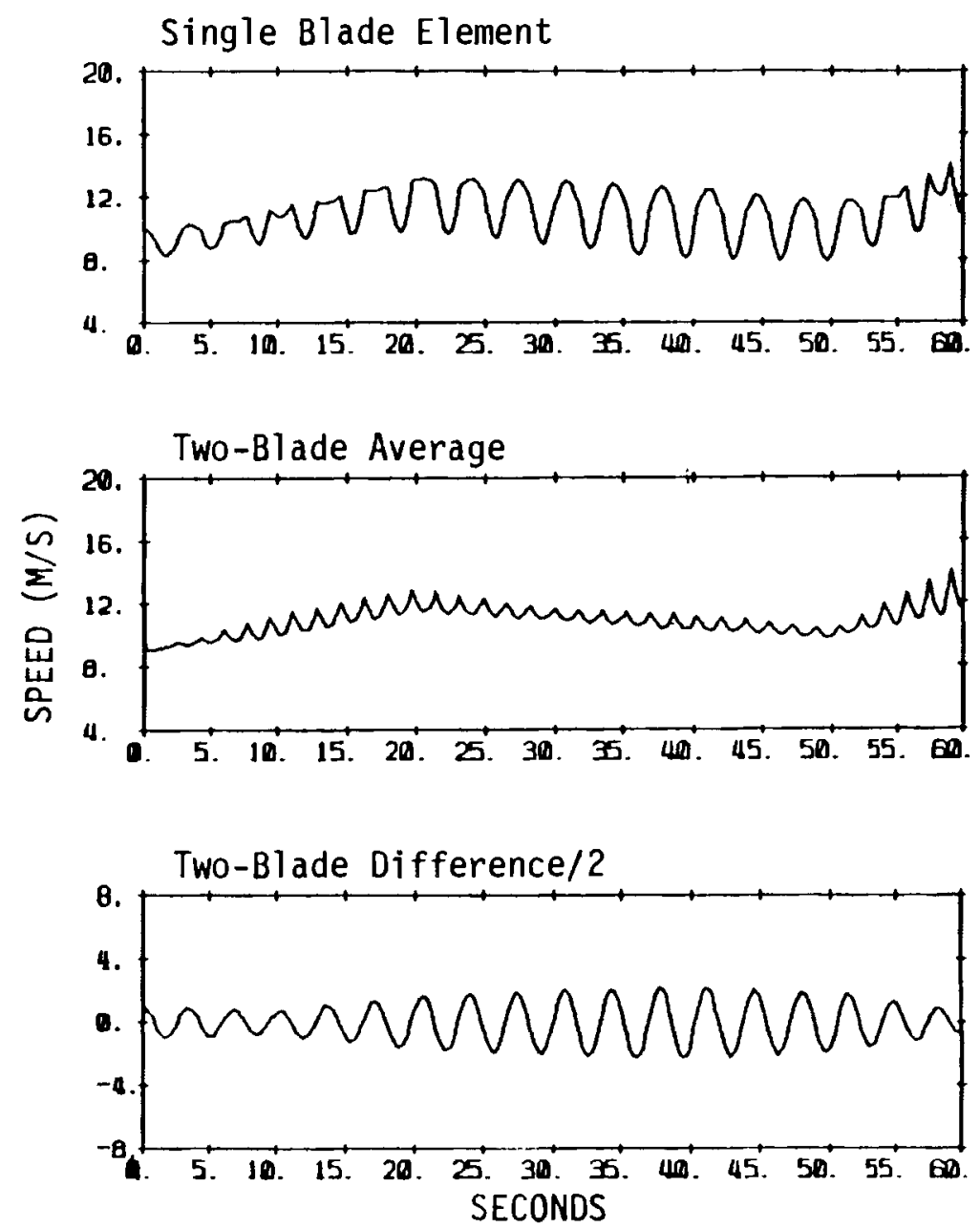

FIGURE 3-4. Sample Comparison of Type 1 Turbine Simulations with Goodnoe Hills Tower Data for a) 1-s Samples and b) Interpolation From 10-s Samples 


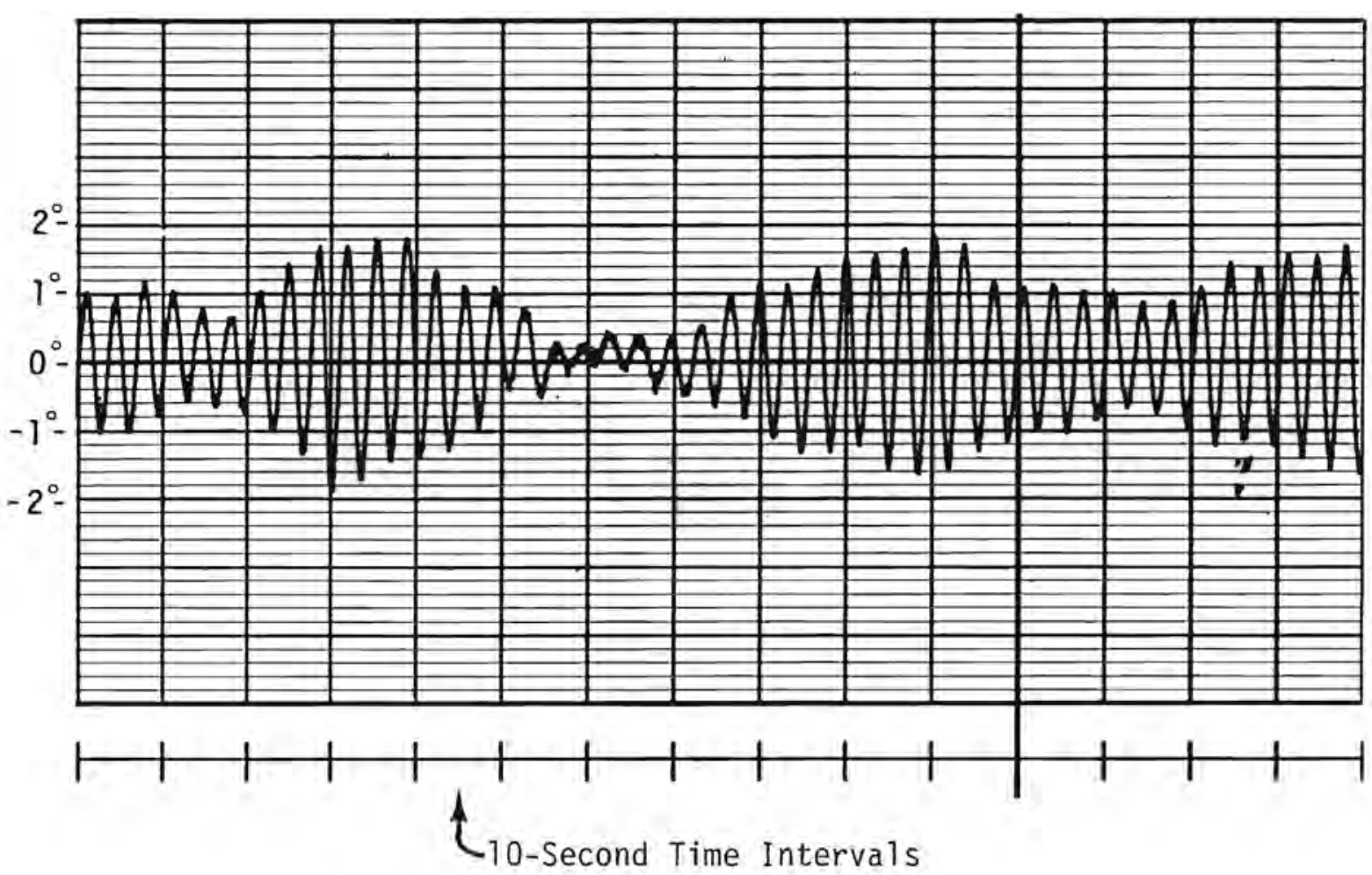

FIGURE 3-5. Sample Record of MOD-2 Teeter Angle Beginning on the Right at 2324:00, March 10,1982, at Goodnoe Hills, Washington 


\subsection{WIND SHEAR CLIMATOLOGY}

This section describes the climatology of wind shear profiles at the WKY-TV tower site for three large wind turbine types. The first part of this section (4.1) describes the methodology used in the analysis of the wind shear profiles. The results of the wind shear profile analysis are described and presented in 4.2 in the form of a) seasonal and annual frequency distributions of the wind shear profiles derived from 10-s sampled winds and hourly average winds, and b) contours of the seasonal and annual percent frequency of wind shear profiles for daytime, nighttime, and all hours derived from 10-s sampled winds.

The analysis is based on 10-s sampled winds and hourly average winds collected at the $481-\mathrm{m}$ WKY-TV tower $10 \mathrm{~km}$ northeast of Oklahoma City, Oklahoma. One year's wind data (October 1976 through September 1977) were available from the tower. The area surrounding the tower consists of gently rolling terrain with no more than a 40-m change in elevation within a 4-km radius of the tower. The land area is used for agriculture. Wooded areas are spotty and confined generally to gullies and near small ponds.

\subsection{METHODOLOGY FOR WIND SHEAR PROFILE ANALYSIS}

The hub height and highest and lowest sampling points (based on $77 \%$ of the distance from the hub to each blade tip) used for the top and bottom levels, respectively, were shown in Table 3-1 for the three types of wind turbines considered in this analysis. For interpolating wind speeds over the height range of the effective blade diameters of the three types of turbines, only four levels of wind data from the WKY-TV tower were needed. The levels used were $26 \mathrm{~m}, 45 \mathrm{~m}, 89 \mathrm{~m}$, and $177 \mathrm{~m}$. The wind speeds were linearly interpolated to each wind turbine's hub height.

In order to reduce the volume of $10-\mathrm{s}$ wind data to be used in the analysis, only windy hours of the year during which a large wind turbine would be operating a substantial part of the time were selected. Since hourly average wind speed data were also available from the WKY-TV tower for the same time period 
as the 10-s data, the hourly average data were used to screen the windy periods. Those hours of the year having a mean hourly speed of at least $7 \mathrm{~m} / \mathrm{s}$ at either the 45-m or 89-m level were selected for analyzing the frequency of occurrence of 10-s wind shear profiles. Table 4-1 lists for each month the percentage of total hours that had mean hourly wind speeds of $7 \mathrm{~m} / \mathrm{s}$ or greater.

\section{TABLE 4-1. Percentage of Total Hours With Mean Hourly Wind Speeds Greater Than or Equal to $7 \mathrm{~m} / \mathrm{s}$ at Either $45 \mathrm{~m}$ or $89 \mathrm{~m}$ at the WKY-TV Tower}

\begin{tabular}{lc}
\multicolumn{1}{c}{ Month } & Percent \\
\cline { 1 - 1 } January & 32.75 \\
February & 44.11 \\
March & 51.08 \\
Apri1 & 44.17 \\
May & 47.85 \\
June & 41.25 \\
July & 34.81 \\
August & 36.56 \\
September & 37.78 \\
October & 36.96 \\
November & 32.50 \\
December & 39.00
\end{tabular}

The frequency of occurrence of wind shear profiles within the operating ranges for the three large wind turbines was then analyzed. (Table 4-2 1ists the operating ranges specified for each type of wind turbine.) The analysis is presented in the form of joint frequency distributions of velocity differences for top-to-hub versus hub-to-bottom in $\Delta V$ intervals of $1 \mathrm{~m} / \mathrm{s}$, as shown in Figures 4-2 through 4-16 at the end of subsection 4.2.1.

TABLE 4-2. Wind Speed Operating Ranges Used for the Wind Turbines. Speeds are at hub height.

\begin{tabular}{llll} 
& \multicolumn{1}{c}{ Cut-in } & & Cut-out \\
\cline { 2 - 3 } Type 1 Turbine & $6.26 \mathrm{~m} / \mathrm{s}(14 \mathrm{mph})$ & $20.12 \mathrm{~m} / \mathrm{s}(45 \mathrm{mph})$ \\
Type 2 Turbine & $4.0 \mathrm{~m} / \mathrm{s}(9 \mathrm{mph})$ & $26.8 \mathrm{~m} / \mathrm{s}(60 \mathrm{mph})$ \\
Type 3 Turbine & $7.1 \mathrm{~m} / \mathrm{s}(15.9 \mathrm{mph})$ & $26.8 \mathrm{~m} / \mathrm{s}(60 \mathrm{mph})$
\end{tabular}


A key to interpreting the information within each cell of the joint frequency distributions is presented in Figure 4-1. For convenience, $\Delta V$ top-tohub is referred to as $\Delta V$ upper or $\Delta V_{u}$, whereas $\Delta V$ hub-to-bottom is referred to as $\Delta V$ lower or $\Delta V_{\ell}$. The dashed line is inserted merely for reference in comparing profiles and approximates the 1/7 power law for hub-height wind speeds of about $9 \mathrm{~m} / \mathrm{s}$. Profiles are plotted in relation to the height above ground shown in the scale in the left portion of Figure 4-1.

The percent frequency of occurrence of each $\Delta V_{u}$ versus all $\Delta V_{\ell}$, and vice versa, is tallied in the total percent figures along the right and bottom of the joint frequency distributions shown in Figures 4-2 through 4-16. These total percent figures also include those occurrences outside the range of $\Delta V$ values.

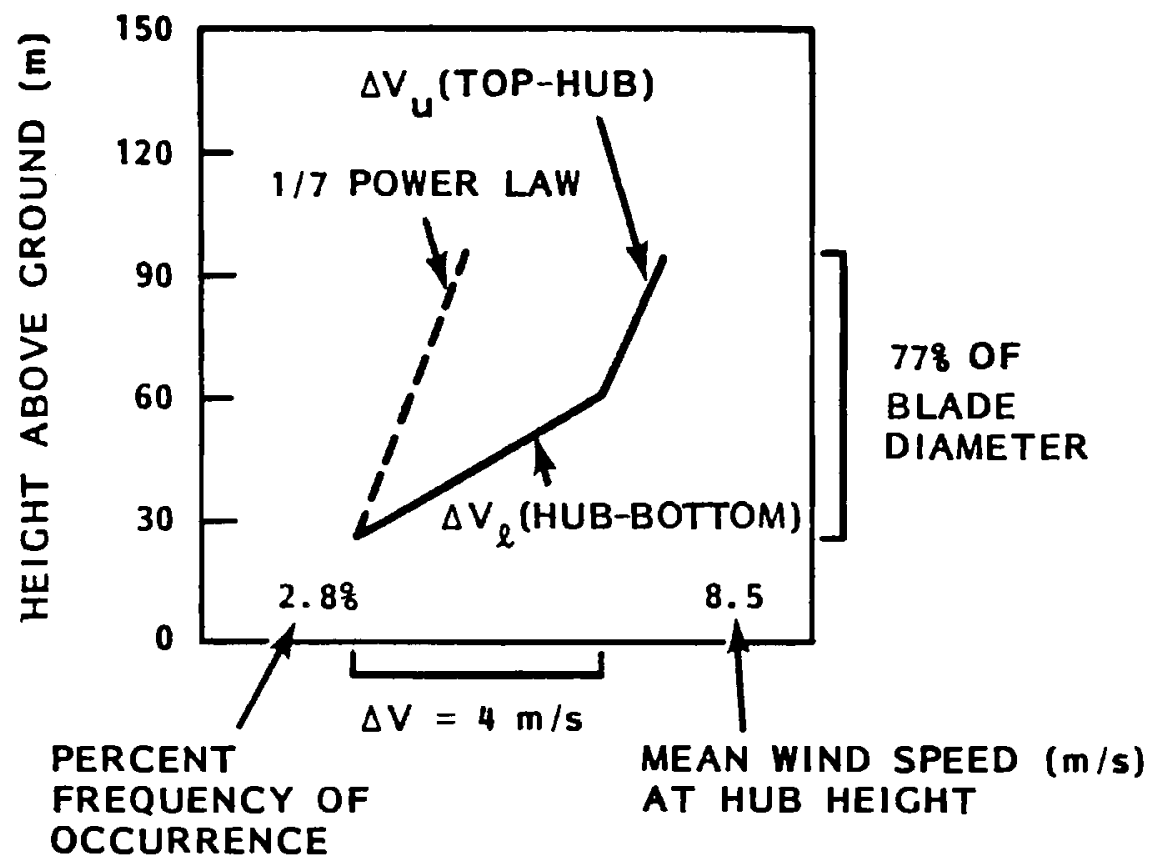

FIGURE 4-1. Key to Interpretation of Information Within Each Ce11 of the Wind Shear Profile Tables (see Figures 4-2 to 4-16). The example shown above is for a Type 1 turbine and a $\Delta V_{u}$ of $1 \mathrm{~m} / \mathrm{s}$ and $\Delta V_{\ell}$ of $4 \mathrm{~m} / \mathrm{s}$. 
Percent frequency contours of the wind shear profiles for 10 -s sampled winds were also constructed for the three wind turbine types. This method of analysis allows for an easy comparison of the diurnal and seasonal variability of the wind shear profiles (see Figures 4-17 through 4-24 at the end of subsection 4.2 .2 for examples of these contour analyses).

\subsection{RESULTS OF WIND SHEAR PROFILE ANALYSIS}

\subsubsection{Joint Frequency Distribution Analyses of Wind Shear Profiles}

Joint frequency distributions of hourly average and 10-s wind shear profiles within operating ranges of the wind turbines (see Table 4-2) are shown for Type 1,2, and 3 turbines for a representative month of each season in Figures 4-2 to 4-13 and for the year (based on the average of the four months) in Figures 4-14 through 4-16. Only those hours in each month that were used in the analysis of 10-s wind shears were used in the analysis of hourly average wind shears (see Table 4-1).

The distribution of hourly average wind shear profiles shows a much smaller spread than the distribution of $10-\mathrm{s}$ profiles. For example, in the nine cells in the upper left and nine cells in the lower right of Figure 4-2b, no occurrence of wind shear profiles is indicated when hourly average data are used. However, $18.5 \%$ of the profiles derived from 10-s sampled winds are found in these same cells in Figure $4-2 a$. This implies that a rotating blade would experience a much wider range of wind shear profile conditions and a higher percentage of extreme shears than indicated by the hourly average wind shear profiles.

Sensitivity analyses using 2-min and 5-min sampled winds indicated that the frequency distribution of wind shear profiles based on 2-min and 5-min sampled winds is not significantly different than that based on 10-s sampled winds. Thus, 2-min to 5 -min instantaneous winds may be used to estimate the frequency distribution of wind shear profiles as reliably as 10-s sampled winds. However, the frequency distribution of shear profiles based on 2-min averaged winds more closely resembles the hourly average results than the 2-min instantaneous samples. 
Substantial variations in the distribution of the 10-s wind shear profiles among the three types of wind turbines and over the four seasons are apparent from an examination of the figures. For the Type 1 and Type 2 turbines, autumn and winter generally indicate a wider spread (greater range) of $10-s$ wind shear profile conditions than do spring and summer. For the Type 3 turbine, seasonal variations in wind profile distributions are much less pronounced.

Speed differences in the lower half of the disk of rotation are typically greater than those in the upper half and are greatest for the Type 2 turbine. For example, in Figures $4-14 a$ to $4-16 a$, the 10-s shear analyses show that the Type 2 turbine experiences shears of $4 \mathrm{~m} / \mathrm{s}$ or greater in the lower half of the disk about 3 times more frequently than the Type 1 turbine and about 18 times more frequently than the Type 3 turbine.

Extreme $\Delta V$ values of $6 \mathrm{~m} / \mathrm{s}$ or greater across the effective blade diameter, as shown in upper portion of Figure $2-3$, occur only $0.5 \%$ of the time during the year for the Type 3 turbine, $6 \%$ of the time for the Type 1 turbine, and $18 \%$ of the time for the Type 2 turbine (see Figures $4-14 a$ to $4-16 a$ ). These profiles are more frequent in the autumn and winter than in the spring and summer for the Type 1 and Type 2 turbines.

Small $\Delta V$ values (less than $1 \mathrm{~m} / \mathrm{s}$ across the effective blade diameter) are experienced about 2 to 3 times more frequently for the Type 3 turbine than the Type 1 or Type 2 turbine. Wind shear profiles approximately equal to the $1 / 7$ power 1 aw (across the effective disk of rotation) occur about 15 to $20 \%$ of the operating time for the Type 3 turbine, about 10 to $15 \%$ for the Type 1 turbine, and about 5 to $10 \%$ for the Type 2 turbine.

Wind shear profiles with a maximum or minimum speed at hub height, as shown in the example in the lower part of Figure 2-3, can present a wind turbine with a forcing function quite different from that generally expected. Shear profiles with a maximum speed at hub height (relative to upper and lower levels) can be seen on the upper left side of the matrix of cells in Figures 4-2 through 4-16. Using the notation $\left(\Delta V_{u}, \Delta V_{l}\right)$ to identify cell 
locations within the matrix, these shear profiles are represented by cells $(-1,5)$ through $(-1,1)$. Annually, these profiles occur about $4.2 \%$ of the operating time for the Type 1 turbine, 1.3\% of the time for the Type 2 turbine, and only $0.1 \%$ for the Type 3 turbine (see Figures $4-14 a$ through $4-16 a$ ). However, these estimates are dependent on the number and height of the measurement levels above ground. It is anticipated that the low number of occurrences of these profiles for the Type 3 turbine may not be representative because only two measurement levels are within the height of the blade diameter. In addition, the other level $(177 \mathrm{~m})$ is so far above the turbine blade that it has only a relatively small influence on the winds sampled by the turbine blade.

Shear profiles with a maximum speed at hub-height levels appear to be most prevalent during the winter months. For example, the frequency of occurrences of these profiles for the Type 1 turbine varies from $1.4 \%$ in the summer (Figure 4-11) to $7.6 \%$ in the winter (Figure 4-5). Even the hourly average data show occurrences of these profiles in the winter, but the frequencies are less than one-third those indicated by the 10-s data analyses. No occurrences of these profiles are indicated by the hourly average data analyses for the other three seasons.

Shear profiles with a minimum at hub-height levels are represented by cel1s $(1,-1)$ to $(4,-1)$ and have a frequency of occurrence $1.6 \%$ for the Type 1 turbine, $2.5 \%$ for the Type 2 turbine, and $1.7 \%$ for the Type 3 turbine. These shear profiles are most prevalent in the winter for the Type 2 and Type 3 turbines. No occurrences of these profiles are indicated by the hourly average data analyses for any of the four seasons. 
(a)

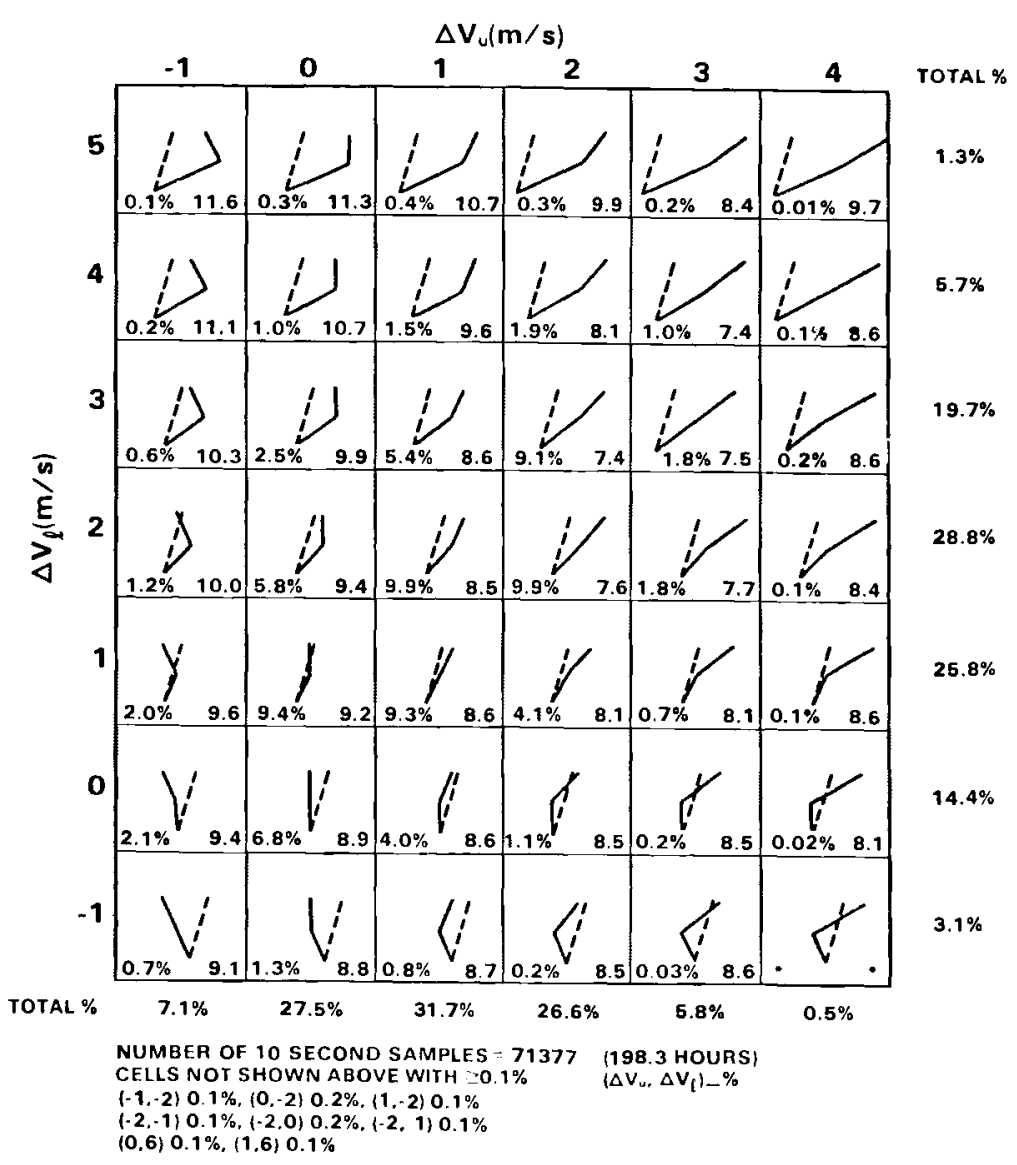

(b)

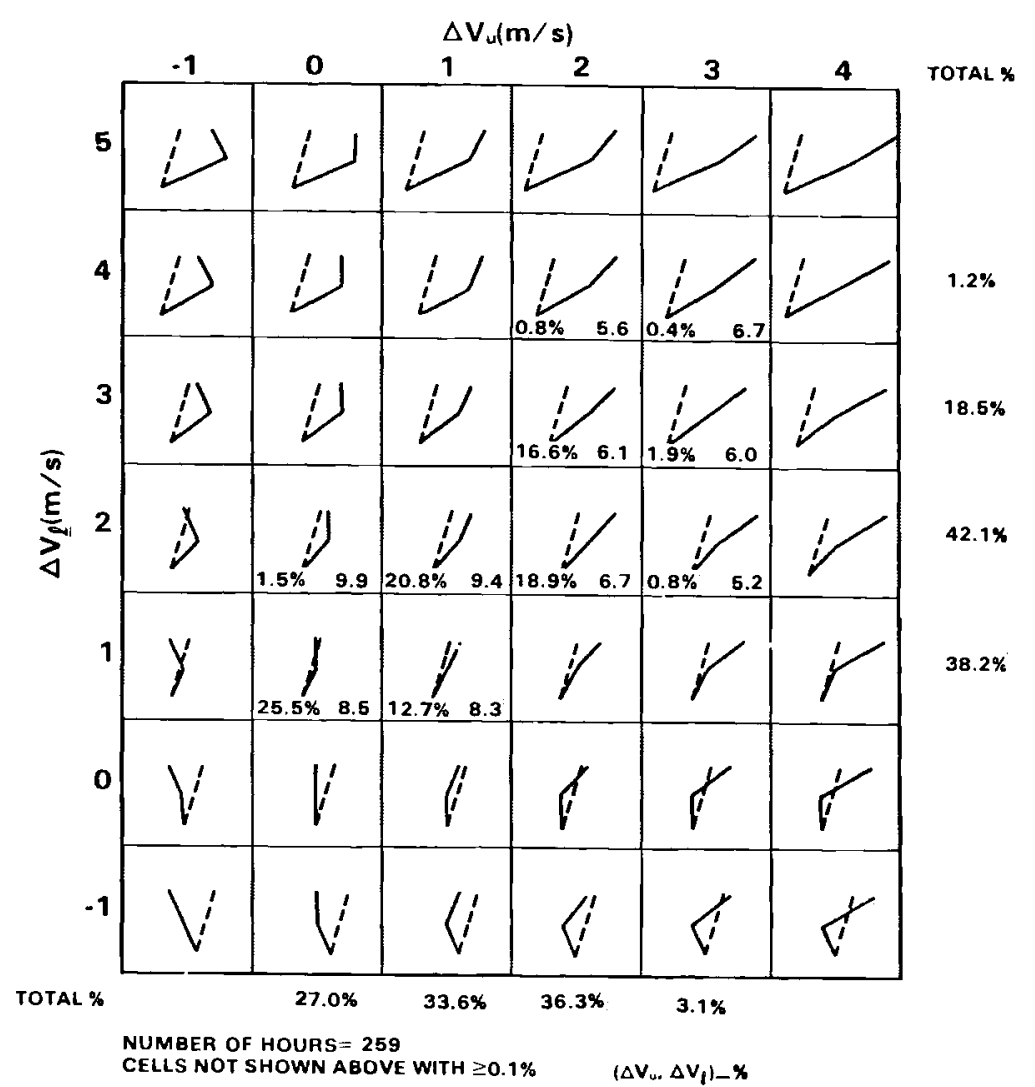

FIGURE 4-2. Frequency of Occurrence of Wind Shear Profiles for a Type 1 Turbine During Windy Hours in October 1976 (See Table 4-1) for Conditions Within Turbine Operating Range (see Table 4-2) Using (a) 10-s Sampled Winds, and (b) Hourly Average Winds. For interpretation of graphs and numbers within the cells, see Figure 4-1. The percent figures at the right and bottom represent the sums of the frequency values for the lower and upper velocity differences respectively. 
(a)

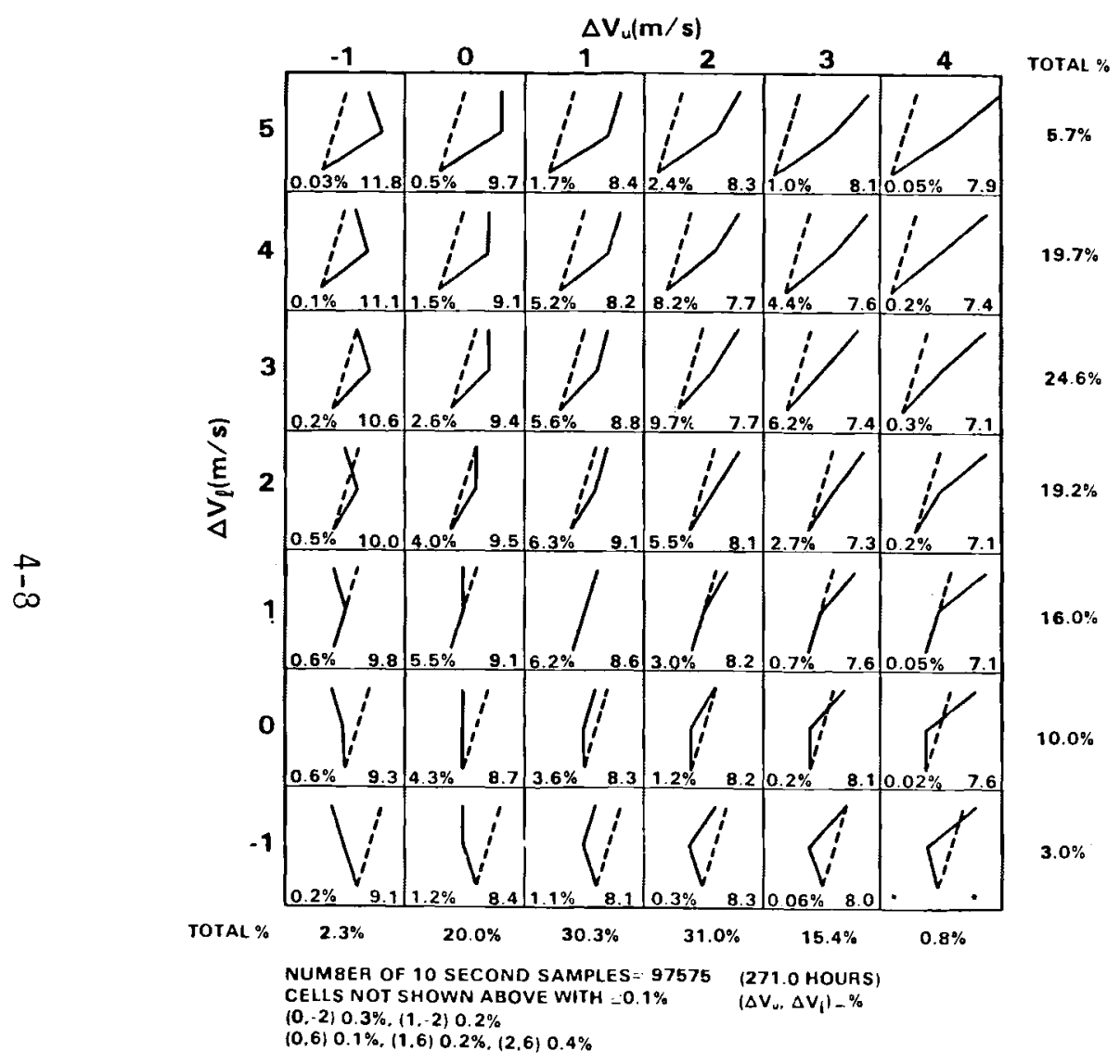

(b)

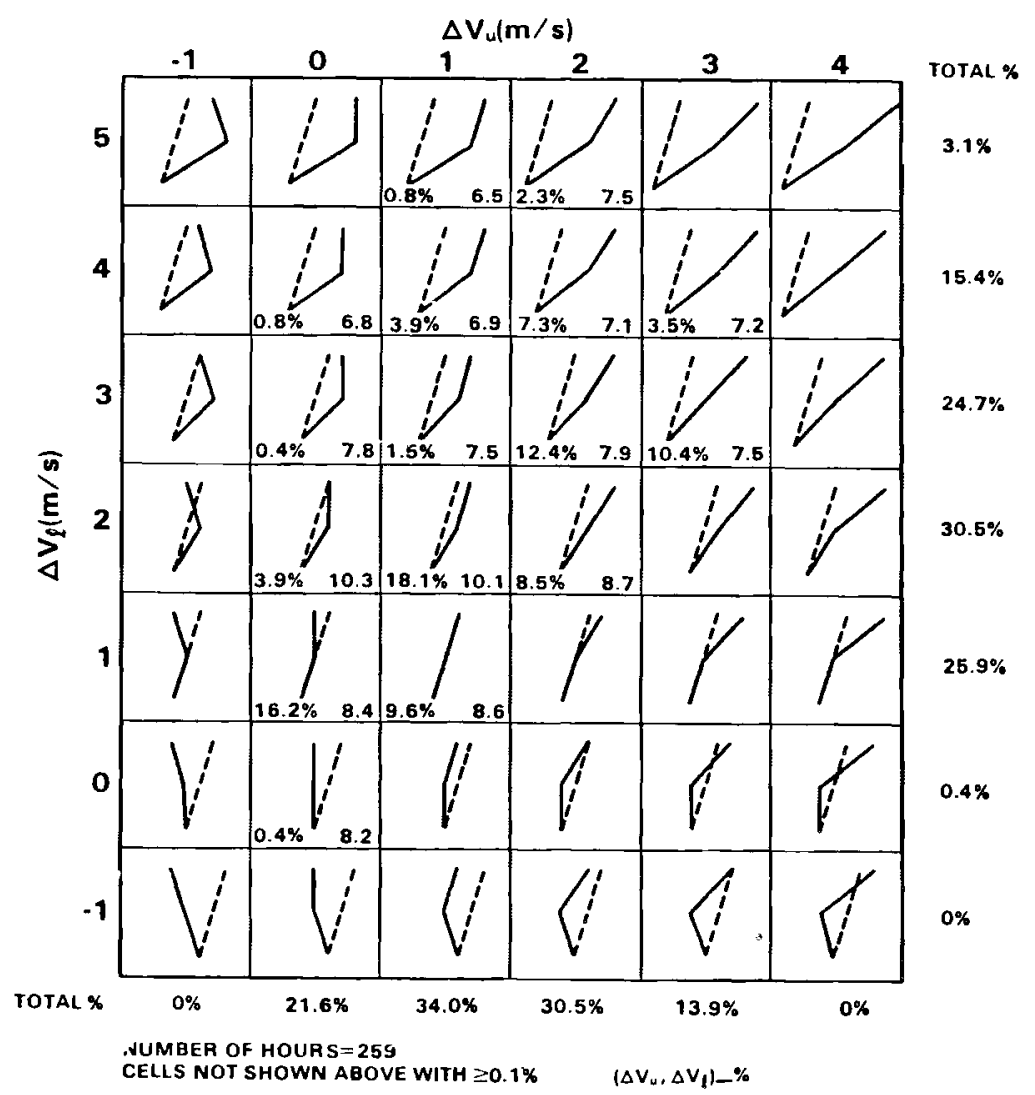

FIGURE 4-3. Type 2 Turbine for Autumn (October 1976). See Figure 4-2 for detail. 
(a)

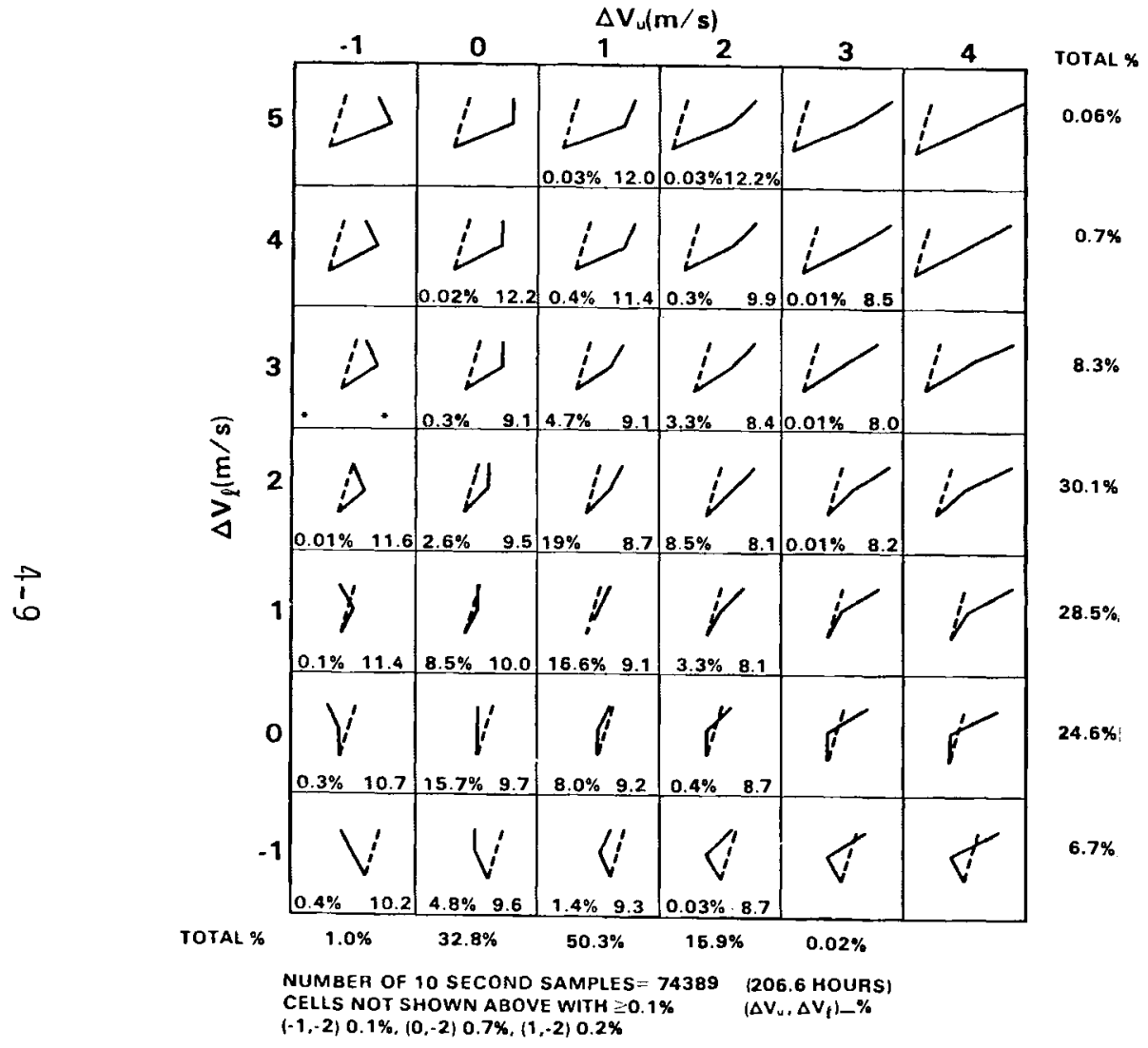

(b)

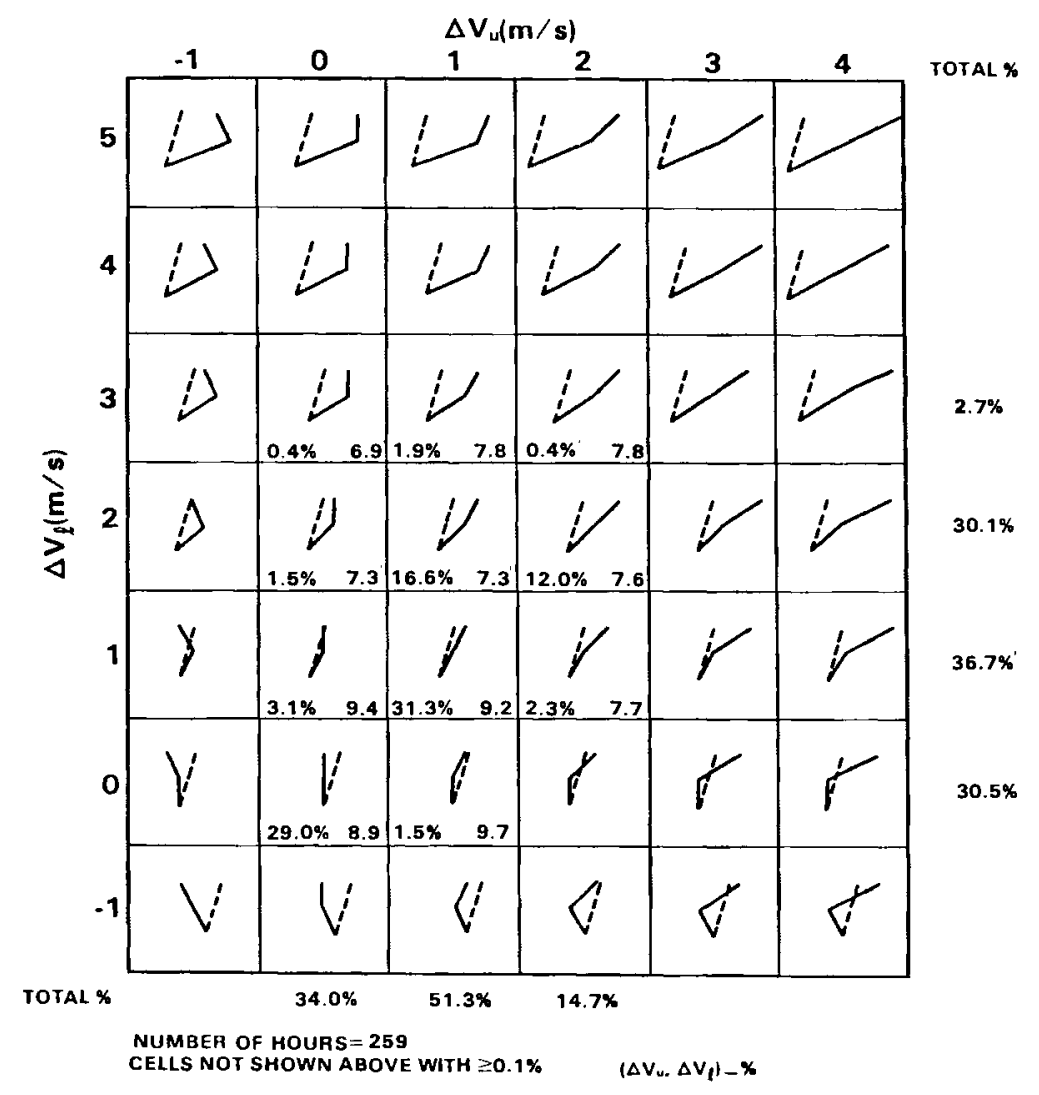

FIGURE 4-4. Type 3 Turbine for Autumn (October 1976). See Figure 4-2 for detail. 
(a)

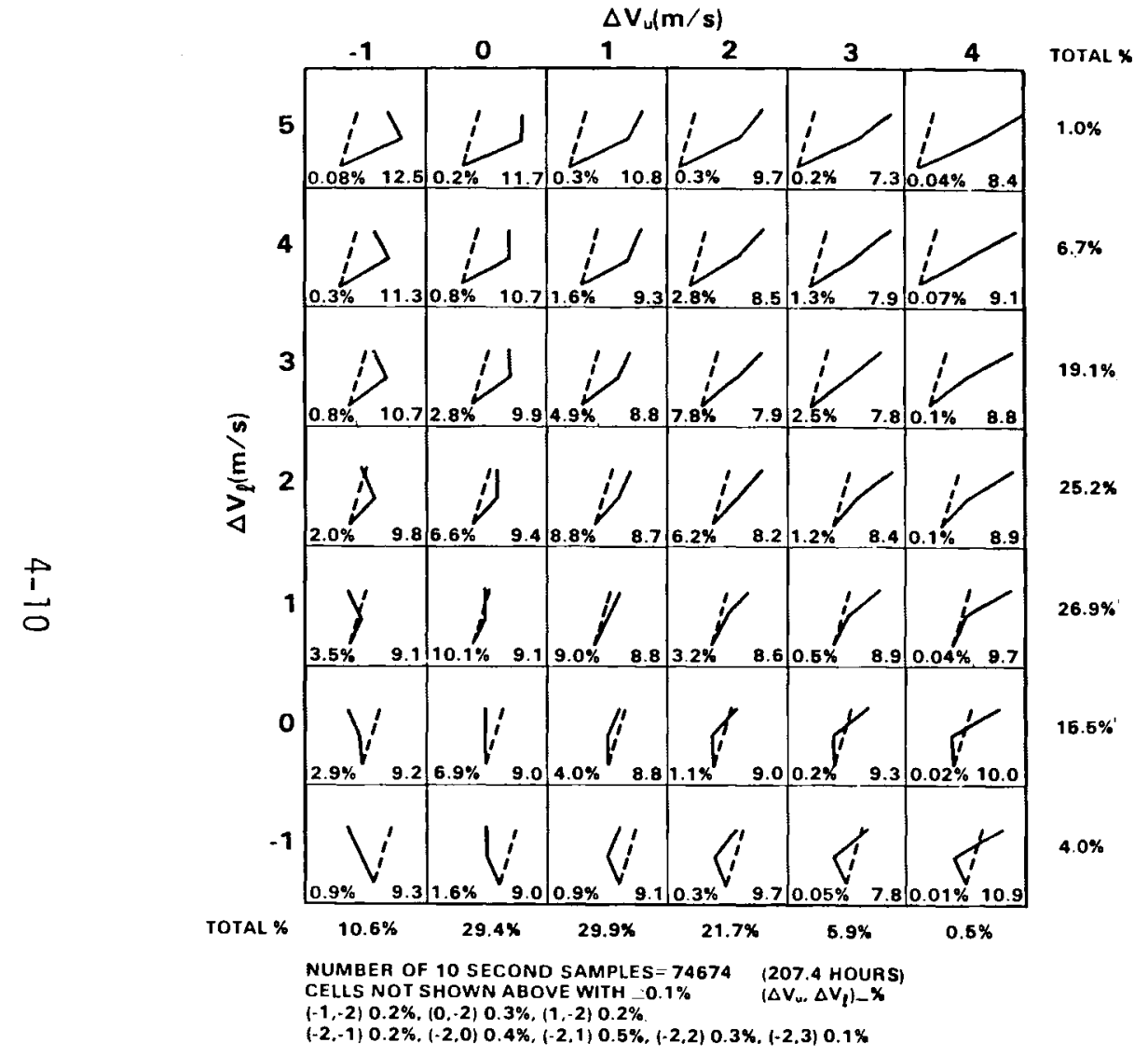

(b)

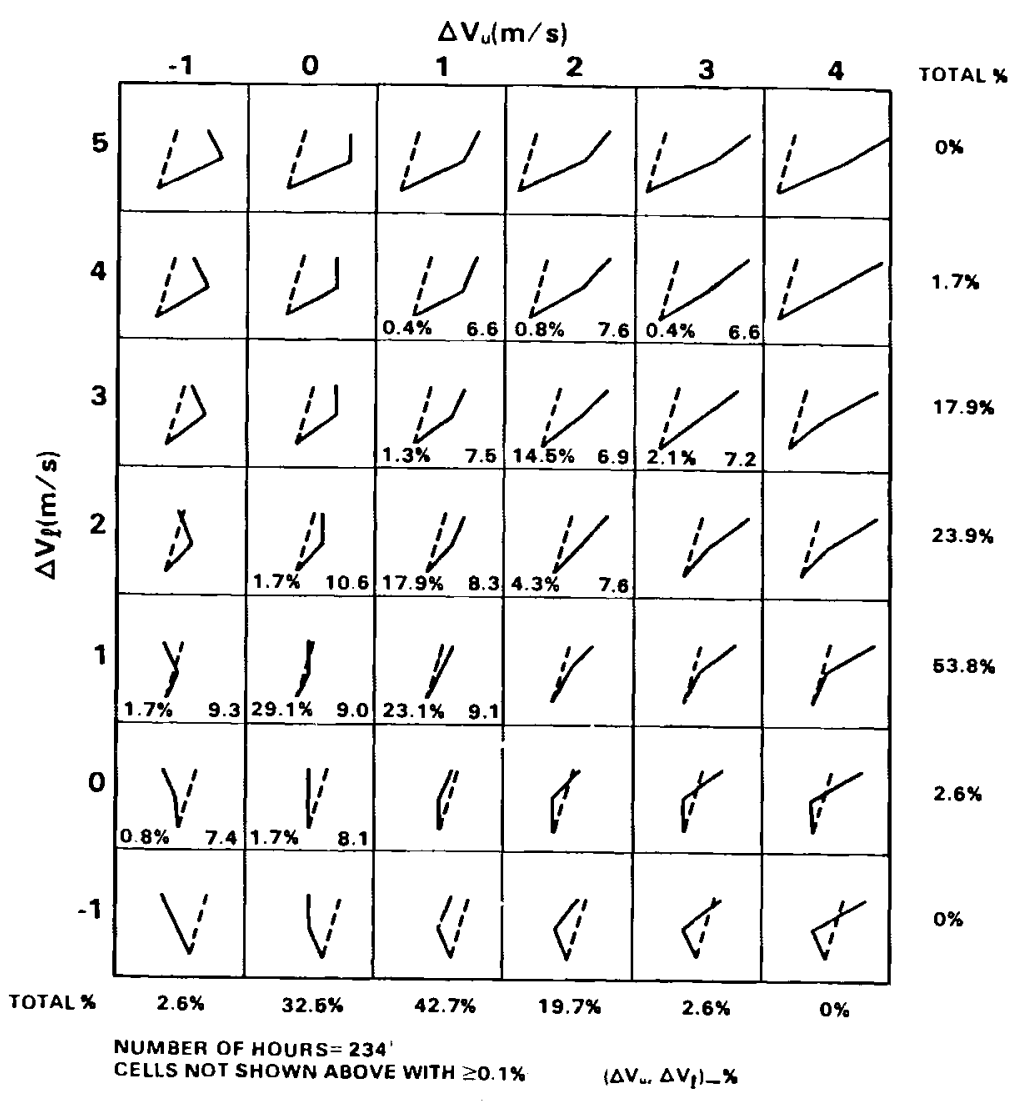

FIGURE 4-5. Type 1 Turbine for Winter (January 1977). See Figure 4-2 for detail. 
(a)

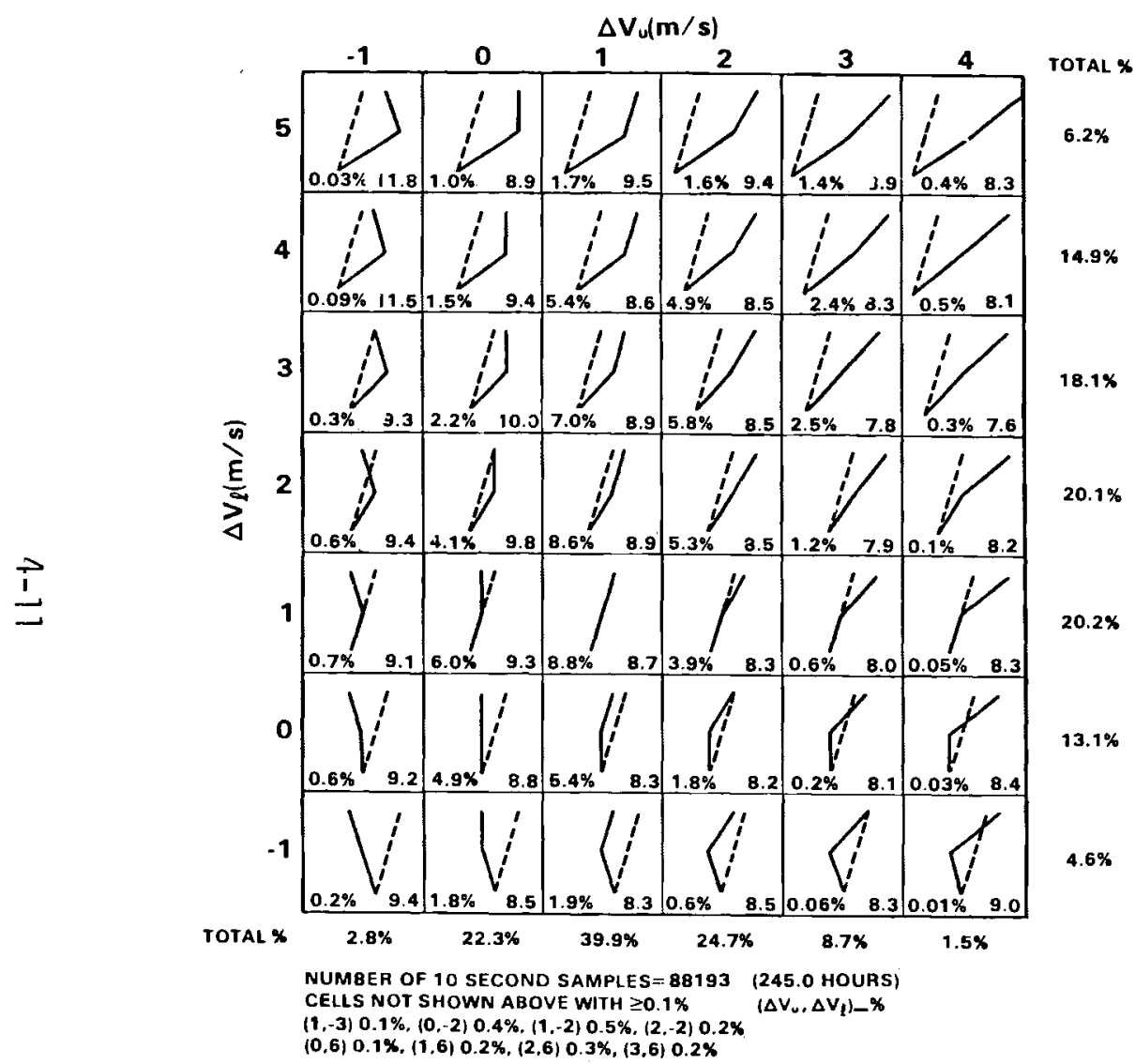

(b)

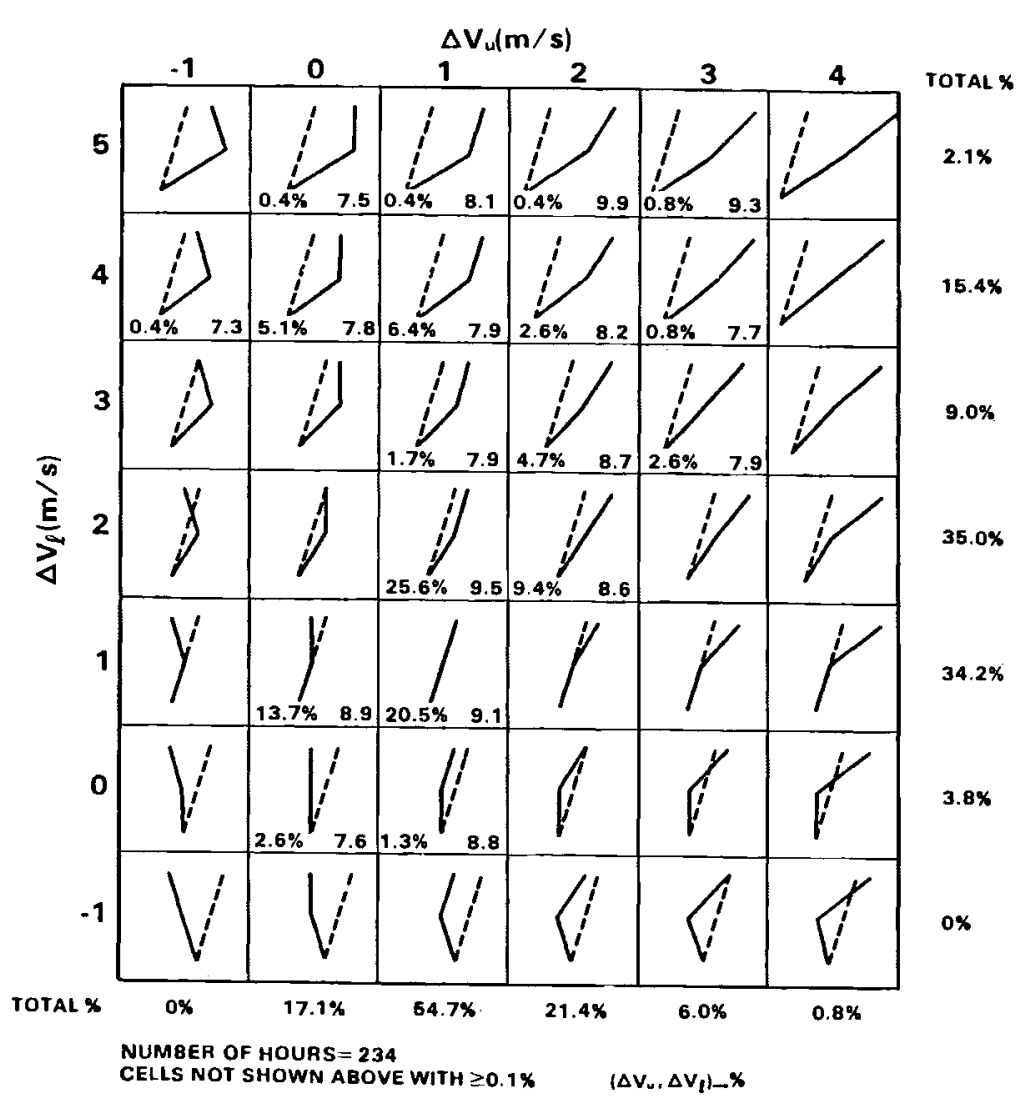

FIGURE 4-6. Type 2 Turbine for Winter (January 1977). See Figure 4-2 for detail. 
(a)

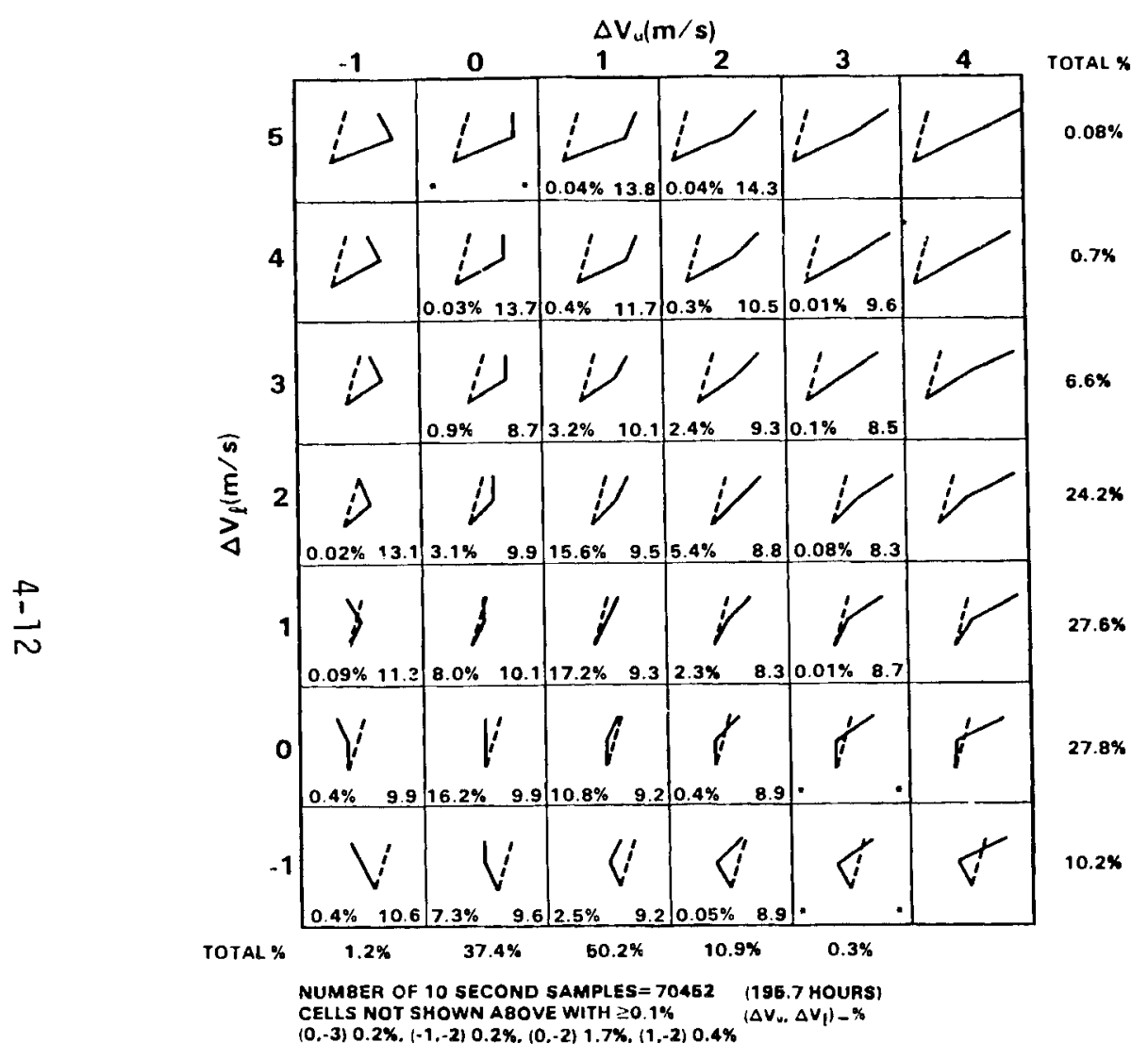

(b)

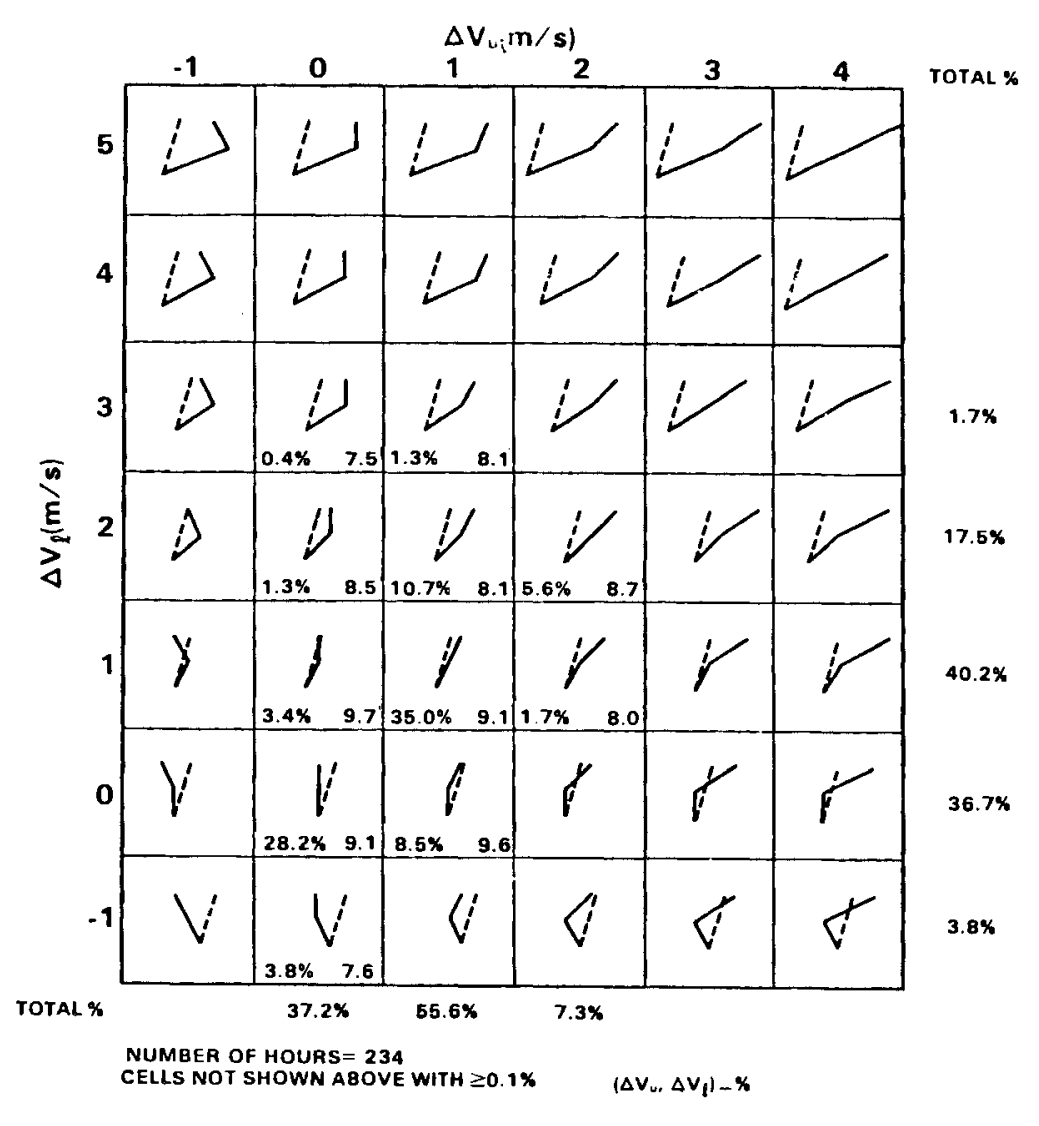

FIGURE 4-7. Type 3 Turbine for Winter (January 1977). See Figure 4-2 for detail. 
(a)

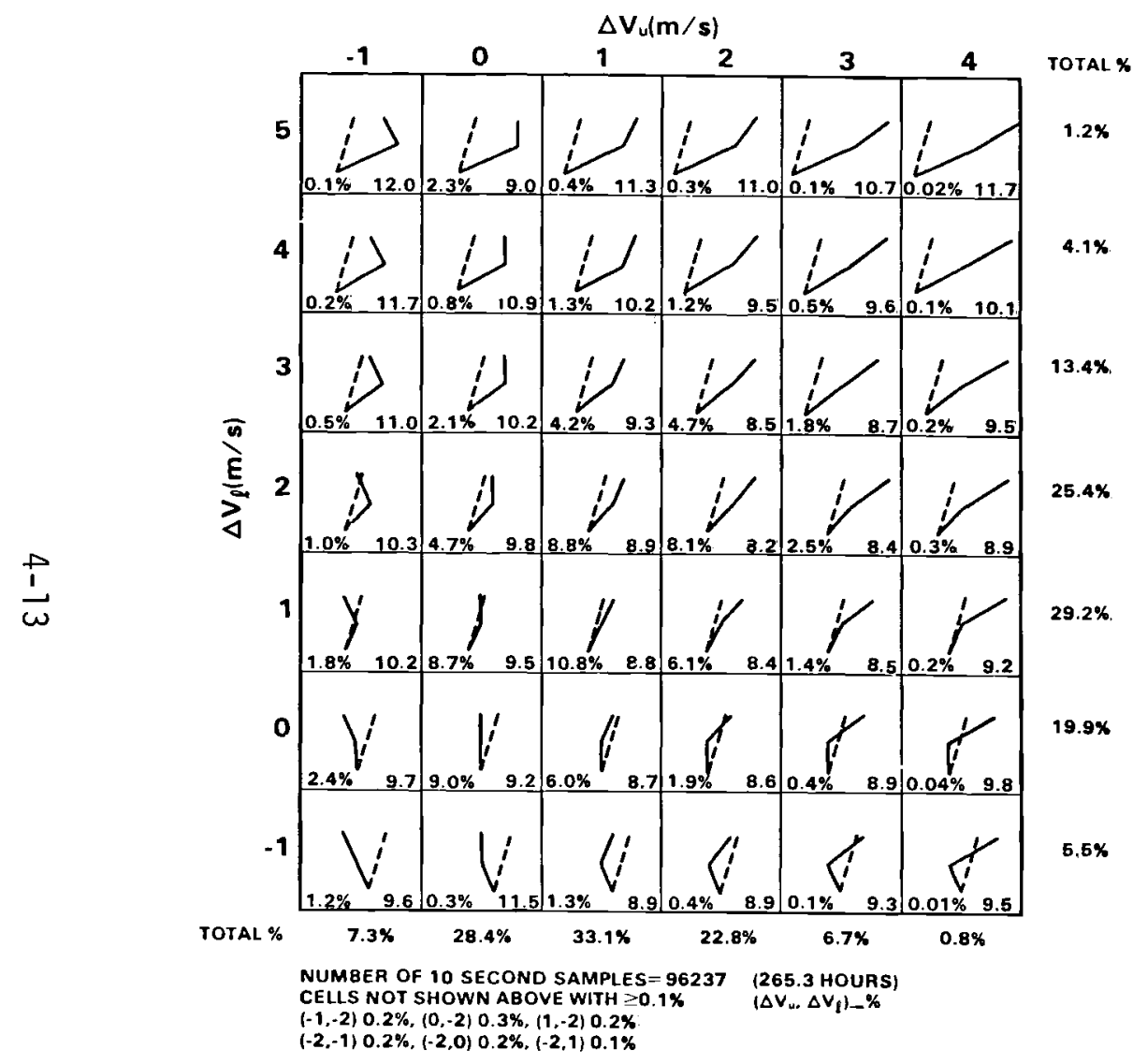

(b)

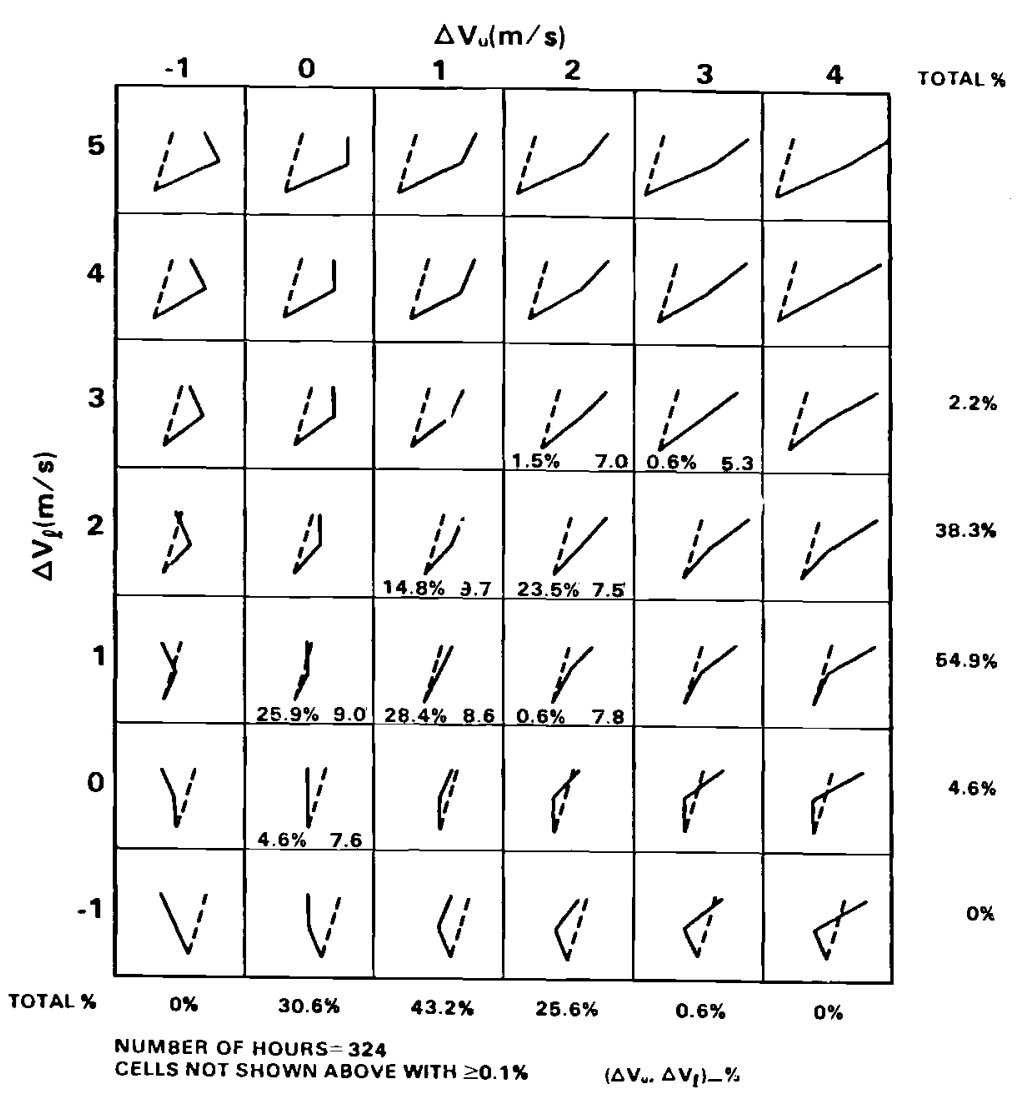

FIGURE 4-8. Type 1 Turbine for Spring (Apri1 1977). See Figure 4-2 for detail. 
(a)

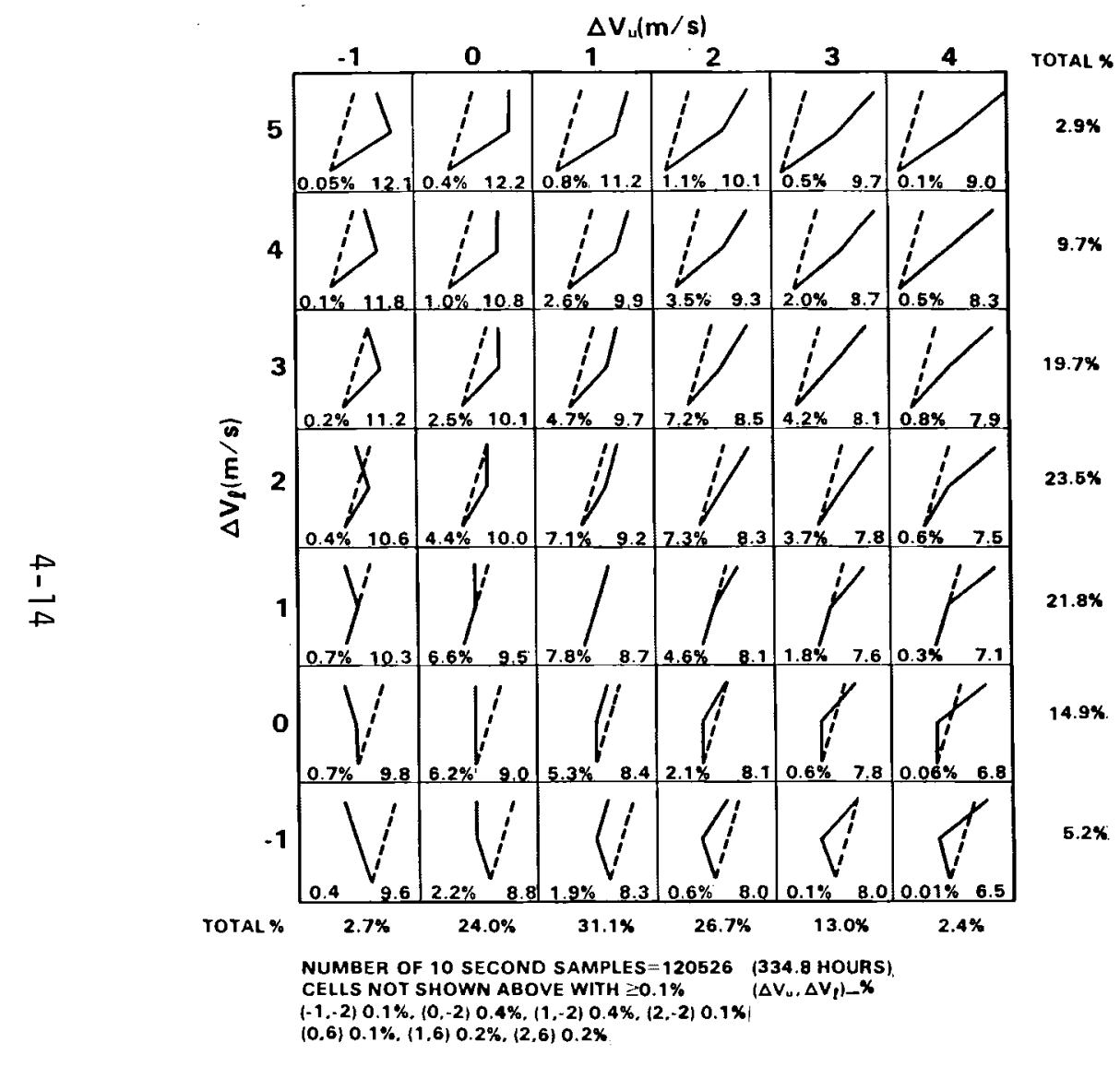

(b)

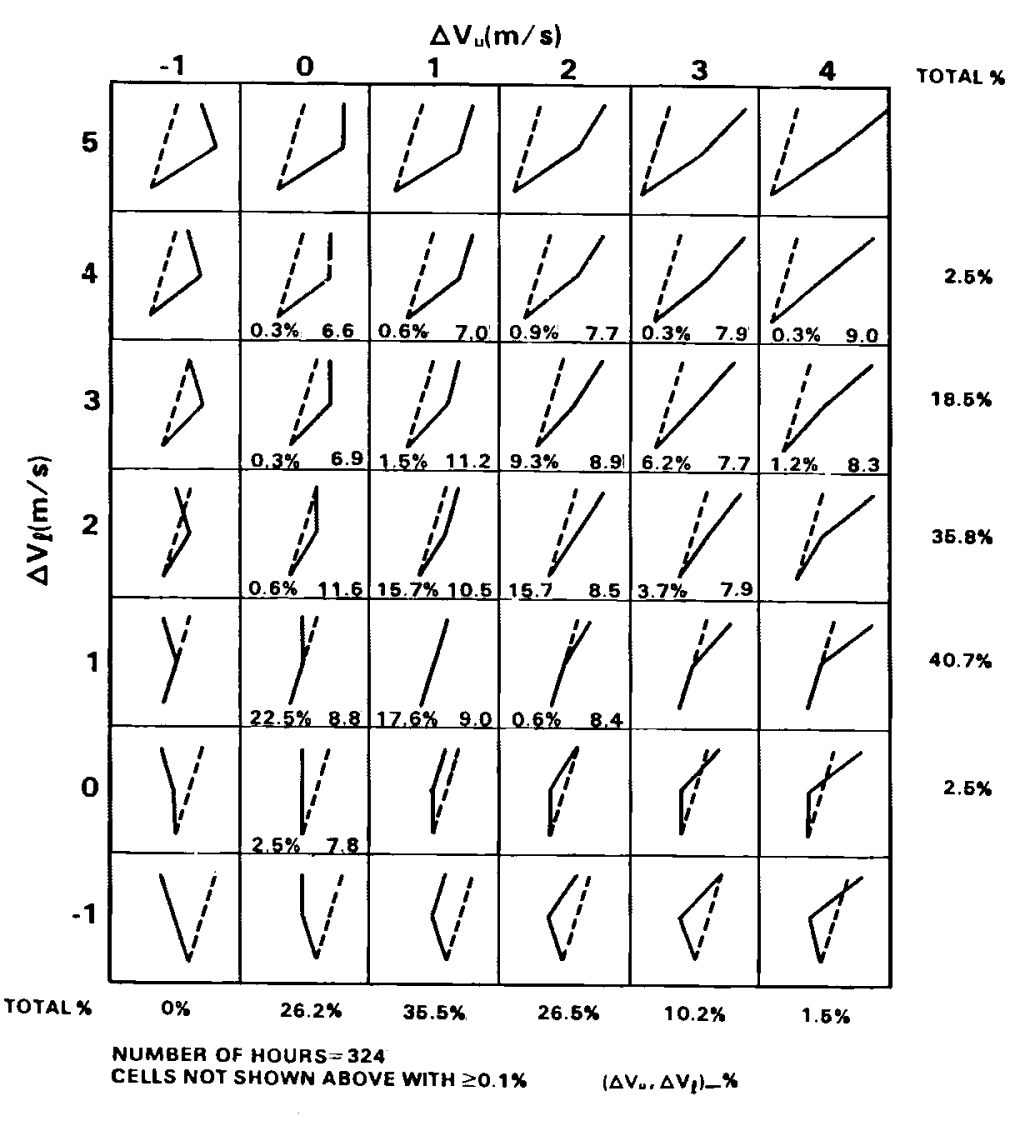

FIGURE 4-9. Type 2 Turbine for Spring (Apri1 1977). See Figure 4-2 for detail. 
(a)

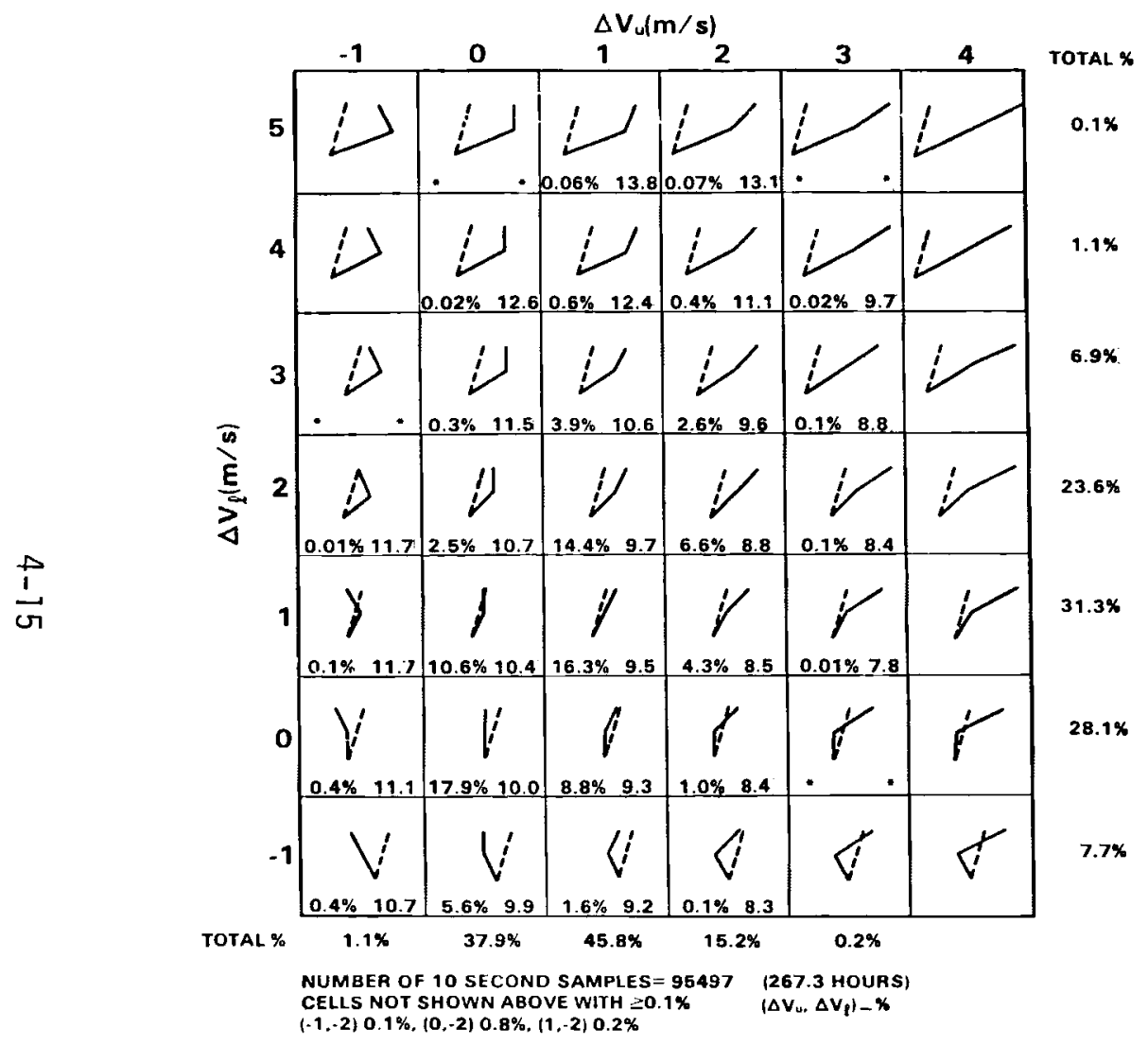

(b)

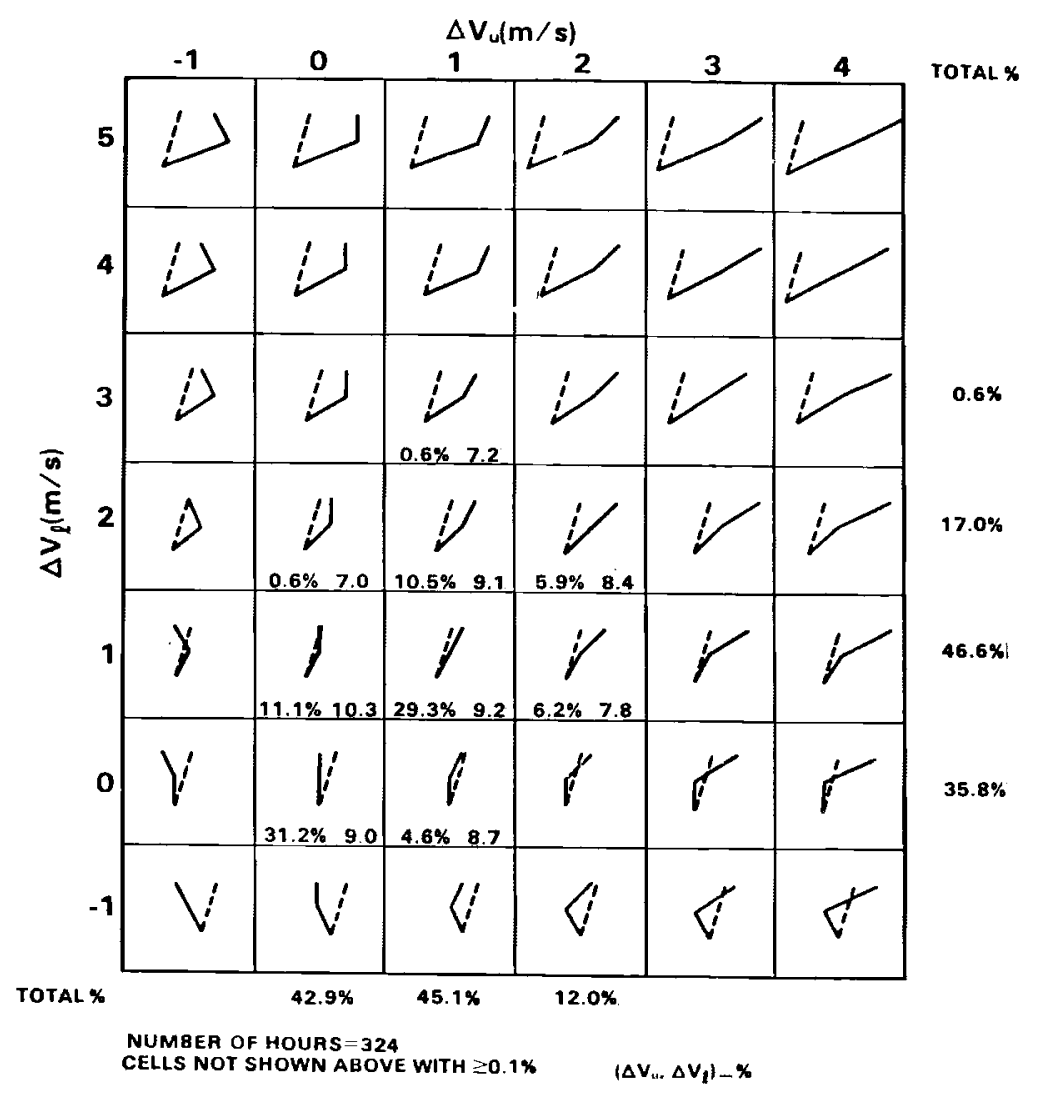

FIGURE 4-10. Type 3 Turbine for Spring (April 1982). See Figure 4-2 for detail. 
(a)

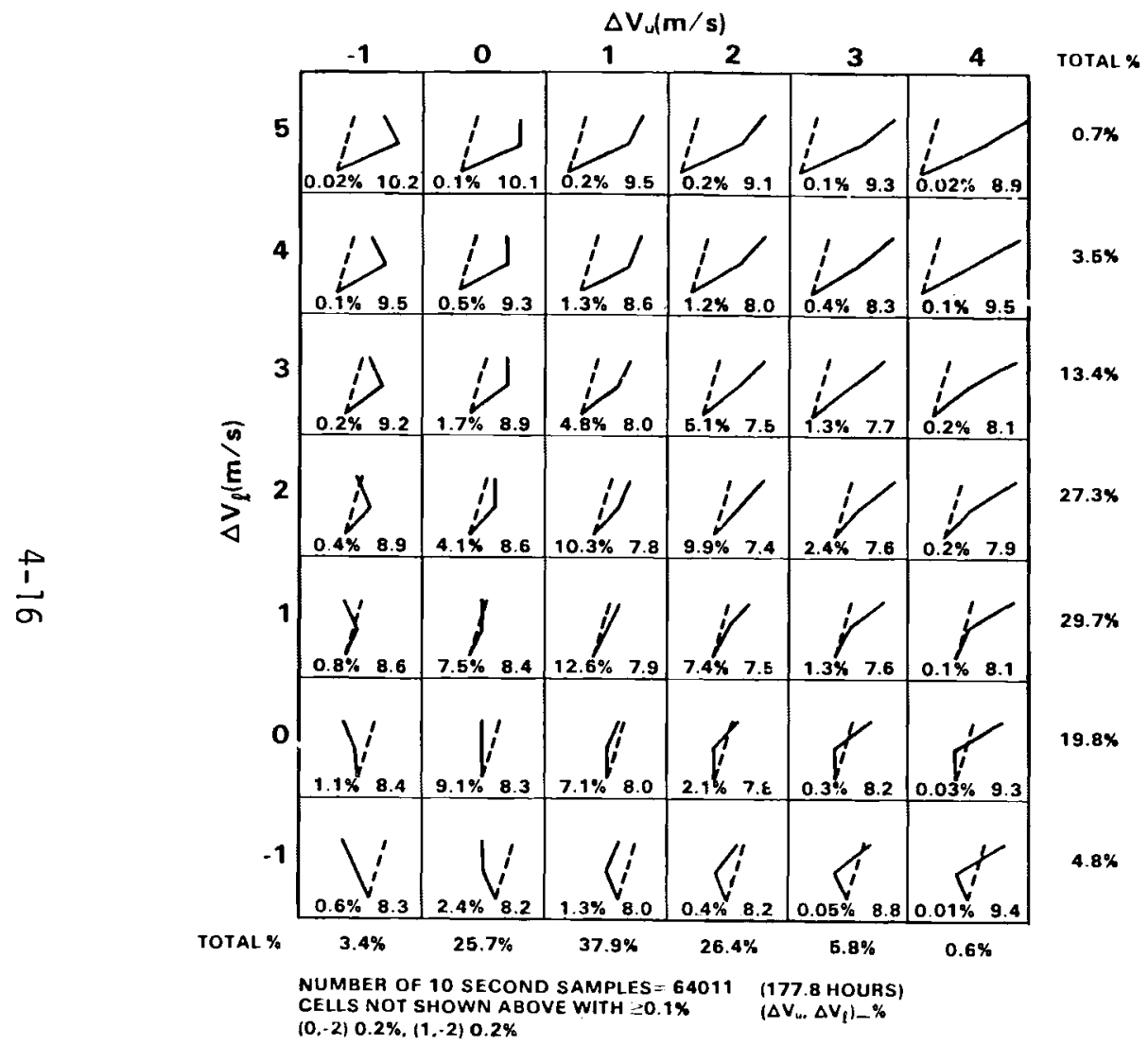

(b)

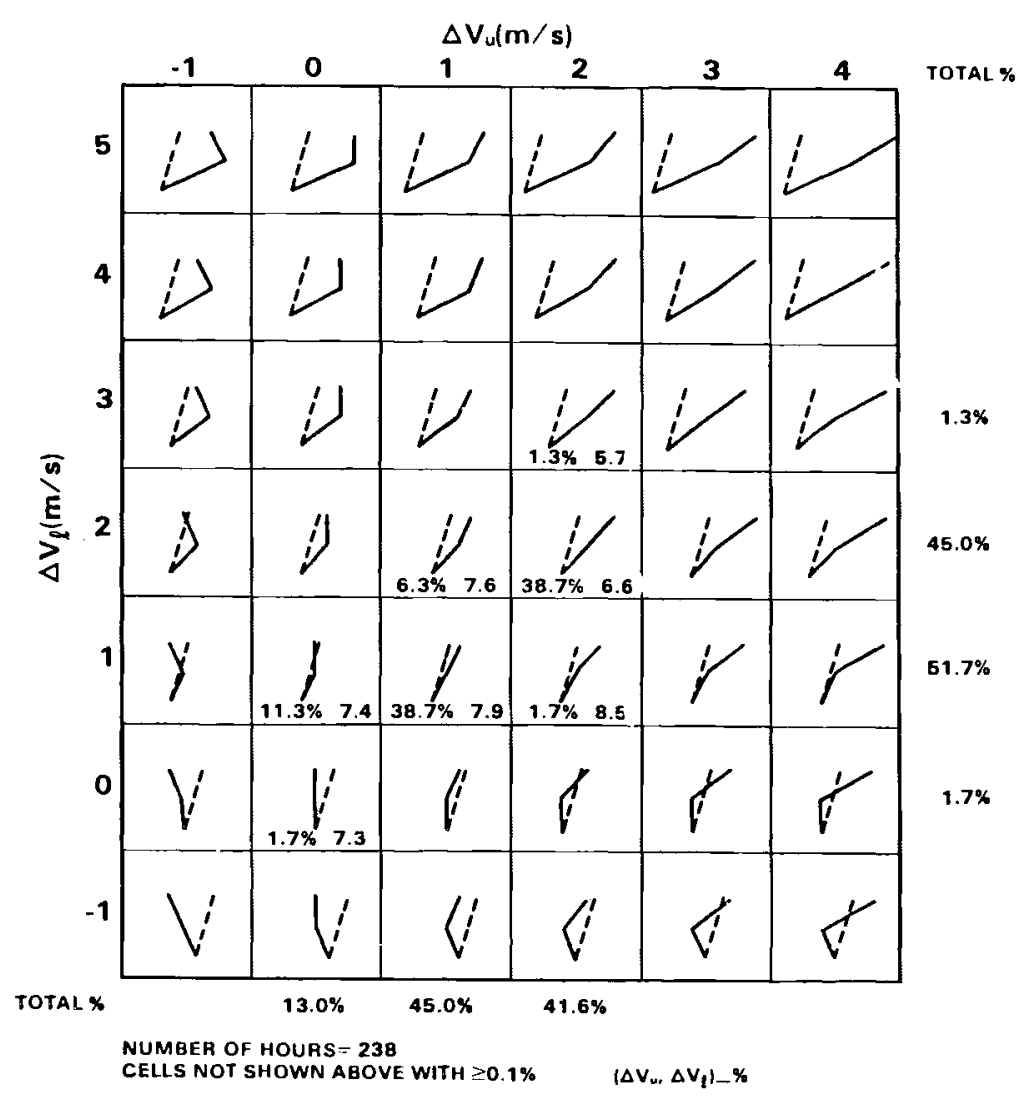

FIGURE 4-11. Type 1 Turbine for Summer (July 1977). See Figure 4-2 for detail. 
(a)

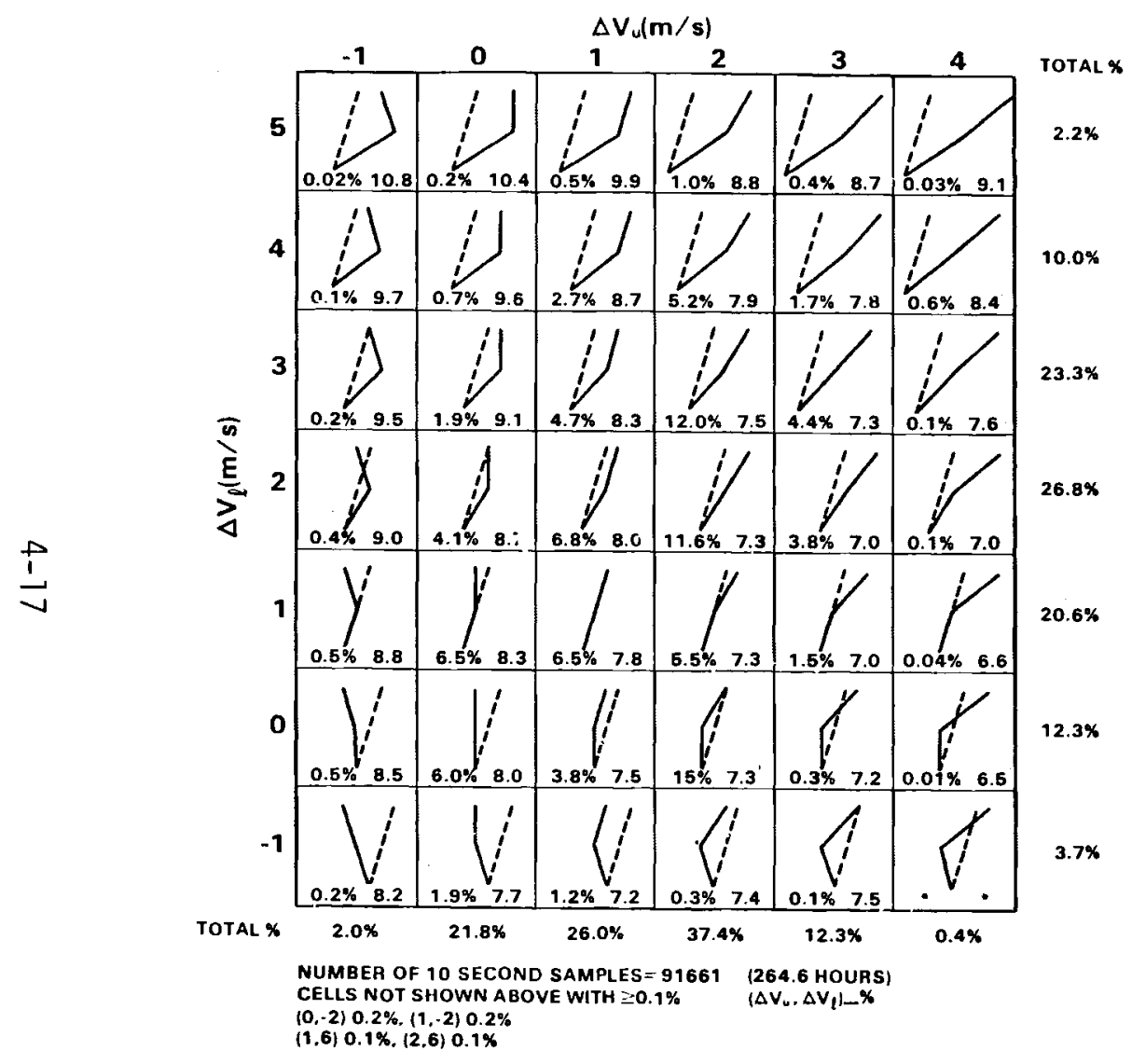

(b)

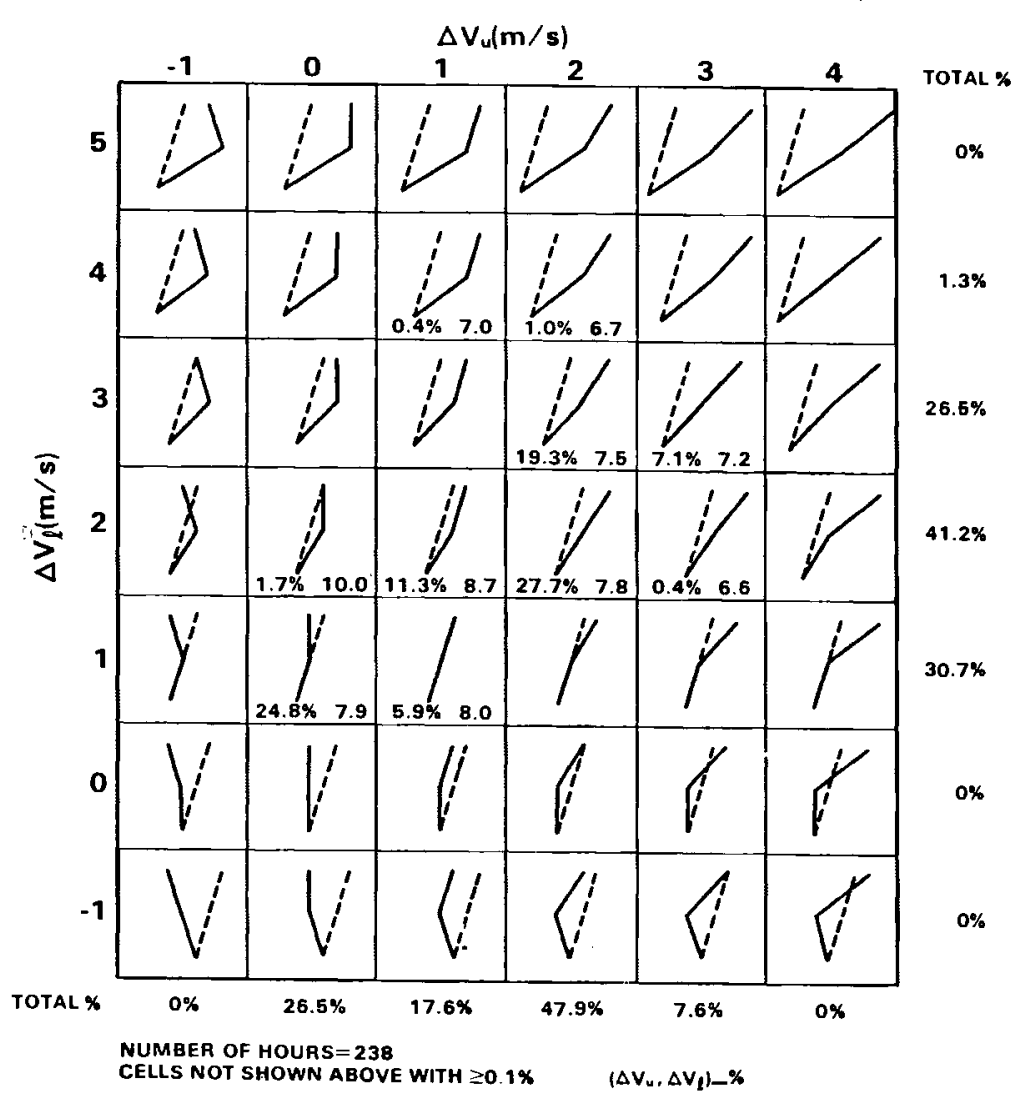

FIGURE 4-12. Type 2 Turbine for Summer (Ju1y 1977). See Figure 4-2 for detail. 
(a)

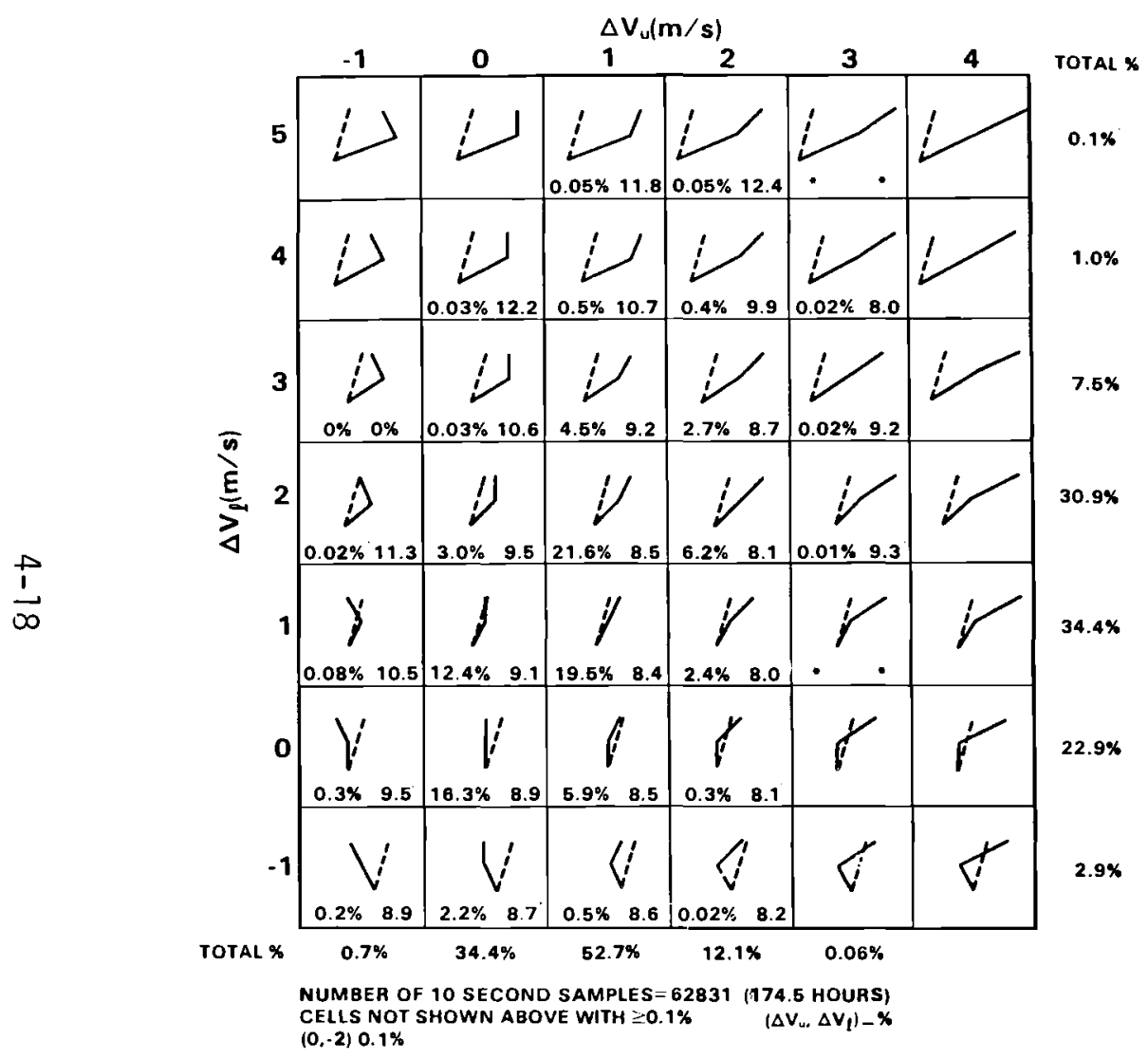

(b)

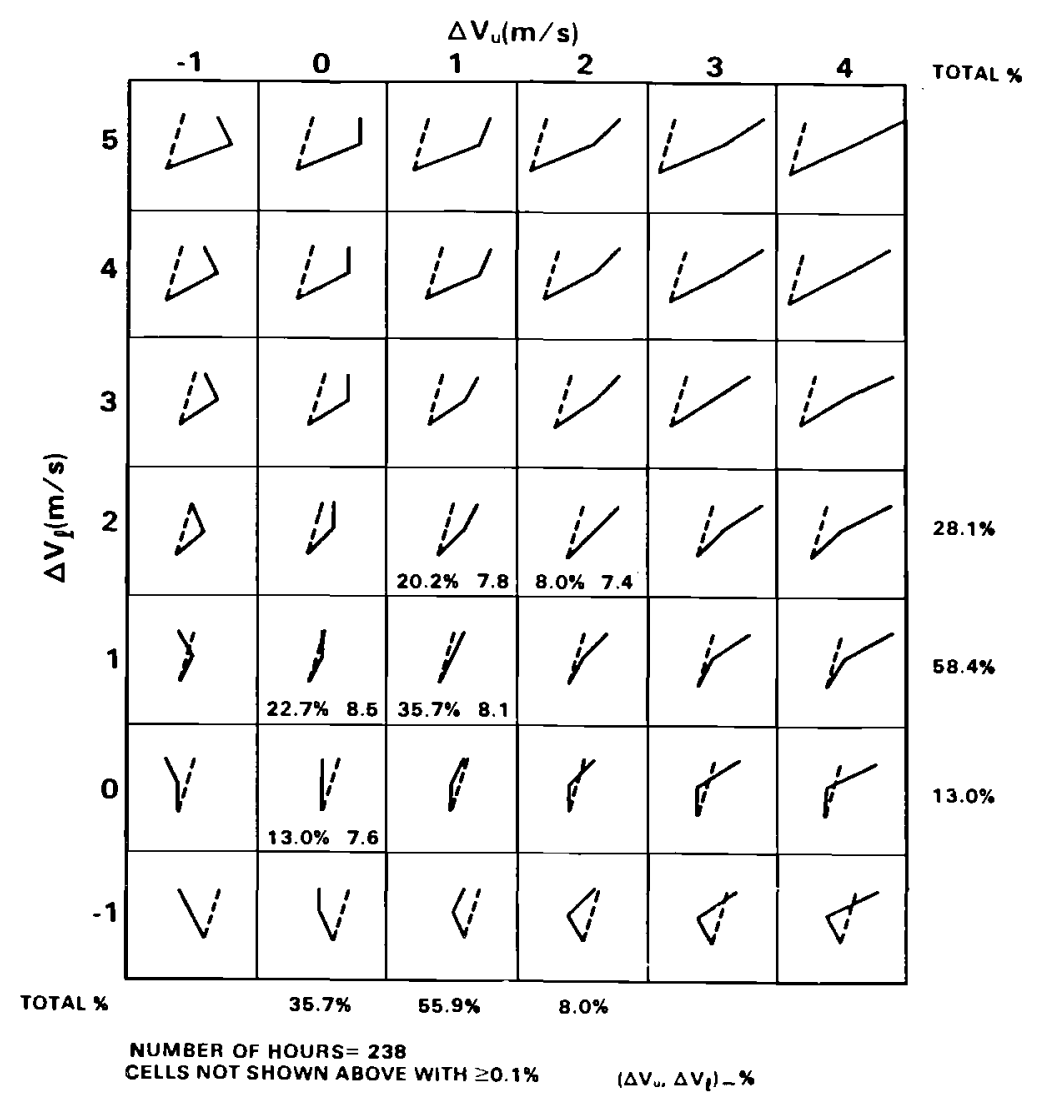

FIGURE 4-13. Type 3 Turbine for Summer (July 1977).

See Figure 4-2 for detail. 
(a)

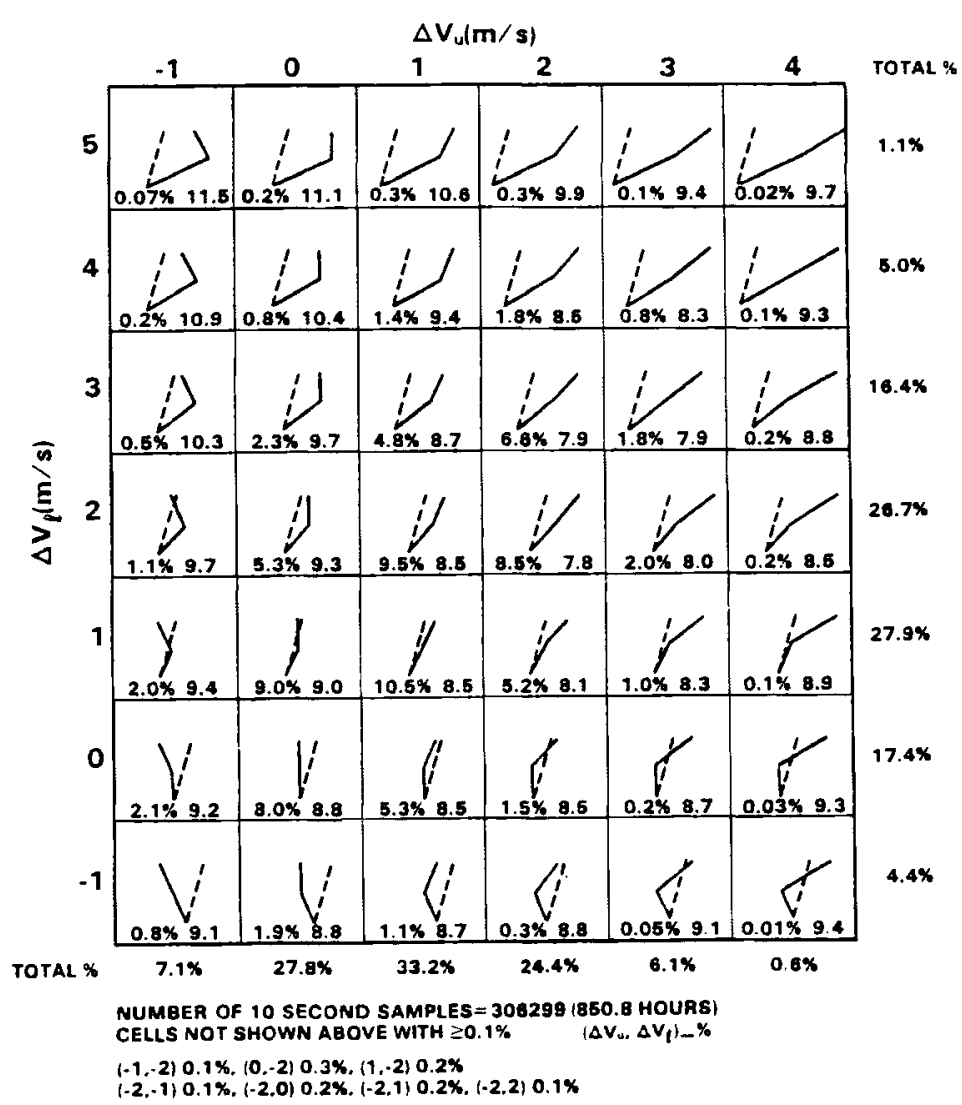

(b)

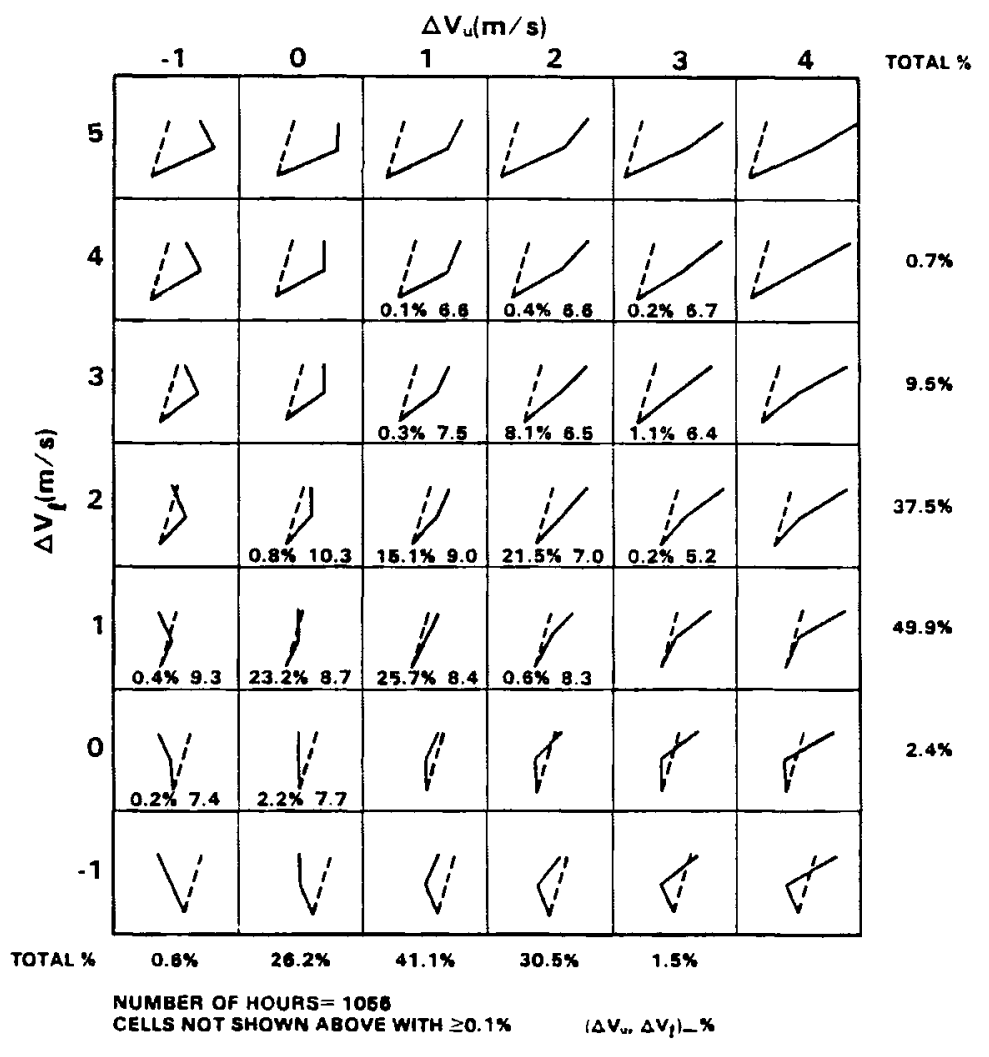

FIGURE 4-14. Type 1 Turbine - Annual Average. See Figure 4-2 for detail. 
(a)

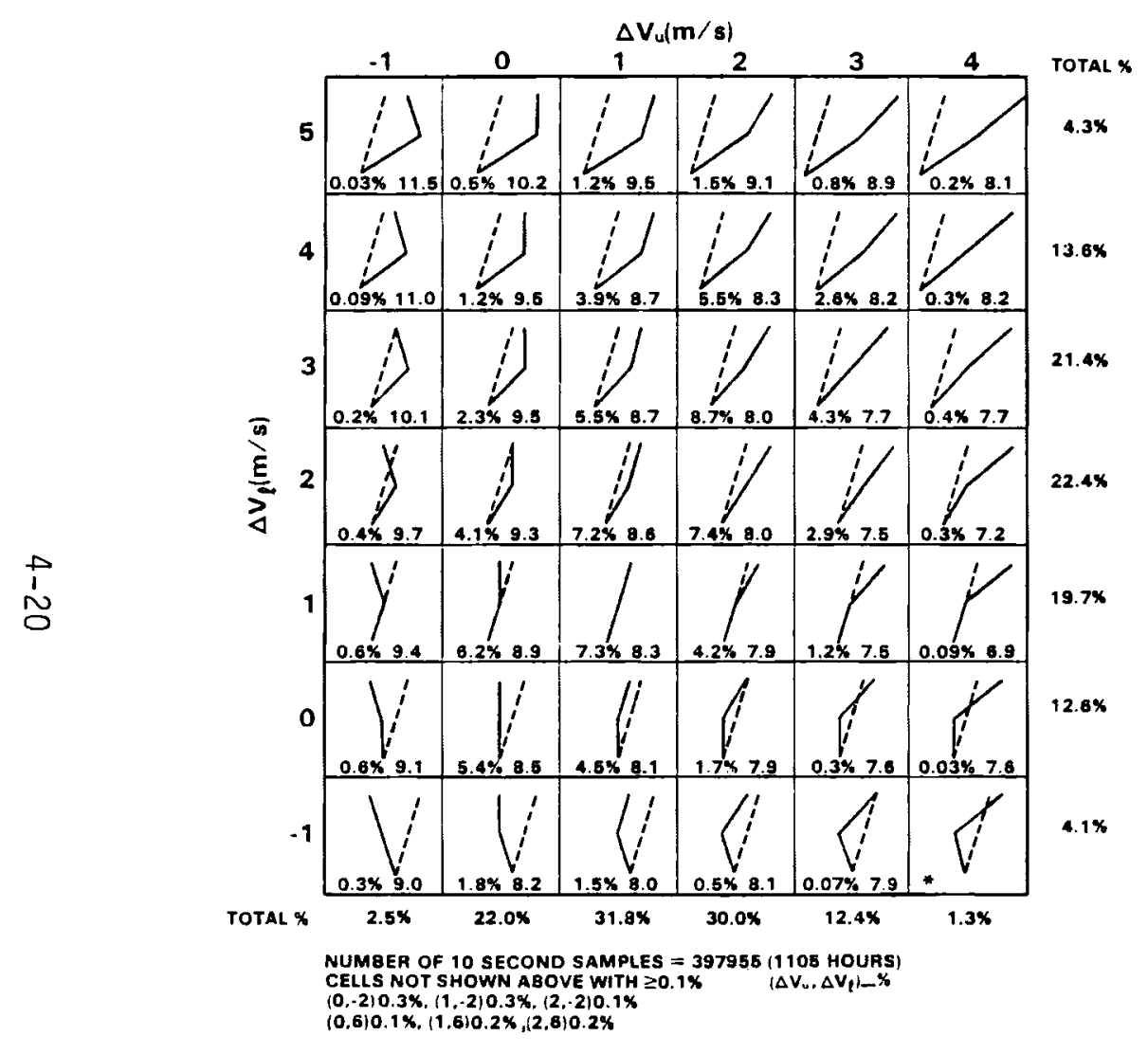

(b)

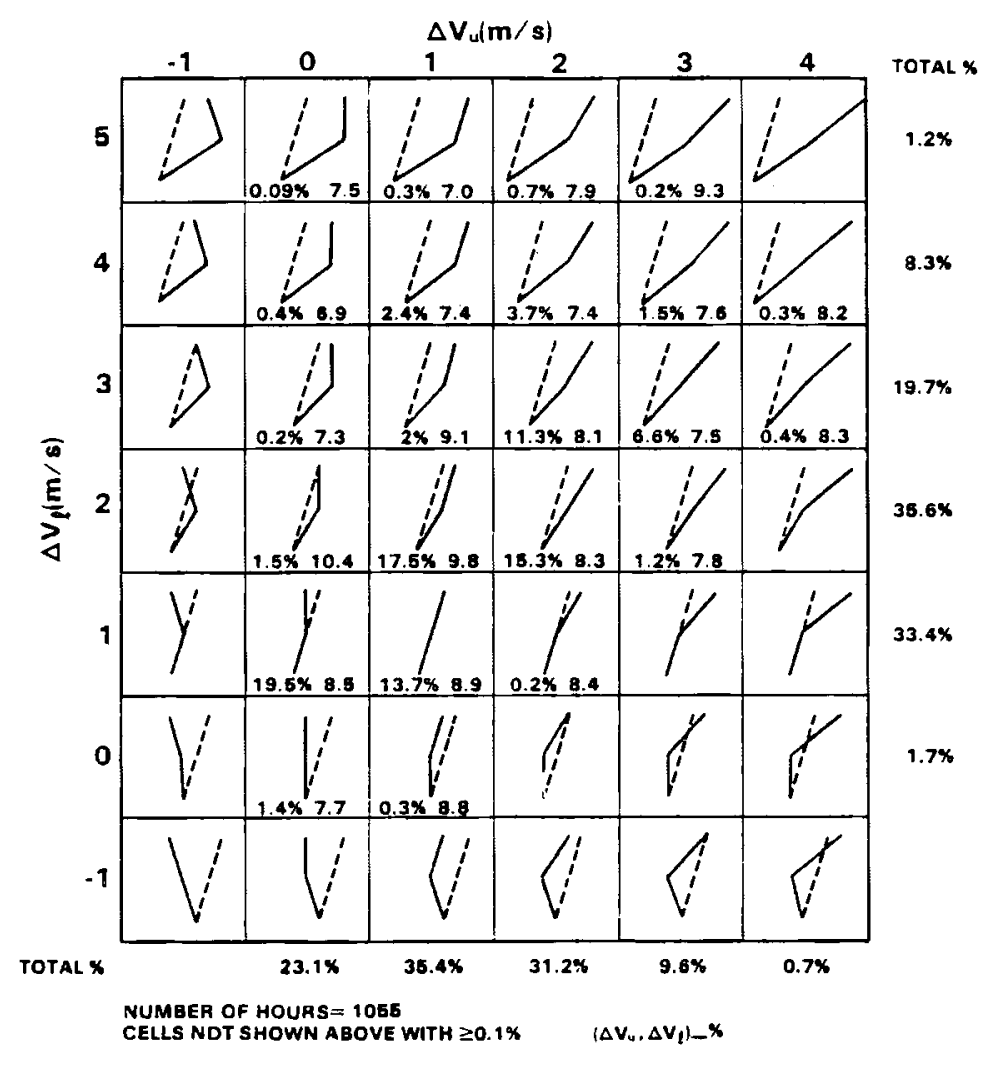

FIGURE 4-15. Type 2 Turbine - Annual Average. See Figure 4-2 for detail. 
(a)

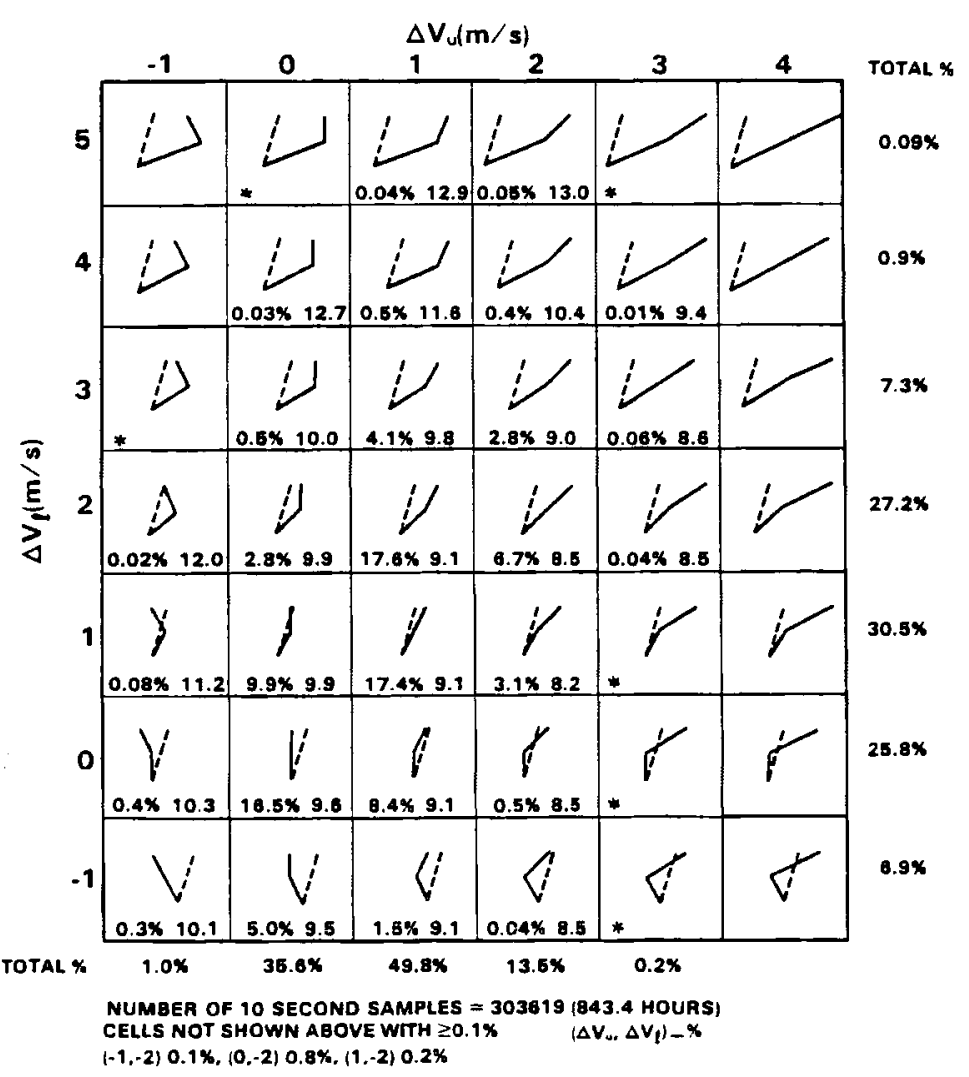

(b)

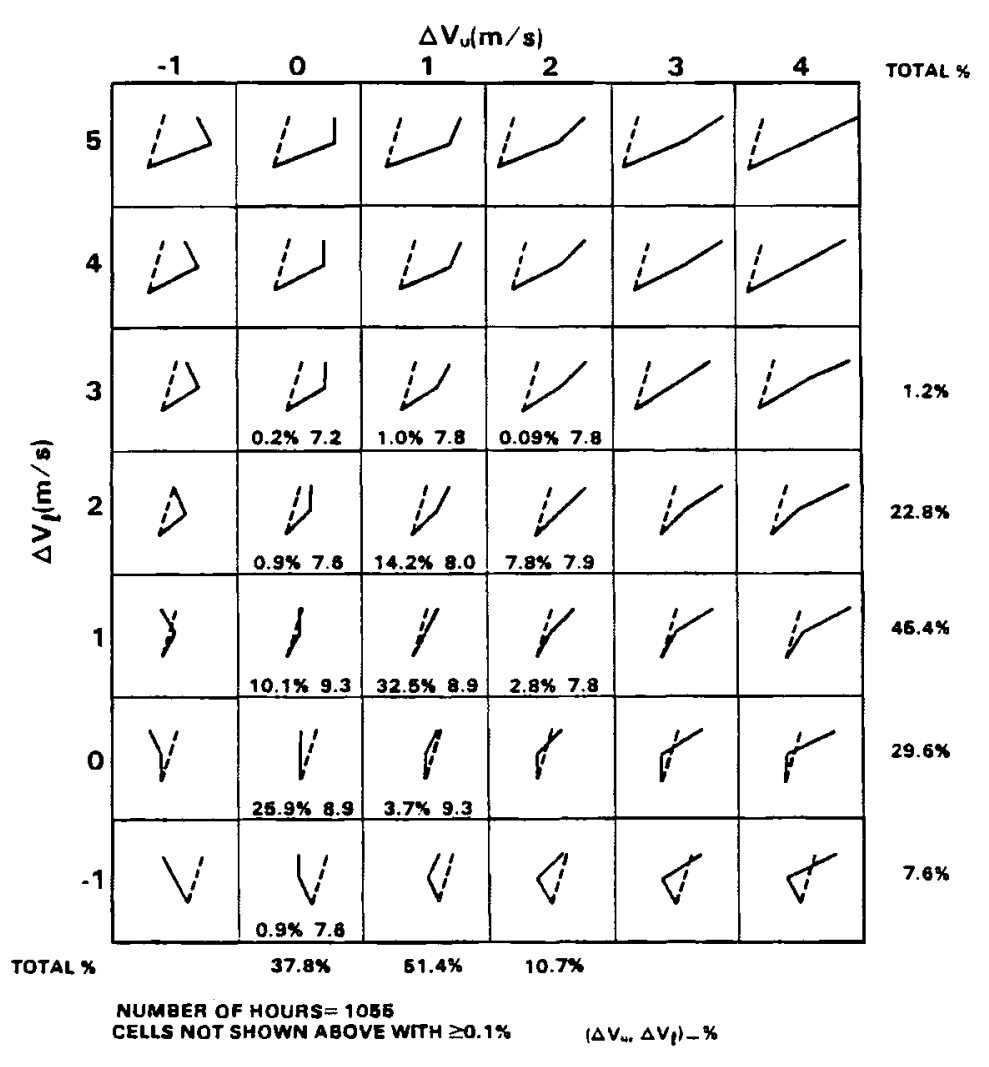

FIGURE 4-16. Type 3 Turbine - Annual Average.

See Figure 4-2 for detail. 


\subsubsection{Contours of Wind Shear Profiles}

A contour analysis of the joint frequency distribution of wind shear profiles for the three wind turbines is shown for a representative month in each season and the year (based on an average of the four months) for daytime and nighttime hours in Figures 4-17 to 4-20 and for all hours in Figures 4-21 to 4-24. This method of analysis allows one to more easily compare the distribution of wind shear profiles for the three different types of wind turbines and the diurnal and seasonal variations. (The first four percent frequency contours are $0.1,0.5,1.0$, and 2.0 respectively, and subsequent contours are in intervals of two percent.)

In determining the daytime and nighttime hours for each month, a constant duration of daylight was specified for each month, which corresponded approximately to the duration of daylight for the middle of the month. From this, an average sunrise and sunset time for each month was calculated.

The frequency of occurrence of 10-s wind shear profiles was then computed and analyzed for day and night categories for each month. The differences in the occurrence of wind shear profiles between day and night are quite pronounced and change with season. Values of the most frequent $\Delta V_{u}$ and $\Delta V_{\ell}$ are greater during the night than the day. Most frequent nighttime velocity differences across the effective blade diameter range from 3 to $6 \mathrm{~m} / \mathrm{s}$ for the Type 2 turbine, from 2 to $5 \mathrm{~m} / \mathrm{s}$ for the Type 1 turbine, and from 2 to $3 \mathrm{~m} / \mathrm{s}$ for the Type 3 turbine. During daylight hours, wind speeds are typically more constant with height, as the most frequent velocity differences are generally only 0 to $2 \mathrm{~m} / \mathrm{s}$ across the effective blade diameter.

The 0.1 frequency of occurrence contour has been selected to outline the range of $\Delta V_{u}$ and $\Delta V_{\ell}$. The range of $\Delta V_{u}$ and $\Delta V_{\ell}$ values is substantially less for the Type 3 turbine than for either the Type 1 or Type 2 turbines. This is primarily due to two factors: 1) the effective blade diameter of the Type 3 turbine is less than that of the Type 1 and Type 2 turbines, and 2) the bottom of the Type 3 turbine blade is more than $20 \mathrm{~m}$ higher above ground than either the Type 1 or Type 2 turbine blades. For all three turbine configurations, the range of $\Delta V_{\ell}$ values is generally greater than the range of $\Delta V_{u}$ 
values, which indicates that the wind shear is typically greater in the lower portion of the disk of rotation than in the upper portion.

Percent frequency contours of wind shear profiles for each season and the year for day and night combined (a 11 hours within operating range) are shown in Figures 4-21 to 4-24. The contours of maximum frequencies are typically elongated areas, sometimes with double centers, reflecting the wide range of shear profiles between day and night. As in the day/night cases, the Type 3 turbine has a much smaller range of $\Delta V$ values than does the Type 1 and Type 2 turbines. For all three turbine types, there is a wider range of wind shear profiles in winter than in the summer. This is an indication of a greater variety of types of wind shear profiles in winter than in summer. 

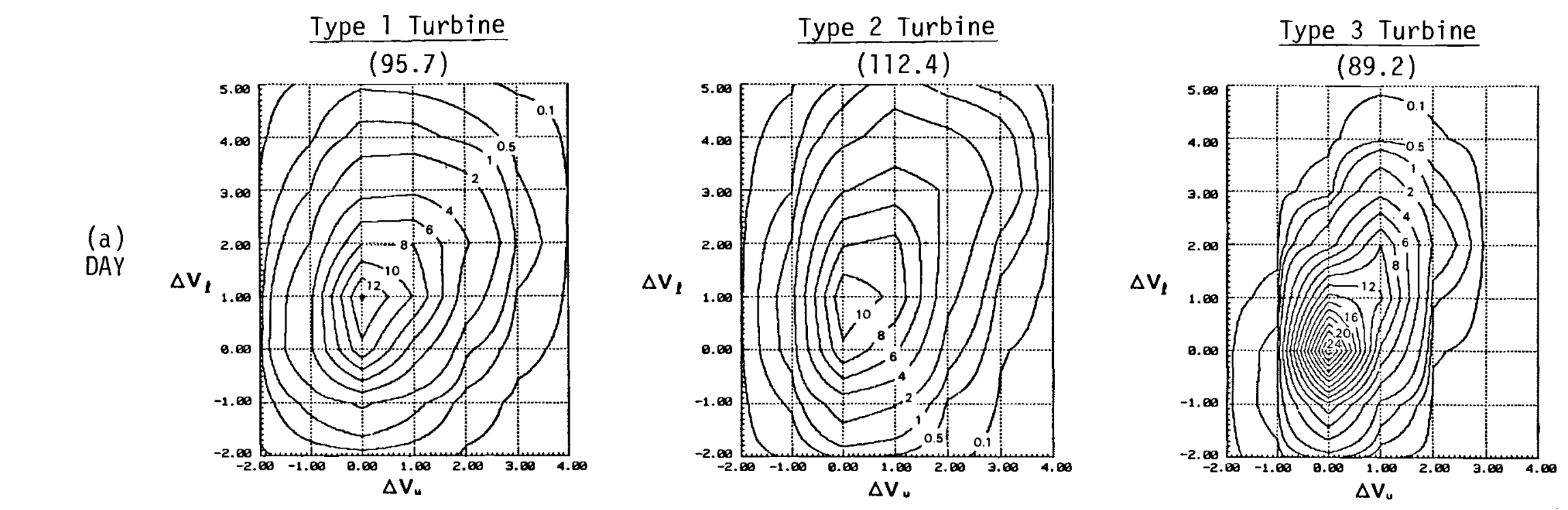

$\stackrel{P}{1}$
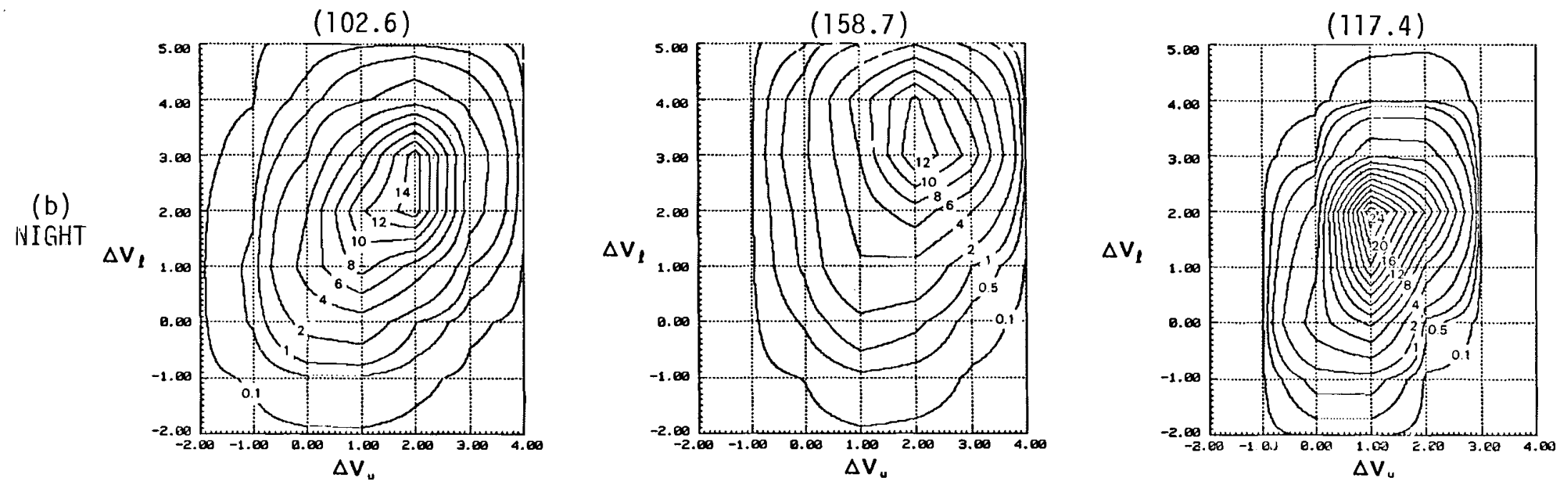

FIGURE 4-17. Percent Frequency Contours of Wind Shear Profiles for October 1976 (Autumn) Under Same Conditions for 10-s Sampled Winds Described in Figure 4-2 for a) Day and b) Night, and Three Types of Wind Turbines. The numbers in parentheses represent the number of equivalent hours within turbine operating range. 
Type 1 Turbine

(a)

DAY

$\stackrel{\leftrightarrow}{\stackrel{1}{n}}$

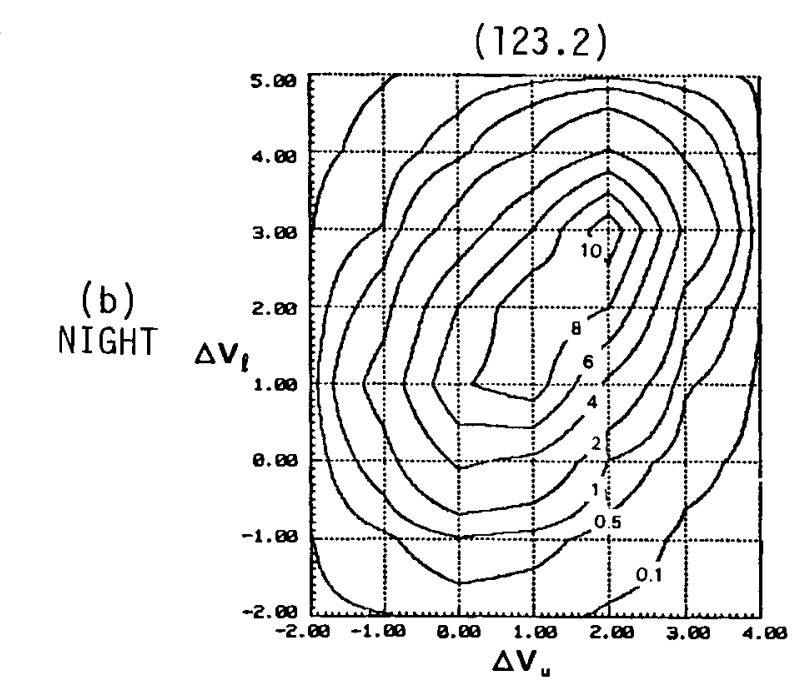

Type 2 Turbine

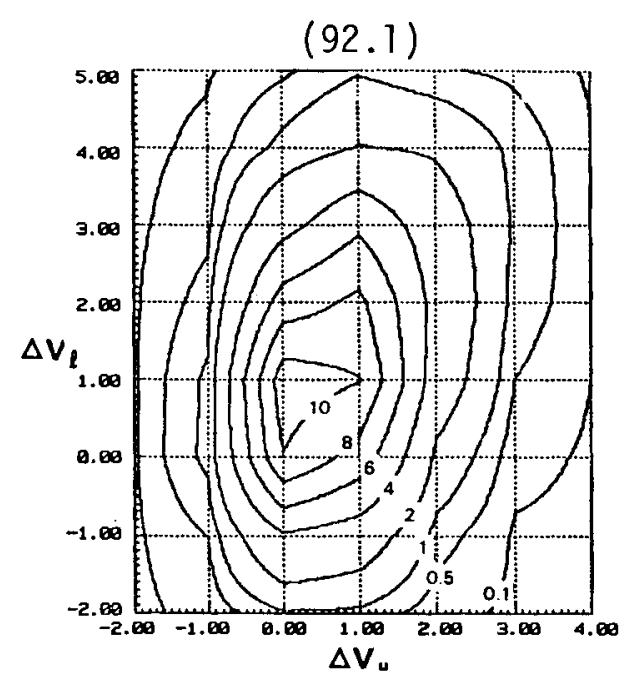

(152.9)

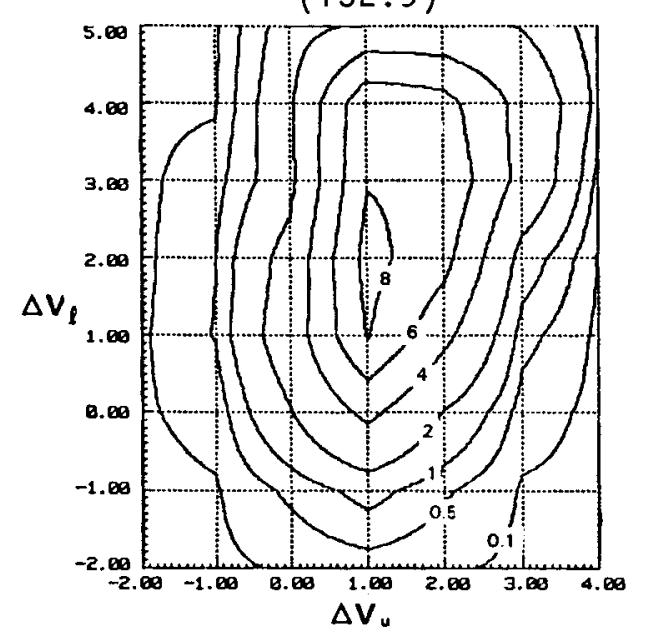

Type 3 Turbine
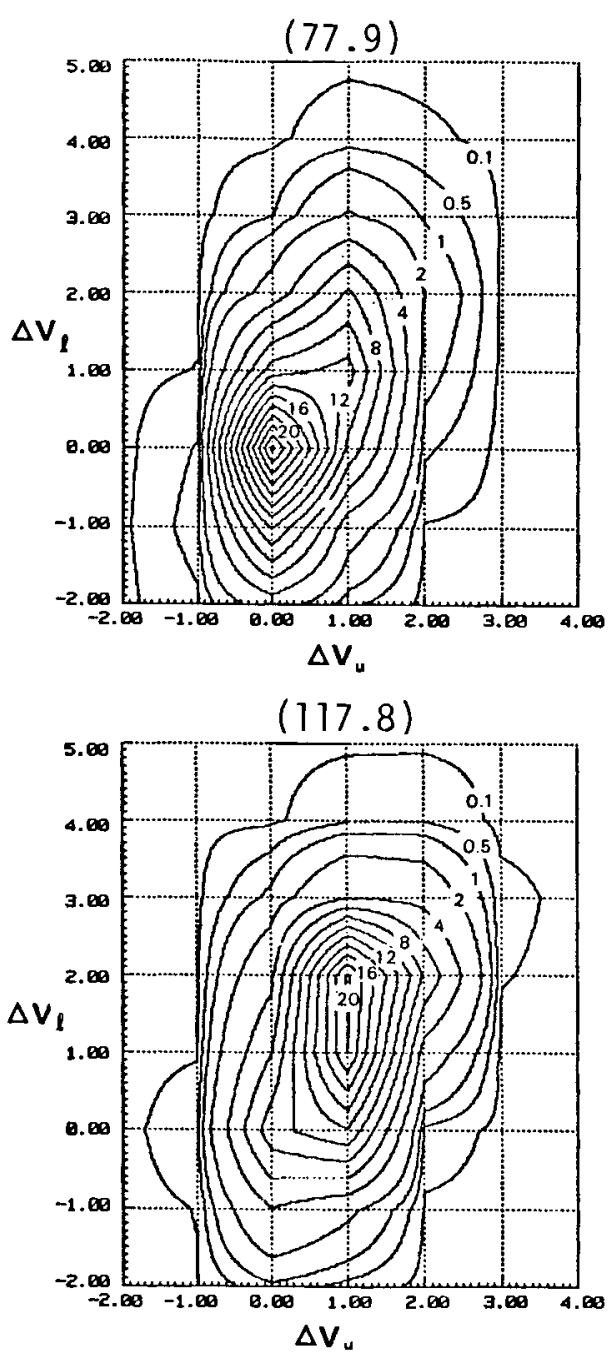

FIGURE 4-18. Percent Frequency Contours for Winter (January 1977). See Figure 4-17 for detail. 
Type 1 Turbine

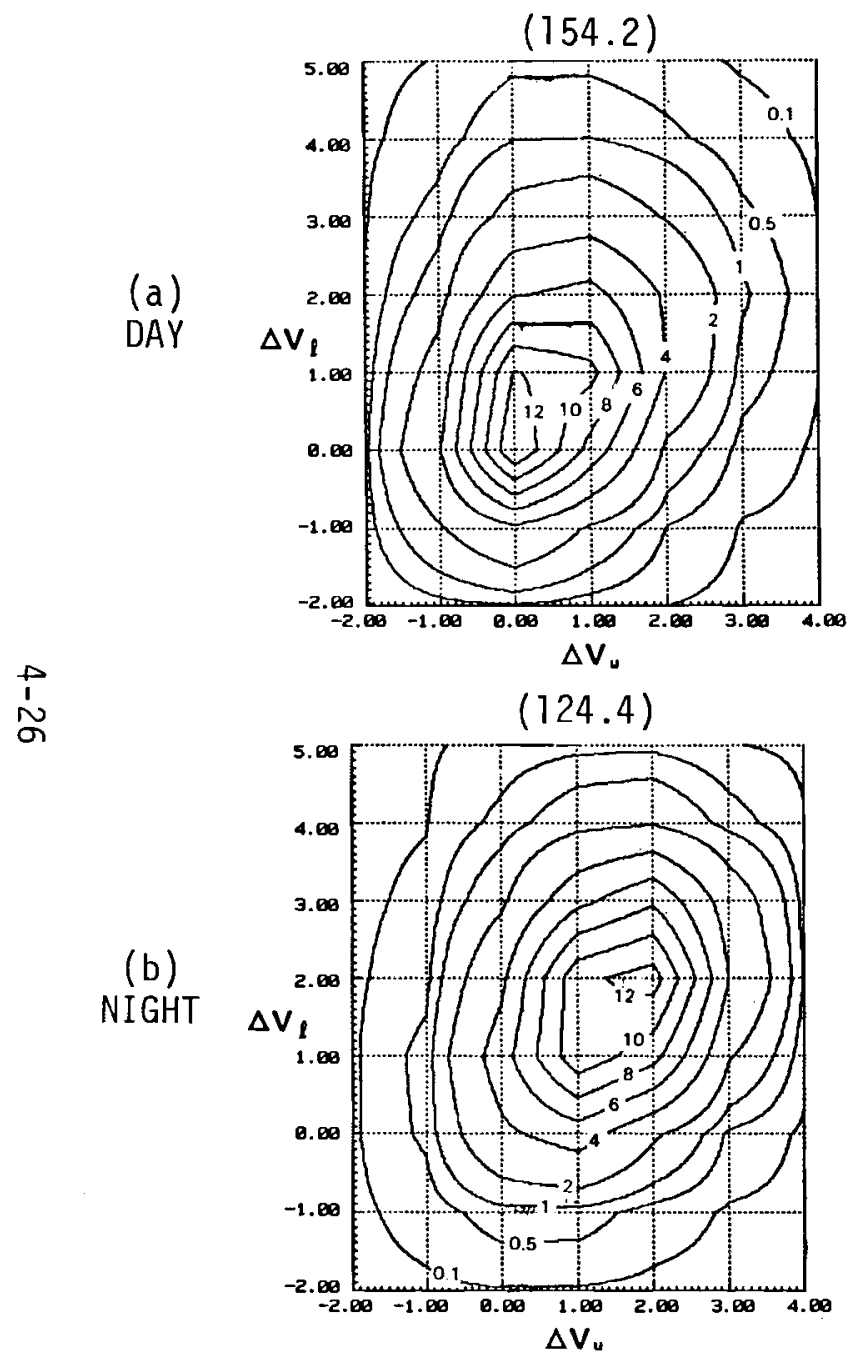

Type 2 Turbine

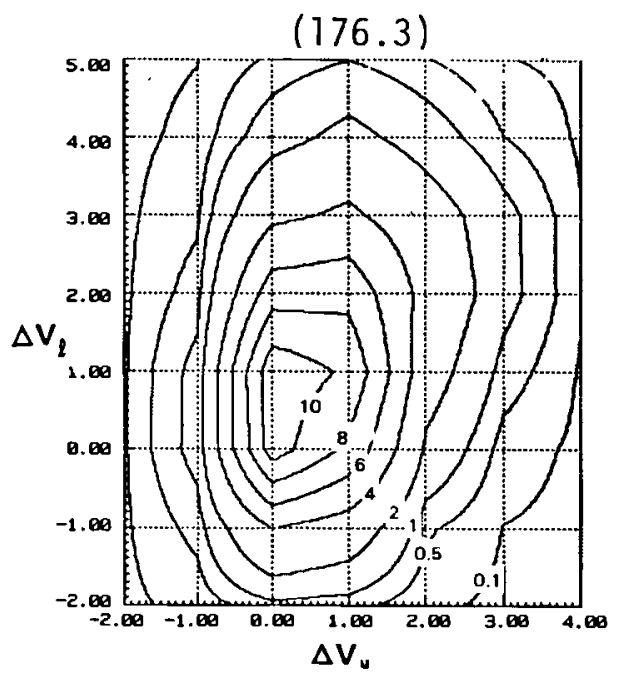

(158.5)

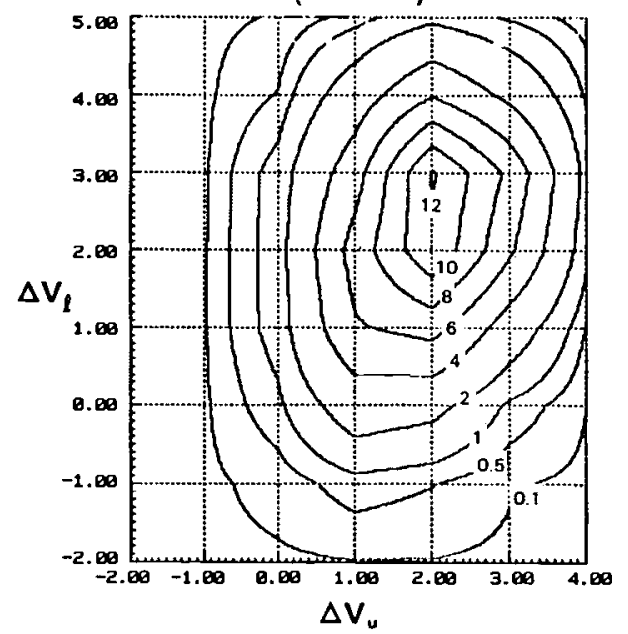

Type 3 Turbine
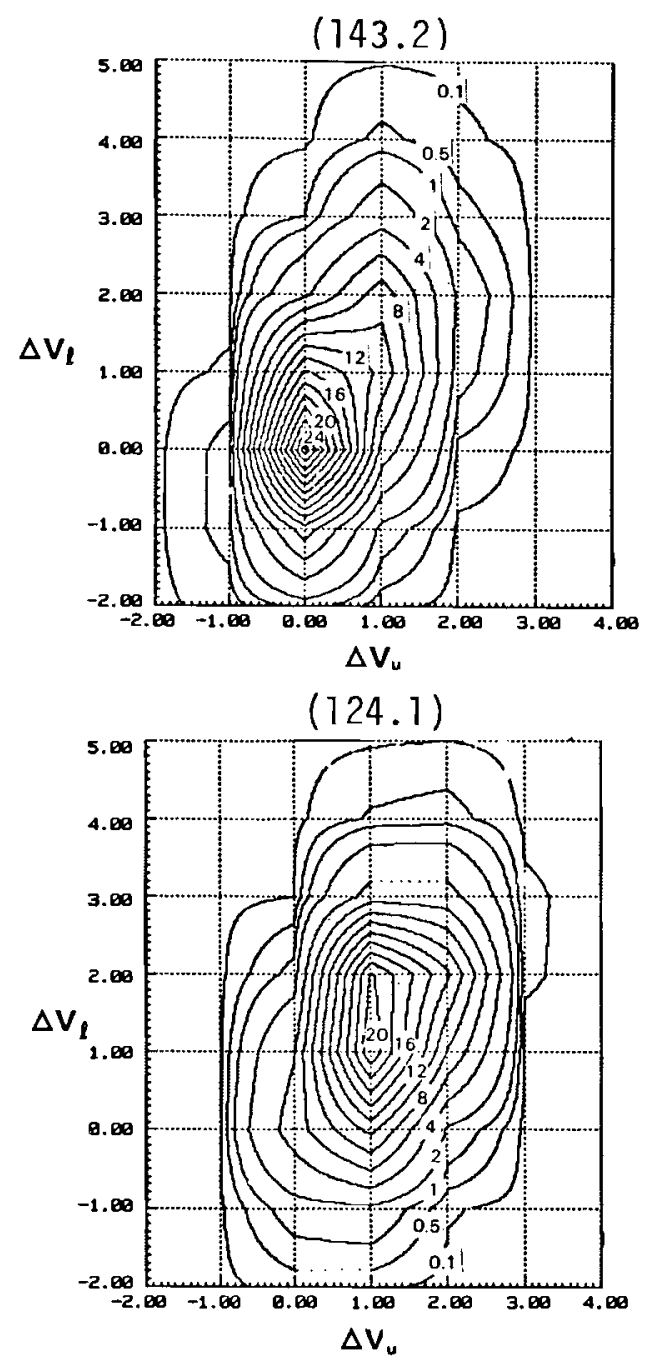

FIGURE 4-19. Percent Frequency Contours for Spring (Apri1 1977). See Figure 4-17 for detai1. 
Type 1 Turbine

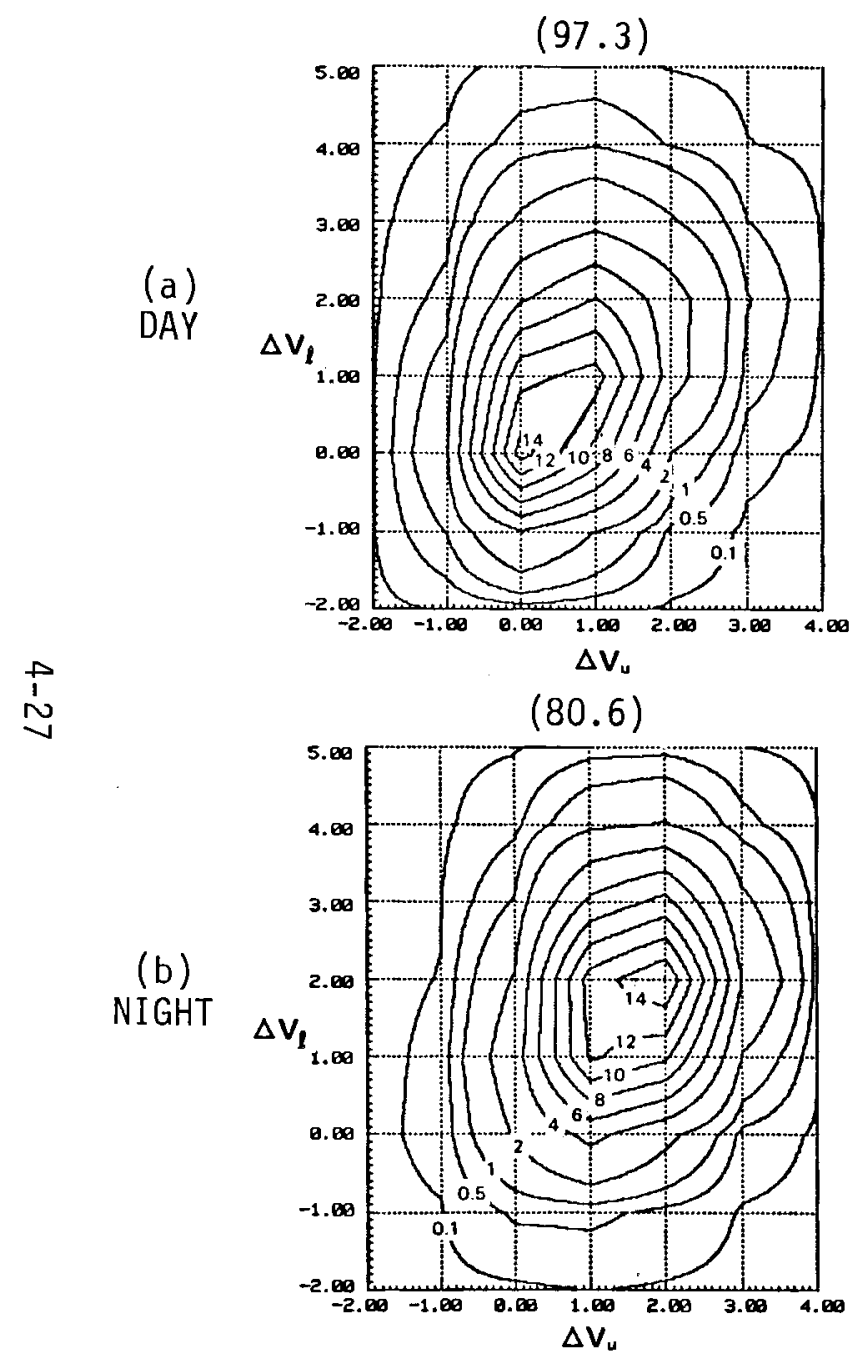

Type 2 Turbine
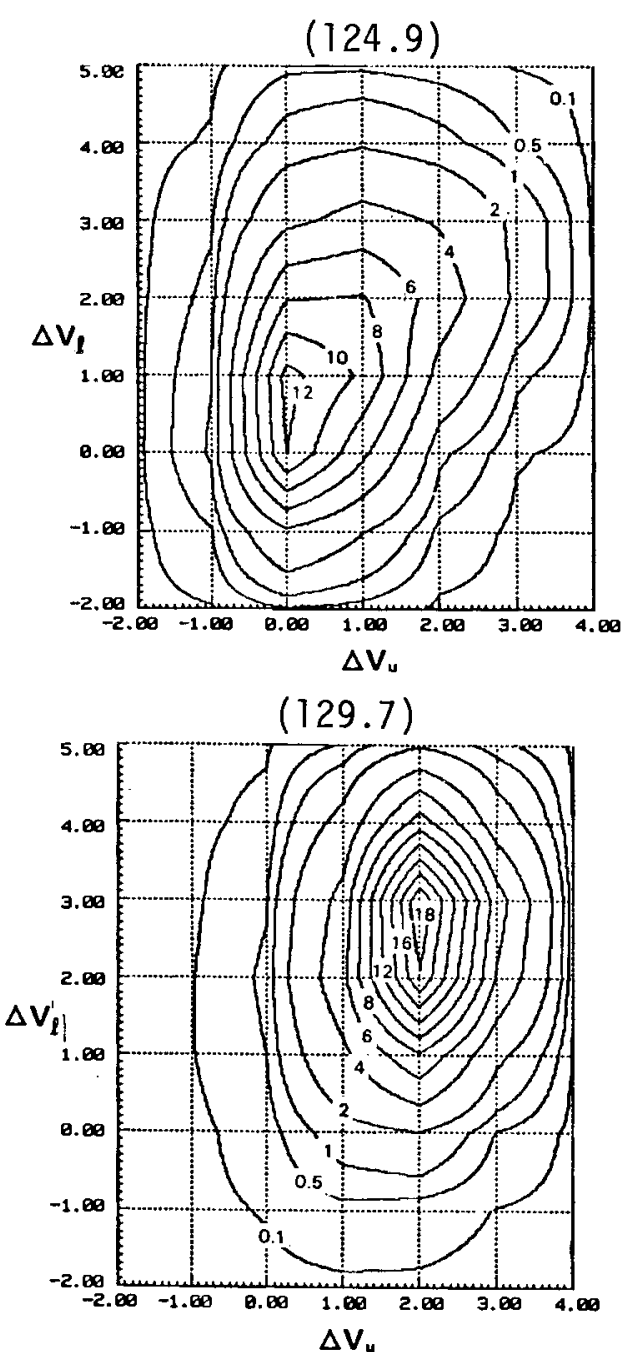

Type 3 Turbine
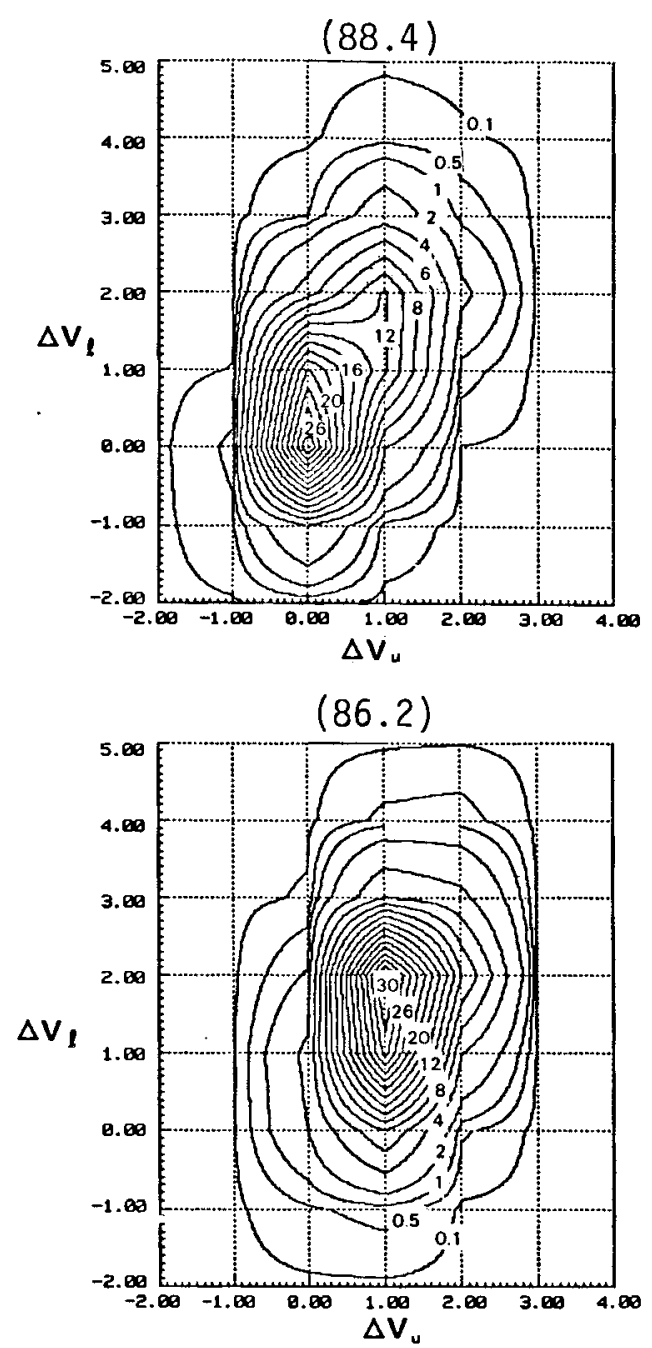

FIGURE 4-20. Percent Frequency Contours for Summer (July 1977). See Figure 4-17 for detail. 
Type 1 Turbine

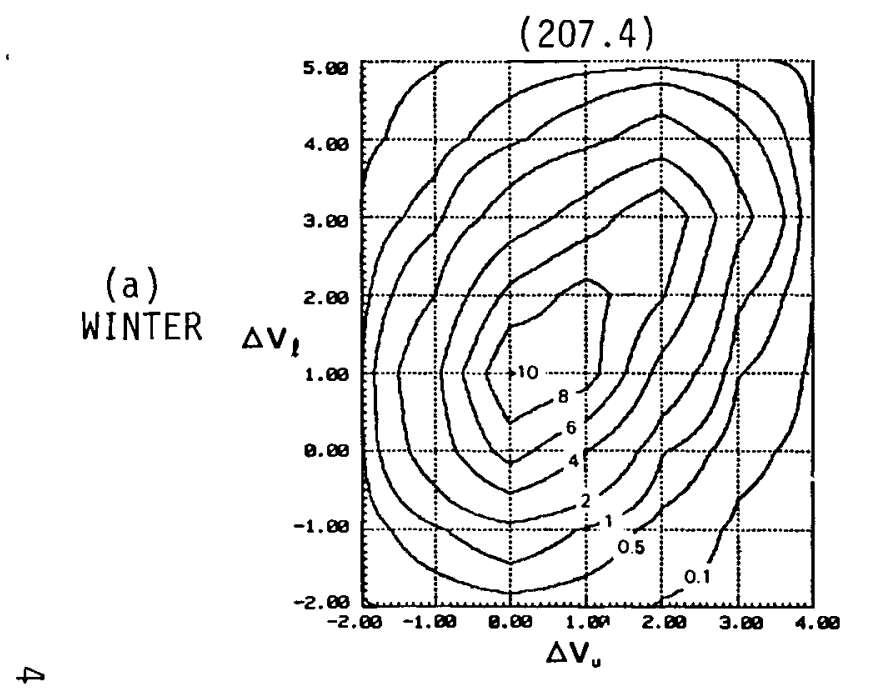

$\underset{\infty}{\mathfrak{i}}$

(b) SUMMER

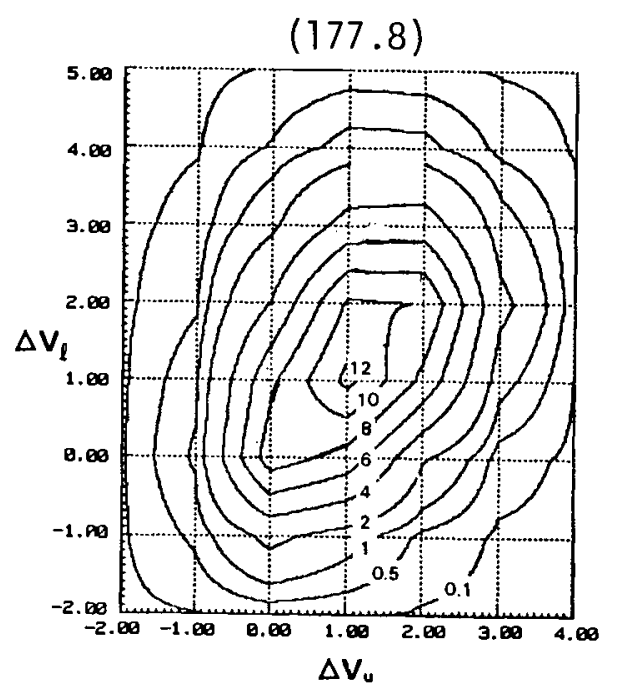

Type 2 Turbine
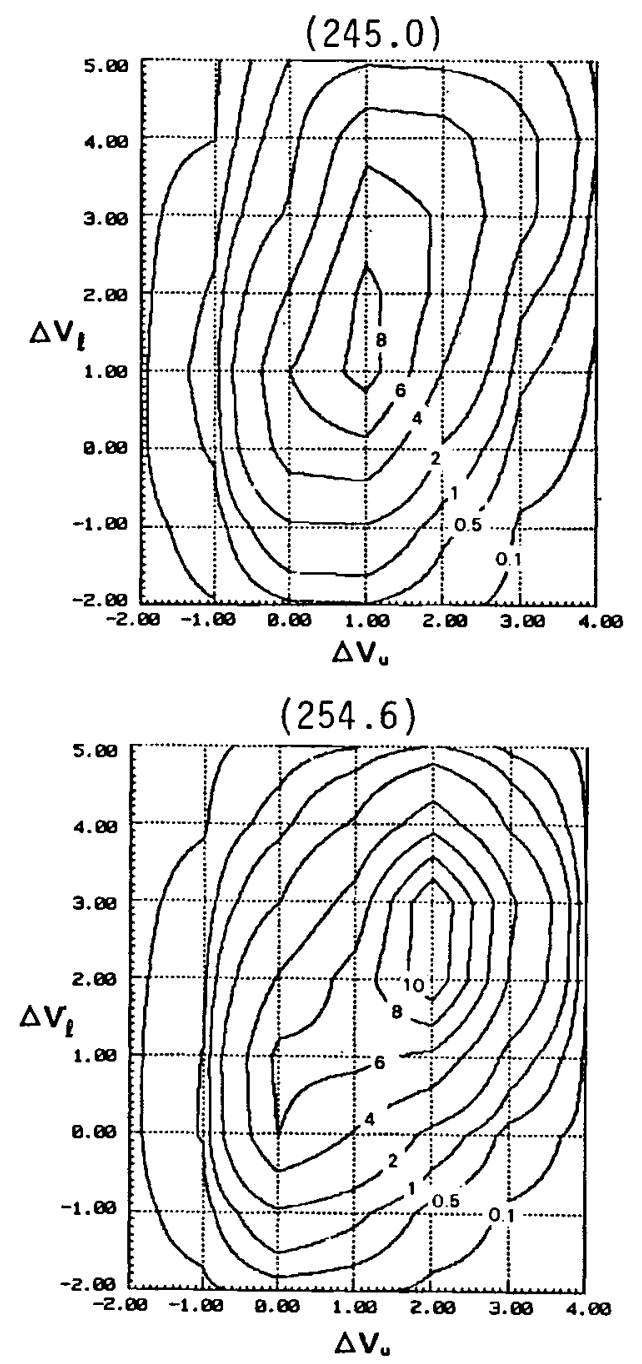

Type 3 Turbine
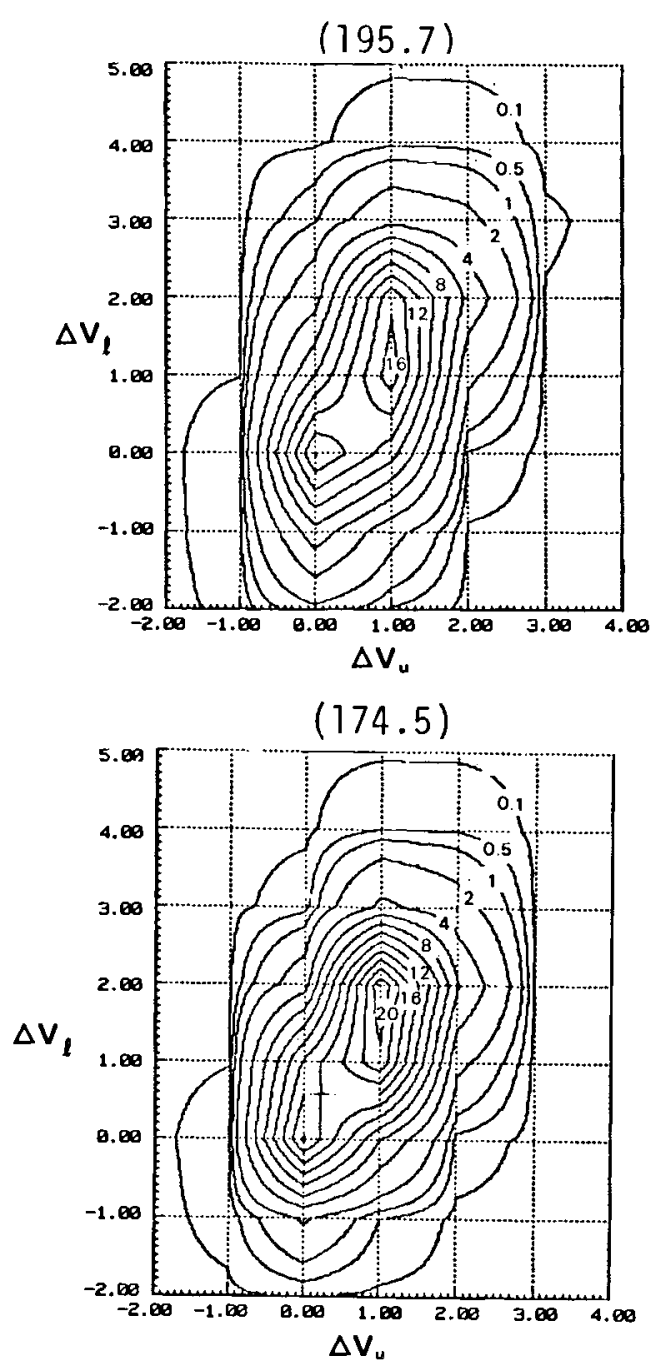

FIGURE 4-21. Percent Frequency Contours (A11 Hours) for (a) Winter (January 1977) and (b) Summer (July 1977). See Figure 4-17 for detail. 
Type 1 Turbine

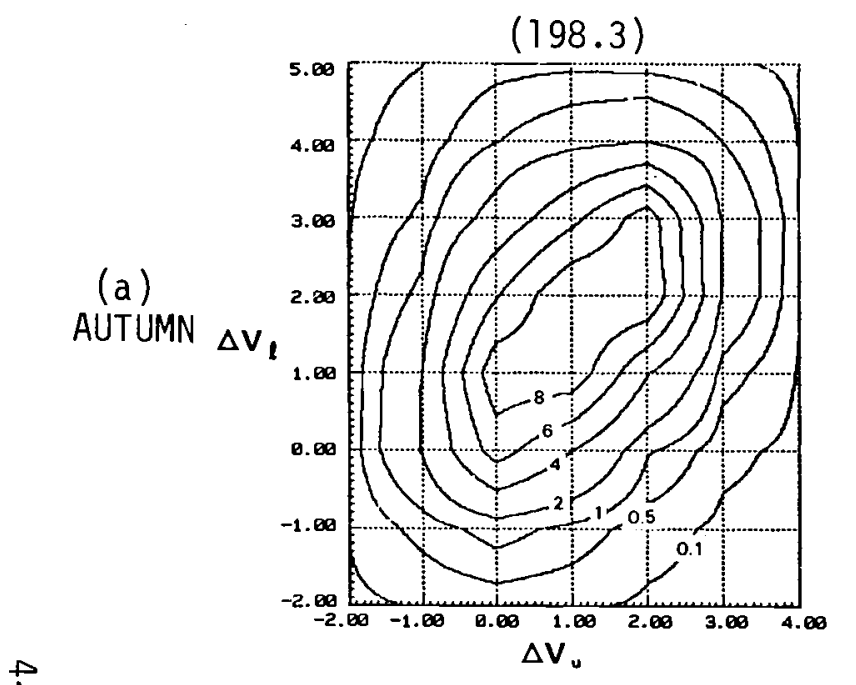

$\stackrel{1}{1}$

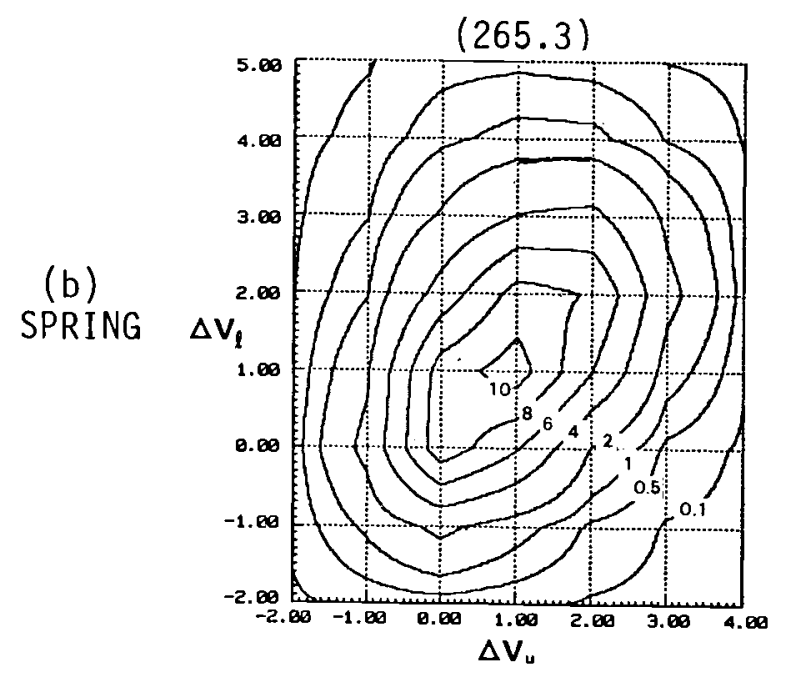

Type 2 Turbine
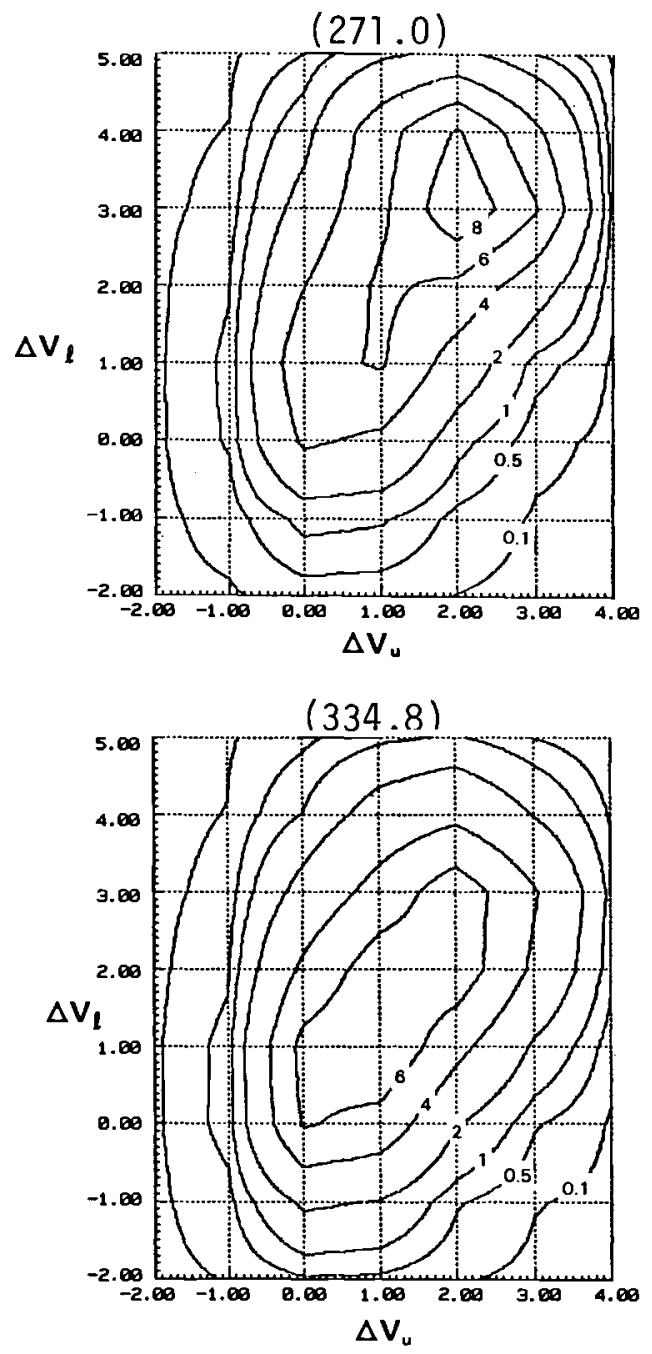

Type 3 Turbine
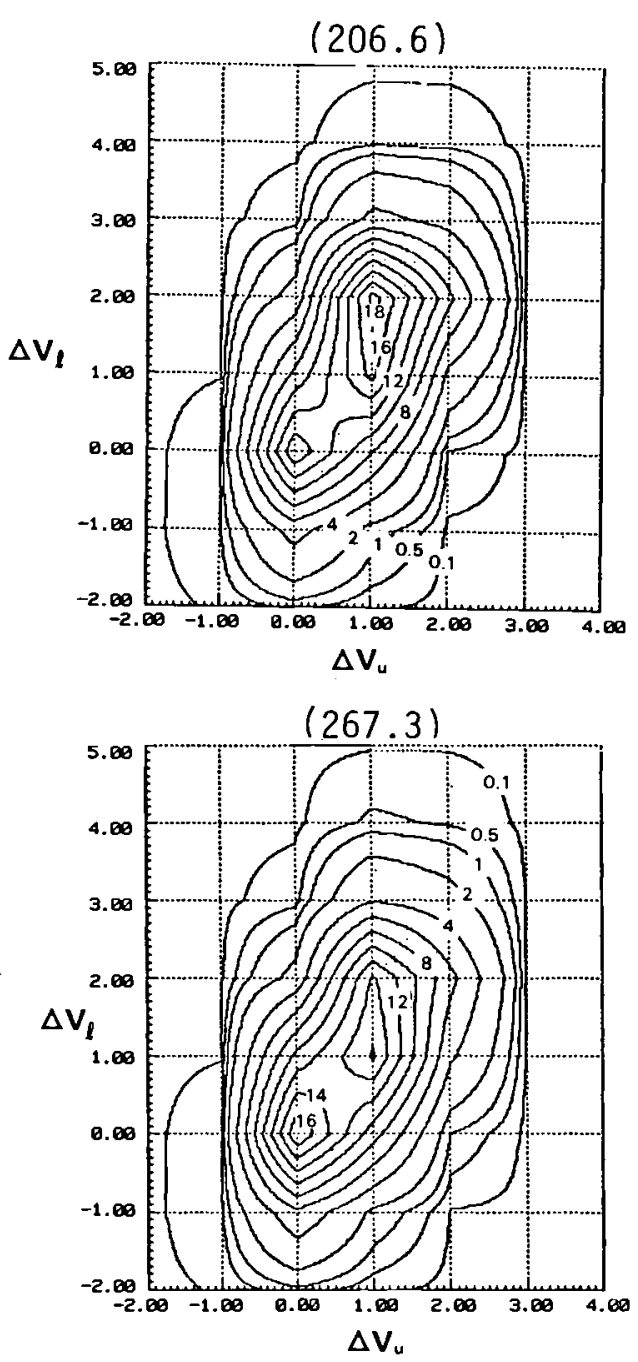

FIGURE 4-22. Percent Frequency Contours (A11 Hours) for (a) Autumn (October 1976) and (b) Spring (April 1977). See Figure 4-17 for detail. 

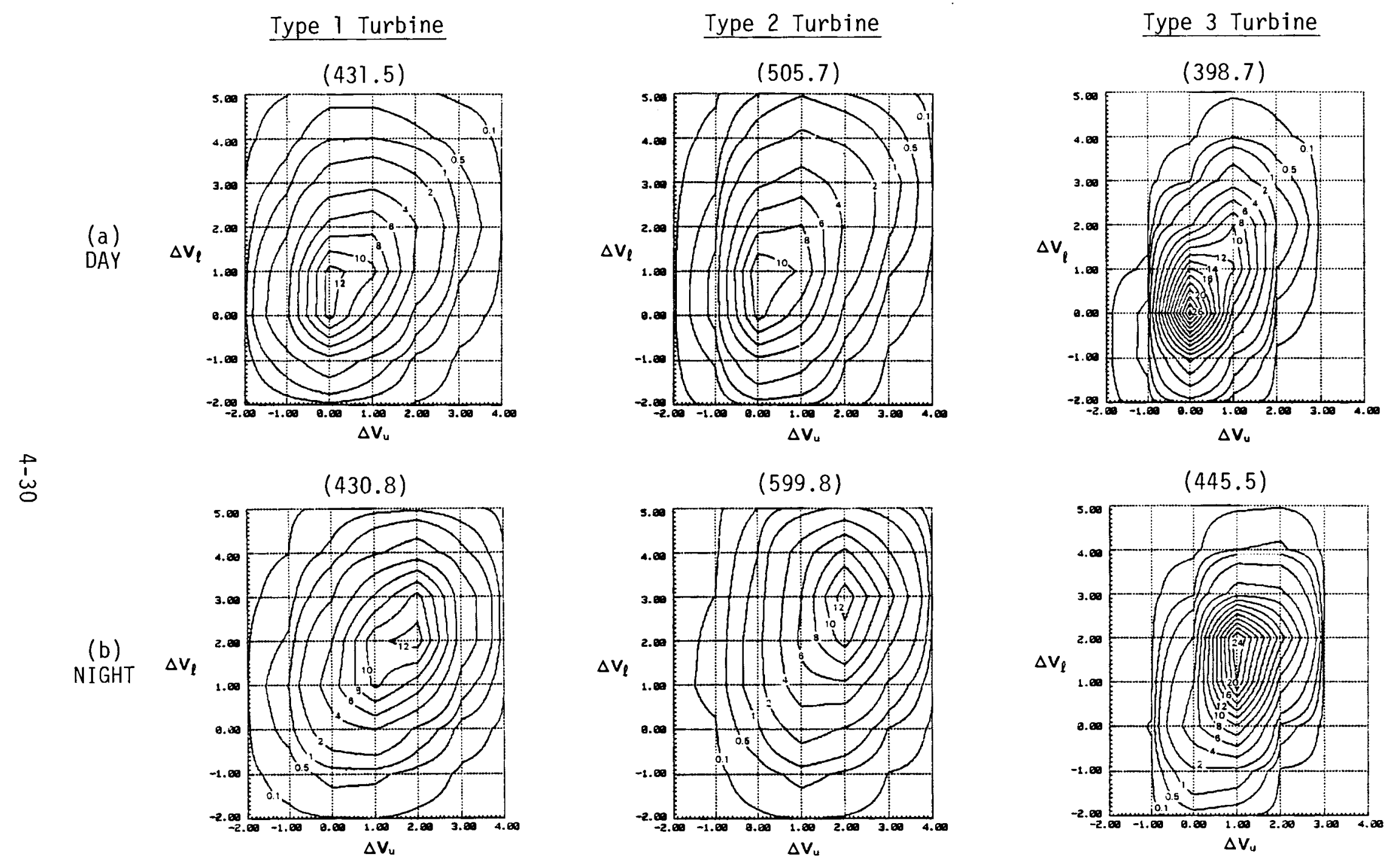

FIGURE 4-23. Percent Frequency Contours - Annual Average. See Figure 4-17 for detail. 

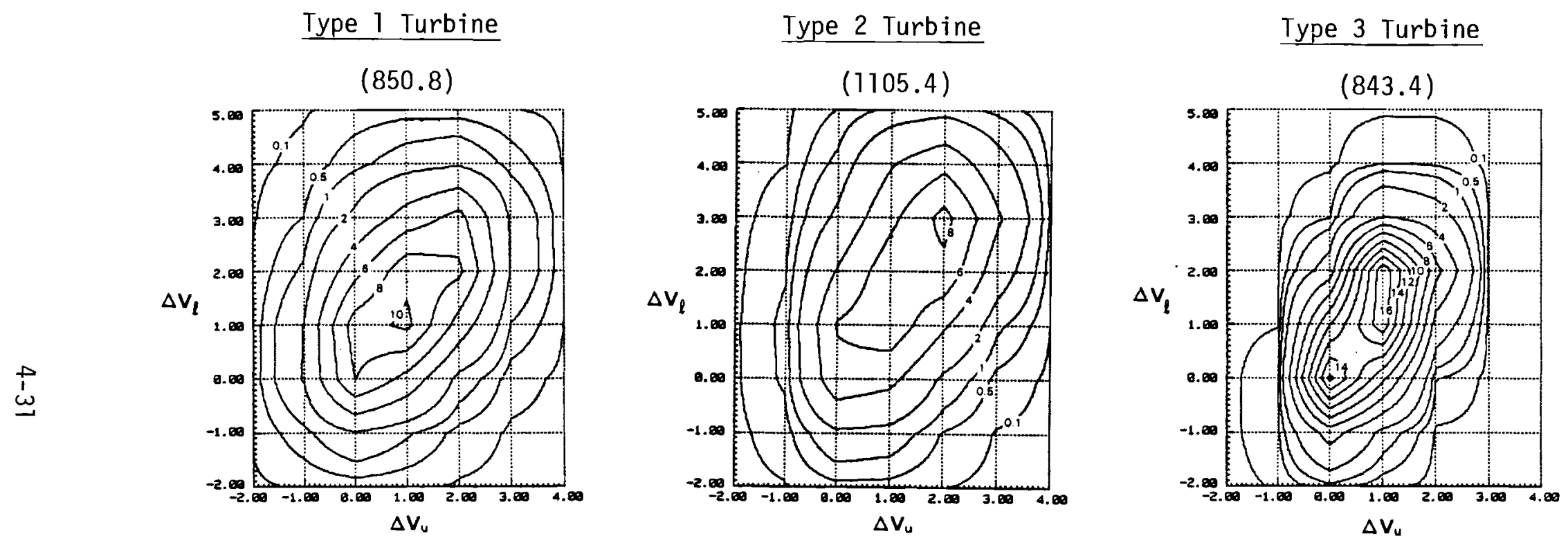

FIGURE 4-24. Percent Frequency Contours (A11 Hours) - Annual Average. See Figure 4-17 for detail. 


\subsection{CONCLUSIONS AND RECOMMENDATIONS}

The major conclusions that can be drawn from the preliminary analysis of the body of climatological information presented in this report are:

- The joint frequency distributions of wind shear profiles show that there are several times as many cells with occurrences for 10-s sampled winds as for hourly averaged winds. These ratios by turbine configuration are:
- Type 1 Turbine
3 to 1
- Type 2 Turbine
2 to 1
- Type 3 Turbine
2.5 to 1 .

The hourly averaged winds do not show the occurrence of severe and unusual profiles found in the 10-s sampled winds. This implies that a rotating blade would experience a much wider range of shear conditions and a higher percentage of extreme shears than indicated by the hourly average data.

- Sensitivity analyses using WKY-TV 10-s data indicate that 2-min to 5-min instantaneous winds may be used to estimate the frequency distribution of wind shear profiles as reliably as 10-s sampled winds.

- The joint frequency distributions of wind shear profiles also show significant differences between wind turbine types in the distribution and number of cells that occur. The Type 3 turbine would experience a considerably less severe velocity difference and fewer unusual profiles than either the Type 1 or Type 2 turbines.

- Percent frequencies of occurrence of wind shear values of $6 \mathrm{~m} / \mathrm{s}$ or greater over the effective height (77\% of the overall height) of the rotor disk during the time when wind speeds are within the operating range of the three turbines are:
- Type 1 Turbine
$5.6 \%$
- Type 2 Turbine
$17.6 \%$
- Type 3 Turbine
$0.5 \%$.

- The joint frequency distribution of wind shear profiles varies dramatically between night and day. Frequently occurring velocity differences in $\mathrm{m} / \mathrm{s}$ over the effective height of the rotor disk are: 


$$
\begin{aligned}
& \text { Night Day } \\
& \text { - Type } 1 \text { Turbine } 2 \text { to } 5 \quad 0 \text { to } 2 \\
& \text { - Type } 2 \text { Turbine } 3 \text { to } 6 \quad 0 \text { to } 2 \\
& \text { - Type } 3 \text { Turbine } 2 \text { to } 3 \quad 0 \text { to } 1 \text {. }
\end{aligned}
$$

It must be pointed out that these results are not universally applicable, because they are based on wind data from a single location in gently rolling terrain with the climatic conditions associated with the southern Great Plains of the continental United States.

One of the major objectives of this prototype study is to suggest a basis for producing more reliable estimates of wind turbine fatigue life and power quality. The variety of profile shapes, showing a significant percentage of occurrence using 10-s sampled wind data, indicates that the consideration of wind shear over the upper and lower halves of the rotor disk is an important factor in wind shear analyses for multimegawatt wind turbines. The rotational analysis, although not rigorously presented in this report, provides qualitative information on the magnitude and frequency variation of the forcing function experienced by a turbine under different shear profile conditions. These types of information are presented for evaluation and comment from turbine design engineers for the purpose of making the development of the input for an analysis of fatigue and power quality more effective and appropriate. This type of analysis should be carried out for other climatic regimes in good wind energy locations to provide a broader base of knowledge for turbine design. Wind shear profile measurements are currently being taken at the MOD-2 site at Goodnoe Hills, Washington, with the advantage of having some turbine data for comparison.

It is also recommended that measurements appropriate to this type of analysis be considered as a part of the final siting criteria for the installation of large turbines, especially in regions where terrain features or landwater proximity suggest the possibility of physical phenomena conducive to severe and unusual wind shear profiles. 


\subsection{REFERENCES}

Connell, J.R. 1981. The Spectrum of Wind Speed Fluctuations Encountered by a Rotating Blade of a Wind Energy Conversion System: Observations and Theory. PNL-4083, Pacific Northwest Laboratory, Richland, Washington.

Doran, J.C. 1981. Some Aspects of Fluctuating Vertical Wind Shears. PNL-3771, Pacific Northwest Laboratory, Richland, Washington. 


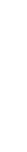




\section{DISTRIBUTION}

No. of

Copies
No. of

Copies

OFFSITE

C. I. Aspliden

Battelle Memorial Institute Washington Operations Office 2030 M Street, N.W. Washington, DC 20036

S. D. Berwager Department of Energy Wind Energy Technology Division 1000 Independence Avenue Forrestal Building, Room 5F059 Washington, DC 20585

Jack Cadogan

Department of Energy

Wind Energy Technology Division Forrestal Building, Room 5F069 1000 Independence Avenue, S.W. Washington, DC 20585

L. V. Divone Department of Energy

Wind Energy Technology Division 1000 Independence Avenue

Forrestal Building, Room 5F059 Washington, DC 20585

G. P. Tennyson

Department of Energy

Albuquerque Operations office P.0. Box 5400

Albuquerque, NM 87115

27 DOE Technical Information Center

Fred Whitson

Bendix Field Engineering Corp. 2582 South Tejon

Englewood, CO 80110
Don Nielson

MS-9A-65

Boeing Engineering and Construction, Co. P.0. Box 3707

Seattle, WA 98124

Nicholas Butler

Bonneville Power Administration P.0. Box 3621

Portland, OR 97208

T. D. Younkins

General Electric Systems

Engineering Department

General Electric Company

1 River Road

Schenectady, NY 12345

Stanley Macklis

General Electric, Co.

Advanced Energy Systems

P.0. Box 8661

Philadelphia, PA 19101

J. M. Kos

Hamilton Standard

Bradley Field Road

Windsor Locks, CT 06096

David Spera

NASA/Lewis Research Center

21000 Brookpark Road

Cleveland, $\mathrm{OH} 44135$

D. L. W. Reddoch

Oak Ridge National Laboratory

P.0. Box $X$

Oak Ridge, TN 37830 
No. of

Copies

R. Thresher

Department of Mechanical Engr. Oregon State University

Corvallis, OR 97331

J. P. Sullivan

School of Aero \& Astronautics

$331 \mathrm{Gr}$ issom Hall

Purdue University

West Lafayette, IN 47907

A. C. Hansen

Rockwell International

P.0. Box 464

Golden, C0 80401

E. G. Kadlec

Sandia Labs 4715

Box 5800

Albuquerque, NM 87165

S. M. Chan

Systems Control, Inc.

1801 Page Mill Road

P.0. Box 10025

Palo Alto, CA 94303

T. Anderson

Westinghouse Electric Co.

P.0. Box 10824

Pittsburgh, PA 15236

R. H. Kirchhoff

Department of Mechanical Engr. University of Massachusetts

Amherst, MA 01003

A. B. Van Rennes

The Bendix Corporation

Executive Offices

Bendix Center

Southfield, MI 48037
No. of

Copies

H. Tieleman

Department of Engineering Science \& Mechanics

Virginia Polytechnic Institute and State University

Blacksburg, VA 24061

R. E. Akins

Wind Energy Division 4715

Sandia National Laboratories

A1buquerque, NM 87185

Dr. Neil Cherry

Lincoln College

Canterbury

NEW ZEALAND

\section{ONSITE}

37 DOE Richland Operations Office

H. E. Ransom

Pacific Northwest Laboratory

W. R. Barchet

W. C. Cliff

J. R. Connell

J. C. Doran

C. E. Elderkin

A. H. Miller

E. L. Owczarski

W. T. Pennell

D. C. Powel1

J. V. Ramsdell

D. S. Renné

H. L. Wegley

L. L. Wendell

R. K. Woodruff

Technical Information Files (5)

Publishing Coordination (2)

WCPE Program Office (15)

2400 Stevens Library 